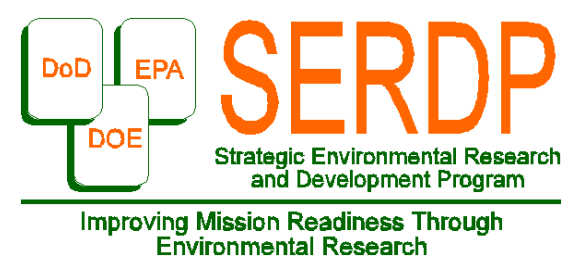

\title{
A Comprehensive Program for Measurement of Military Aircraft Emissions
}

November 2009

Meng-Dawn ('MD') Cheng Distinguished R\&D Staff Member

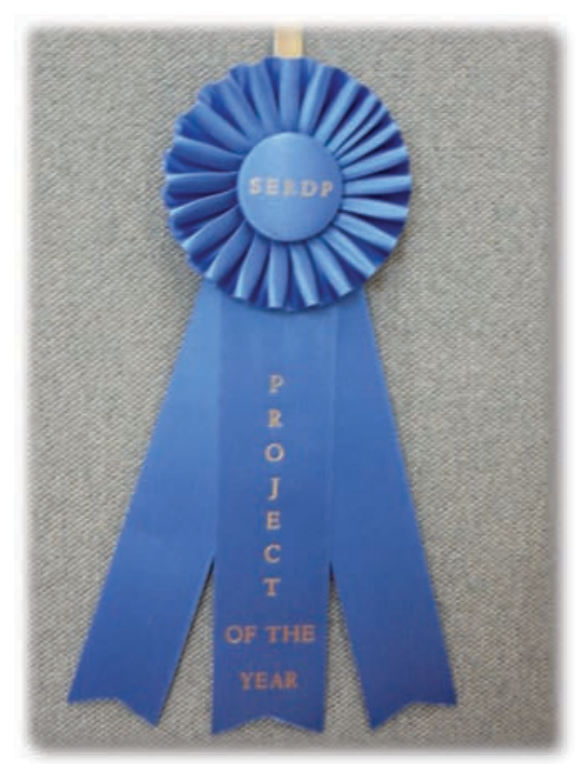




\section{DOCUMENT AVAILABILITY}

Reports produced after January 1, 1996, are generally available free via the U.S. Department of Energy (DOE) Information Bridge.

Web site http://www.osti.gov/bridge

Reports produced before January 1, 1996, may be purchased by members of the public from the following source.

National Technical Information Service

5285 Port Royal Road

Springfield, VA 22161

Telephone 703-605-6000 (1-800-553-6847)

TDD 703-487-4639

Fax 703-605-6900

E-mail info@ntis.gov

Web site http://www.ntis.gov/support/ordernowabout.htm

Reports are available to DOE employees, DOE contractors, Energy Technology Data Exchange (ETDE) representatives, and International Nuclear Information System (INIS) representatives from the following source.

Office of Scientific and Technical Information

P.O. Box 62

Oak Ridge, TN 37831

Telephone 865-576-8401

Fax 865-576-5728

E-mail reports@osti.gov

Web site http://www.osti.gov/contact.html

This report was prepared as an account of work sponsored by an agency of the United States Government. Neither the United States Government nor any agency thereof, nor any of their employees, makes any warranty, express or implied, or assumes any legal liability or responsibility for the accuracy, completeness, or usefulness of any information, apparatus, product, or process disclosed, or represents that its use would not infringe privately owned rights. Reference herein to any specific commercial product, process, or service by trade name, trademark, manufacturer, or otherwise, does not necessarily constitute or imply its endorsement, recommendation, or favoring by the United States Government or any agency thereof. The views and opinions of authors expressed herein do not necessarily state or reflect those of the United States Government or any agency thereof. 
Strategic Environmental Research and Development Program

Project WP 1401

\title{
A Comprehensive Program for Measurement of Military Aircraft Emissions
}

\author{
Meng-Dawn Cheng
}

November 2009

Prepared for

U.S. Department of Energy

Environmental Sciences Division

Oak Ridge National Laboratory

Prepared by

OAK RIDGE NATIONAL LABORATORY

Oak Ridge, Tennessee 37831

Managed by

UT-BATTELLE

For the

U.S. DEPARTMENT OF ENERGY

under contract DEAC-05-00OR22725 


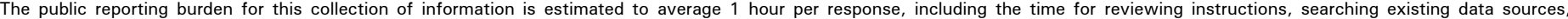

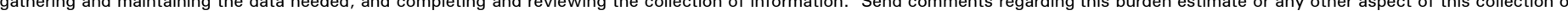

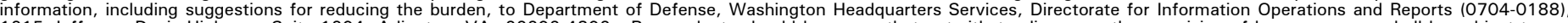

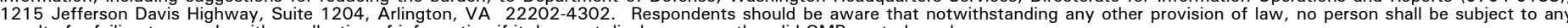
penalty for failing to comply with a collection of information if it does not display a currently valid OMB control number.

PLEASE DO NOT RETURN YOUR FORM TO THE ABOVE ADDRESS.

\begin{tabular}{|c|c|c|}
\hline $\begin{array}{l}\text { 1. REPORT DATE (DD-MM- } Y Y Y Y) \\
\text { 30-09-2009 }\end{array}$ & $\begin{array}{l}\text { 2. REPORT TYPE } \\
\qquad \text { SERDP Project Final Report }\end{array}$ & $\begin{array}{l}\text { 3. DATES COVERED (From - To) } \\
\text { January } 2005 \text { - December } 2008\end{array}$ \\
\hline
\end{tabular}

\section{TITLE AND SUBTITLE} 5a. CONTRACT NUMBER

A Comprehensive Program for Measurements of Military Aircraft Emissions

5b. GRANT NUMBER

5c. PROGRAM ELEMENT NUMBER

\section{AUTHOR(S)}

Meng-Dawn Cheng

\section{5d. PROJECT NUMBER}

5e. TASK NUMBER

SERDP WP-1401

5f. WORK UNIT NUMBER

42

8. PERFORMING ORGANIZATION REPORT NUMBER

ORNL/TM - 2009/256

Oak Ridge National Laboratory

1 Bethel Valley Road, MS 6038

Oak Ridge, TN 37831-6038

9. SPONSORING/MONITORING AGENCY NAME(S) AND ADDRESS(ES)

Strategic Environmental Research and Development Program

901 N. Stuart Road

Arlington, VA 22203 NUMBER(S)

\section{DISTRIBUTION/AVAILABILITY STATEMENT}

Approved for public release; distribution is unlimited.

\section{SUPPLEMENTARY NOTES}

\section{ABSTRACT}

Emissions of gases and particulate matter by military aircraft were characterized in-plume by "extractive" and "optical remotesensing" technologies. Non-volatile particle size distribution, number and mass concentrations were measured with good precision and reproducibly. Time-integrated filter samples were collected and analyzed for smoke number, metals, carbon contents, and sulfate. The geometric mean diameter increased as the engine power increased, which is consistent with downstream observations. The modal diameters at the downstream locations are larger than that at engine exhaust. Elemental analysis indicated little metals were present, while most of the particulate materials were carbon and sulfate (in the JP-8 fuel). The levels of air toxic hydrocarbons were generally below the detection limits except at the idle condition. The results validated sampling and measurement techniques used for non-volatile particulate aircraft emissions, which also highlighted the needs for further research on sampling and measurement for volatile particulate matter and semi-volatile species in the engine exhaust especially at the low engine power setting.

\section{SUBJECT TERMS}

Military aircraft emission, particulate matter, non-volatile particles, remote sensing, JP-8, Fischer-Tropsch

\begin{tabular}{|c|c|c|}
\hline \multicolumn{3}{|c|}{ 16. SECURITY CLASSIFICATION OF: } \\
\hline a. REPORT & b. ABSTRACT & c. THIS PAGE \\
& $\mathrm{U}$ & $\mathrm{U}$ \\
\hline
\end{tabular}

\begin{tabular}{|c|c|}
\hline 17. LIMITATION OF & 18. NUMBER \\
ABSTRACT & OF \\
UUU & PAGES \\
\cline { 2 - 2 } & 88 \\
\hline
\end{tabular}
Meng-Dawn Cheng 19b. TELEPHONE NUMBER (Include area code) 


\section{THIS PAGE IS INTENTIONALLY LEFT BLANK.}




\section{CONTENTS}

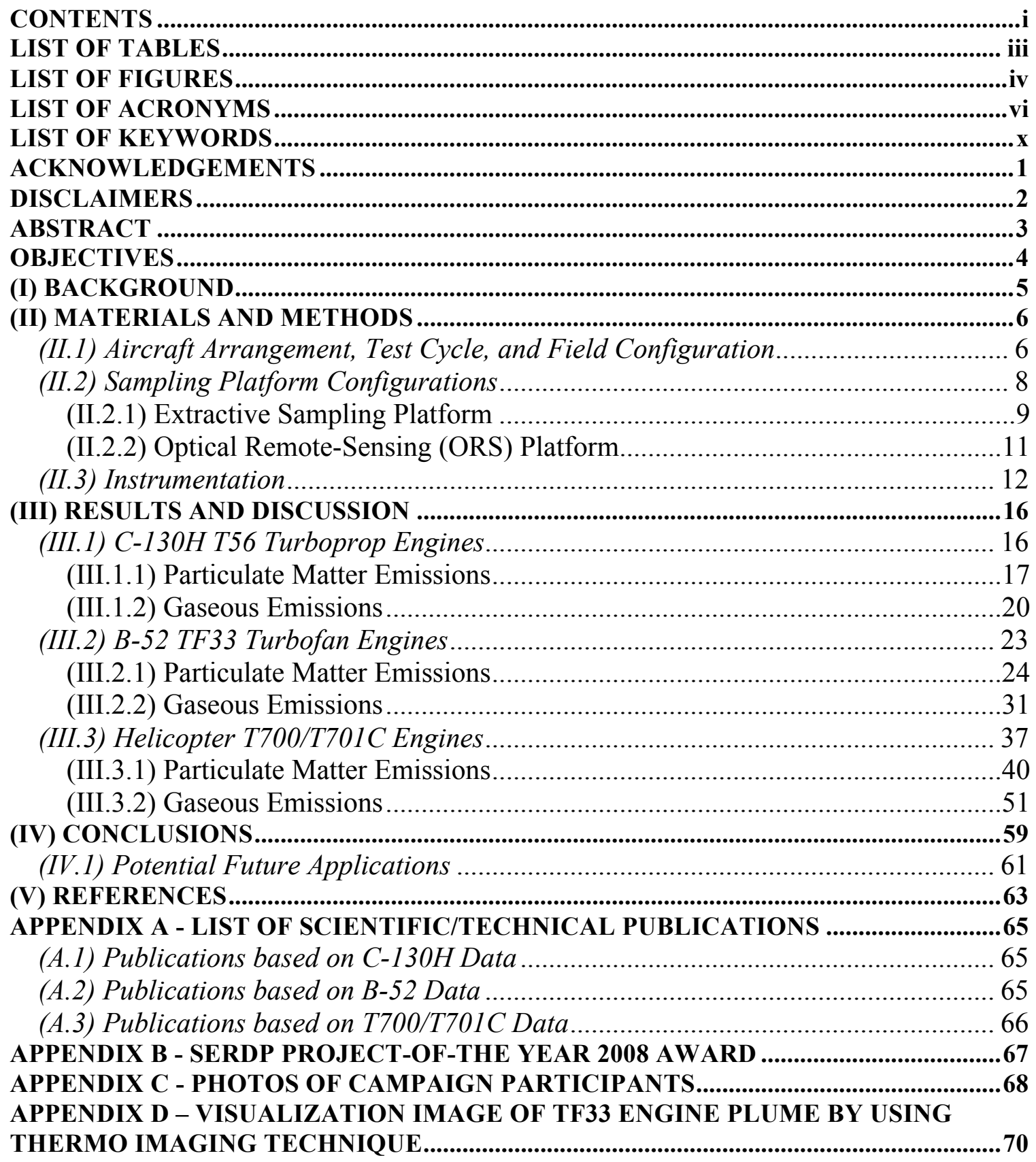


THIS PAGE IS INTENTIONALLY LEFT BLANK. 


\section{LIST OF TABLES}

Table 1. List of Instruments Used in Each of the Three Campaigns from 2005 to 2007

Table 2. Analysis Results of Engine Fuels (JP-8 and FT) Used at HAAF in 2007

Table 3. Emission Indices for Gases Measured by ORS for T700/T701C Engines

Table 4. Emission Indices for Gases Measured by Extractive Sampling for T700/T701C Engines

Table 5. Emission Indices for Selected Gaseous and Particulate Pollutants Summarized for All Engines Tested 


\section{LIST OF FIGURES}

Fig. 1 A C-130H aircraft parked at the Kentucky Air National Guard air field in Louisville, KY in 2005

Fig. 2 A B-52 aircraft parked at the Barksdale Air Force Base in Barksdale, LA in 2006

Fig. 3 Photos of Military helicopters [a] Blackhawk, [b] Apache, which were operated on T700/T701Ctype of engines that were tested in 2007

Fig. 4 Close-up photo of extractive sampling set up for the C-130H campaign

Fig. 5 Schematic of field setup for C-130H campaign

Fig. 6 Remote sensing platform setup for $\mathrm{C}-130 \mathrm{H}$ campaign

Fig. 7 Averaged dilution-corrected particle size distributions for the T56 engines

Fig. 8 Plot of mobility diameter of $\mathrm{C}-130 \mathrm{H}$ particles versus engine power level

Fig. 9 Comparison of C-130H particle mass concentrations obtained by SMPS and TEOM

Fig. 10 Plot of $\mathrm{CO}, \mathrm{CO}_{2}$, and NOx versus engine power condition. Gases measured by MKS FTIR.

Fig. 11 Time-series plots of OP-FTIR and TDLAS measurements of formaldehyde, NO, fuel aliphatics, ethylene, and $\mathrm{CO}$

Fig. 12 Close-up photo of extractive sampling setup for the TF33 engine on a B-52 at Barksdale AFB

Fig. 13 Drawing of ORS instruments setup for the B-52 test at Barksdale AFB

Fig. 14 Plot of TF33 fuel-to-air ratio versus engine power setting

Fig. 15 Plot of smoke number of TF33 engine exhaust versus engine power

Fig. 16 Plot of sulfur-in-sulfate to total sulfur on TF33 particles

Fig. 17 Plot of THCs and OC/TC versus TF33 engine power

Fig. 18 Plot of $\mathrm{CO} / \mathrm{CO}_{2}$ ratio obtained by ORS at various TF33 engine power settings

Fig. 19 Time-series plots of ORS data on acetylene, ethylene, and propylene emitted by TF33 engines

Fig. 20 [a] Graphical description of the model used to derive ORS emission rate

[b] Time series of carbon dioxide data at 3 vertical heights

Fig. 21 Plot of ORS $\mathrm{CO}_{2}$ versus TF33 engine fuel flow for both engines

Fig. 22 Plot of NO emission rates versus TF33 engine fuel flow 
Fig. 23 Plot of formaldehyde to $\mathrm{CO}_{2}$ ratio versus TF33 engine fuel flow

Fig. 24 A close-up photo of the extractive sampling probes for T700/T701C experiments at HAAF

Fig. 25 [a] Relative location of instruments in the fence, [b] ORS instruments setup at HAAF

Fig. 26 Relative distance of various remote sensing instruments to the engine nozzle at HAAF

Fig. 27 Averaged size distributions of T700 engine particles observed at EEP

Fig. 28 Averaged size distributions of T700 engine particles at the 4-m distance from the EEP

Fig. 29 Plot of engine particulate sulfur and sulfate versus T700 engine power setting

Fig. 30 Plot of $\mathrm{SO}_{4} / \mathrm{S}$ ratio and $\mathrm{SO}_{4} / \mathrm{EC}$ ratio against $\mathrm{T} 700$ engine power setting

Fig. 31 Plots of particulate carbon contents measured at 4-m downstream [a] OC/TC, [b] EC/TC

Fig. 32 Plot of OC/EC ratio of T700/T701C particles vs. engine power setting

Fig. 33 Plot of EI_pn versus T700 and T701C engine power setting

Fig. 34 Plot of EI_mass [a] and Smoke Number [b] for T700 and T701C engines

Fig. 35 Schematics of ORNL FPS

Fig. 36 Comparison of FPS with SMPS particle diameters for T700/T701C JP-8 particles

Fig. 37 Transition particle size distributions observed by FPS at HAAF

Fig. 38 Plot of $\mathrm{CO} / \mathrm{CO}_{2}$ ratio versus engine power setting for $\mathrm{T} 700$ and $\mathrm{T} 701 \mathrm{C}$

Fig. 39 Plot of $\mathrm{NO} / \mathrm{CO}_{2}[\mathrm{a}]$ and Formaldehyde [b] vs. engine power setting

Fig. 40 Time series plots of $\mathrm{CO}$ and $\mathrm{CO}_{2}$ for $\mathrm{T} 700$ engine at different dates

Fig. 41 Time series plots of $\mathrm{CO}_{2}$, ethylene, alkanes, and formaldehyde from $\mathrm{T} 700$ engine

Fig. 42 Relative percent differences of EI derived for $\mathrm{CO}$ by using extractive and ORS data 


\section{LIST OF ACRONYMS}

\begin{tabular}{|c|c|}
\hline AAAS & American Association for Advancement of Science \\
\hline AEDC & Arnold Engineering Design Corporation \\
\hline AFM & Atomic Force Microscopy \\
\hline AMS & Aerosol Mass Spectrometer \\
\hline ABFLIPS & Aerosol Beam Focused Laser Induced Plasma Spectrometer \\
\hline $\mathrm{CPC}$ & Condensation Particle Counter \\
\hline CVS & Constant Volume Sampling \\
\hline $\mathrm{CW}$ & Continuous Wave \\
\hline DMA & Differential Mobility Analyzer \\
\hline DOAS & Differential Optical Absorption Spectroscopy \\
\hline DoD & Department of Defense \\
\hline DOE & Department of Energy \\
\hline DOT & Department of Transportation \\
\hline DT & Dilution Tunnel \\
\hline EDX & Energy Dispersive X-Ray Spectrometer \\
\hline EEP & Engine Exhaust Plane \\
\hline EI & Emission Index, same as EF in this report \\
\hline EF & Emission Factor \\
\hline EM & Electron Microscopy; also see TEM and SEM \\
\hline ELPI & Electrical Low-Pressure Impactor \\
\hline EPA & Environmental Protection Agency \\
\hline ESTCP & Environmental Security Technology Certification Program \\
\hline $\mathrm{F} / \mathrm{A}$ & Fuel-Air Ratio \\
\hline FID & Flame Ionization Detector \\
\hline
\end{tabular}




\begin{tabular}{|c|c|}
\hline FPS & Fast Particle Spectrometer \\
\hline FT & Fischer-Tropsch \\
\hline FTIR & Fourier Transform Infrared Spectroscopy \\
\hline FSC & Fuel Sulfur Content, usually in units of parts-per-million by weight or ppmw \\
\hline GA & State of Georgia \\
\hline $\mathrm{GC} / \mathrm{MS}$ & Gas Chromatograph/Mass Spectrometry \\
\hline GM & Geometric Mean Diameter in $\mathrm{nm}$ \\
\hline GSD & Geometric Standard Deviation in $\mathrm{nm}$ \\
\hline GTL & Gas-to-Liquid \\
\hline HAAF & Hunter Army Airfield \\
\hline $\mathrm{HC}$ & Hydrocarbons \\
\hline HPLC & High Pressure Liquid Chromatography \\
\hline HRTEM & High Resolution Transmission Electron Microscope \\
\hline HSG & High speed ground idle \\
\hline IC & Ion Chromatography \\
\hline JP-8 & Jet Propellant \\
\hline KYANG & Kentucky Air National Guard in Louisville, Kentucky \\
\hline KY & State of Kentucky \\
\hline LA & State of Louisiana \\
\hline LES-GDE & Large-Eddy Simulation coupled with General Dynamics Equations \\
\hline LIBS & Laser-Induced Breakdown Spectrometer \\
\hline LIDAR & Light Detection and Ranging \\
\hline LSG & Low speed ground idle \\
\hline MFC & Mass Flow Controller \\
\hline NDIR & Non-Dispersive Infrared Spectrometer \\
\hline
\end{tabular}




\begin{tabular}{|c|c|}
\hline NGDE & Nodal General Dynamics Equations \\
\hline NIOSH & National Institute for Occupational Safety and Health \\
\hline NVPM & Non-Volatile Particulate Matter \\
\hline $\mathrm{OC} / \mathrm{EC}$ & Organic Carbon/Elemental Carbon \\
\hline $\mathrm{OH}$ & State of Ohio \\
\hline OP-FTIR & Open-Path Fourier Transform Infrared Spectroscopy \\
\hline ORISE & Oak Ridge Institute of Science and Education \\
\hline ORNL & Oak Ridge National Laboratory \\
\hline ORS & Optical Remote Sensing \\
\hline PAH & Polyaromatic Hydrocarbons \\
\hline PILS & Particle-in-Liquid Spectrometer \\
\hline PFSS & Partial Flow Sampling System \\
\hline PM & Particulate Matter \\
\hline PSD & Particle Size Distribution \\
\hline RH & Relative Humidity \\
\hline SAE & Society of Aeronautics Engineering \\
\hline SEM & Scanning Electron Microscopy \\
\hline SERDP & Strategic Environmental Research and Development Program \\
\hline SERS & Surface-enhanced Raman Spectroscopy \\
\hline SMPS & Scanning Mobility Particle Sizer \\
\hline $\mathrm{S}$ & Elemental Sulfur \\
\hline $\mathrm{SO} 4$ & Sulfate \\
\hline SVOC & Semi-Volatile Organic Compounds \\
\hline TDMA & Tandem Differential Mobility Analyzer \\
\hline TEOM & Tapered Element Oscillating Microbalance \\
\hline TEM & Transmission Electron Microscopy \\
\hline
\end{tabular}


THCs Total Hydrocarbons

TN State of Tennessee

TERTEL Turbine Engine Research Transportable Emissions Lab

TLAS Tunable Laser Absorption Spectroscopy

UCPC Ultrafine Condensation Particle Counter

UDRI University of Dayton Research Institute

US EPA United States Environmental Protection Agency

VPM Volatile Particulate Matter

WFO Work for Others

WP1627 An identification code for the project supported by SERDP under the thrust area "Weapon Systems and Platforms"

WP AFRL Wright-Patterson Air Force Research Laboratory

WSR Well-Stirred Reactor

XRF X-Ray Fluorescence 


\section{LIST OF KEYWORDS}

Air Toxics

Engine Emission

Extractive Sampling

Fastscan

Fischer-Tropsch

FTIR

JP-8

Military Aircraft

Mobility

Optical Remote Sensing

Particles

Particulate Matter

Turboprop

Turbofan

Turboshaft

Ultrafine

Volatility 
THIS PAGE IS INTENTIONALLY LEFT BLANK. 


\section{ACKNOWLEDGEMENTS}

The SERDP WP-1401 team members acknowledge the success of this project to the assistance and support of the professionals at all three sites. They are the aircraft maintenance and supporting crews at the Kentucky National Guard Base in Louisville, KY, the Barksdale Air Force Base in Shreveport, LA, and the Hunter Army Airfield in Savannah, GA.

We are particularly thankful to the following personnel who provided support during the C-130 campaign in Louisville, KY in 2005. They were: (1) Capt Chris Bishop, maintenance officer, (2) CMS Richard Cwiak, component repair chief, (3) SMS James Amburgey, aircraft scheduler, (4) SMS Wayne Ashley, propulsion element supervisor, (5) Msgt Gary Dunlap, propulsion shop supervisor, (6) Msgt Maurice Johnson, propulsion mechanic, (7) TSgt Patricia Nasby, propulsion mechanic, (8) TSgt James Oliver, propulsion mechanic, (9) TSgt Charles Rodgers, propulsion mechanic, (10) TSgt Joseph Smukler, propulsion mechanic, (11) TSgt Jonathan Wilson, aircraft crew chief, (12) SSgt James Campbell, propulsion mechanic, and (13) Sra Jeffery Perry, propulsion mechanic. Wayne and Gary, in particular, were very kind to us and accommodated the teams in any way they could.

We also express our most sincere thanks and appreciation to SMSgt Steven L. Cadwell, TSgt Steve A. King, SSgt Jonathon M. Craig, and SrA Justin A. Rogers for their logistic and technical support during the B-52 aircraft emissions test campaign at the Barksdale Air Force Base (AFB) in Shreveport, LA in 2006. The Barksdale AFB $2^{\text {nd }}$ Maintenance Group personnel, led by SMSgt Cadwell and TSgt King, worked long hours to plan and support the five-day test campaign in 2006. Their efforts were first-class and vital for the successful completion of these tests on the TF33 engines.

The tireless support by the aircraft maintenance crew in the Aviation Branch at the Hunter Army Airfield (HAAF) in Savannah, GA was essential for the success of our final campaign, and we acknowledge their assistance to our emissions test in 2007. In particular, we thank Joseph D. Lukas, Jr., who was a project officer/COR, Chief, Aviation Branch, Maintenance Div., DOL at HAAF. We also appreciate the hard work by Daniel Houck, Robert Henson, Jason Mikelonis, and Robert Shell who headed the maintenance crew at the test-cell facility. We are also grateful for the hospitality of personnel from the Department of Environmental Protection at Ft. Stewart.

The SERDP WP-1401 team consists of the following members (listed in alphabetical order of the last name): Michel Chase (Arcadis), Meng-Dawn Cheng (PI, ORNL), Edwin Corporan (Co-PI, AFRL), Matthew DeWitt (UDRI), Michael Derlicki (Arcadis), Walter Fisher (Galt Tech), Bruce Harris (US EPA), Rami Hashmonay (Arcadis), Robert Kagann (Arcadis), Christopher Klingshirn (UDRI), Bradley Landgraf (Student, Allegany College), Doh-Won Lee (Postdoc, ORISE), Shannon Mahurin (ORNL), Curt Maxey (ORNL), Dibyendu Muhkerjee (Postdoc, ORISE), James Park, Jr. (ORNL), Richard Shores (US EPA), and John Storey (ORNL).

Finally, we wish to thanks Diane Kosier for her assistance in formatting the report. Her attention to the details of manuscript production was invaluable.

This project was financially supported by the Department of Defense Strategic Environmental Research and Development Program (SERDP) under the project number WP 1401. Oak Ridge National Laboratory, in coordination with the Air Force Research Laboratory at Wright-Patterson Air Force Base, assumed the lead organization responsibility for planning and 
execution of the project. Oak Ridge National Laboratory is managed by UT-Battelle, LLC, for the U.S. Dept. of Energy under contract DE-AC05-00OR22725.

\section{DISCLAIMERS}

The mention of commercial instruments, model numbers, tradenames, chemicals and chemical manufacturers do not represent the endorsement of the author and other SERDP WP 1401 team members nor the organizations the author and team members are associated with.

This technical report has been authored by a contractor of the U.S. Government under contract DE-AC05-00OR22725. Accordingly, the U.S. Government retains a nonexclusive, royalty-free license to publish or reproduce the published form of this contribution, or allow others to do so, for U.S. Government purposes. 


\begin{abstract}
Emissions of gases and particulate matter by military aircraft were characterized inplume by "extractive" and "optical remote-sensing (ORS)" technologies. Non-volatile particle size distribution, number and mass concentrations were measured with good precision and reproducibly. Time-integrated particulate filter samples were collected and analyzed for smoke number, elemental composition, carbon contents, and sulfate. Observed at EEP the geometric mean diameter (as measured by the mobility diameter) generally increased as the engine power setting increased, which is consistent with downstream observations. The modal diameters at the downstream locations are larger than that at EEP at the same engine power level. The results indicate that engine particles were processed by condensation, for example, leading to particle growth in-plume. Elemental analysis indicated little metals were present in the exhaust, while most of the exhaust materials in the particulate phase were carbon and sulfate (in the JP-8 fuel). $\mathrm{CO}, \mathrm{CO}_{2}, \mathrm{NO}, \mathrm{NO}_{2}, \mathrm{SO}_{2}, \mathrm{HCHO}$, ethylene, acetylene, propylene, and alkanes were measured. The last five species were most noticeable under engine idle condition. The levels of hydrocarbons emitted at high engine power level were generally below the detection limits. ORS techniques yielded real-time gaseous measurement, but the same techniques could not be extended directly to ultrafine particles found in all engine exhausts. The results validated sampling methodology and measurement techniques used for non-volatile particulate aircraft emissions, which also highlighted the needs for further research on sampling and measurement for volatile particulate matter and semi-volatile species in the engine exhaust especially at the low engine power setting.
\end{abstract}




\section{OBJECTIVES}

The objectives of this three-year project were: (1) to develop a comprehensive emissions

measurement program by employing both extractive and remote-sensing measurement techniques, (2) to develop the emission indices or factors for selected gas and particulate pollutants emitted by military aircraft of fixed- and rotating-wing configurations, and (3) to test new sampling and measurement strategy and technology for military aircraft emissions measurement. 


\section{(I) BACKGROUND}

Emissions by military and civilian aircraft continue to contribute to the increase of $\mathrm{NO}_{\mathrm{x}}$, volatile organic compounds, and particulate matter (PM) in the regional and global atmosphere. Since aircraft directly inject pollutants into the atmosphere, jet engine emissions may play a significant role in the alteration of atmospheric chemistry, the life cycles of cloud nuclei and contrails that play a critical role in climate forcing and radiation balance. With air travel for various industrial and military activities expected to increase in the near future, we would anticipate aircraft emissions to increase. The United States Air Force spent more than $\$ 6$ billion for aviation fuel in FY 2006. This corresponds to between 3 and 4 billion gallons per year ( $\sim 10 \%$ of total domestic aviation fuel use). Considering PM emissions as an example, the fleet-averaged emission index for soot has been estimated to be approximately $40 \mathrm{mg} / \mathrm{kg}$ of fuel burned [International Civil Aviation Organization (ICAO) Data Base]. This renders approximately $600,000 \mathrm{~kg}$ of particulate matter, which are emitted each year by US military aircraft alone. However, the portion of the emissions contributed to each aircraft platform is unknown. The level of emissions from military engines corresponds roughly to $5 \times 10^{24}$ particles per year with an average size of 50 -nm diameter and an average density of $2 \mathrm{~g} / \mathrm{cm}^{3}$ (Howard, 1996).

Military aircraft emissions are dominated by a fleet of high payload aircraft, such as the C-130 cargo planes and the B-52 bombers used by US Air Force. These aircraft consume the majority of fuel used by the USAF (60-70\%) due to their large payloads, frequent flight missions and older engine technology; i.e., lower-efficiency engines. For example, smoke numbers for these aircraft are in the 30s or $40 \mathrm{~s}$, while fighter jets are typically in the single digits range that is near the detection limit of smoke number. The USAF intends to continue operation of these aircraft for the foreseeable future (e.g., the B52 aircraft is expected to remain in service until about 2050). Thus, the importance on accurately knowing their emission factors cannot be overstated.

Emission factors of nitrogen oxides $\left(\mathrm{NO}_{\mathrm{x}}\right)$, particulate matter $(\mathrm{PM})$, and air toxics from military aircrafts are needed for meeting regulatory requirements of air quality standards of the clean air act amendments of 1990 and the National Ambient Air Quality Standard (NAAQS). Accurate emission index or emission factor is limited or lacking for some of the military aircraft engines. The data paucity of military aircraft emissions hampers environmental assessment and design of effective control strategies for the emissions at military airfields around the country.

There is no agency-certified aircraft emissions measurement methodology. The sampling method currently used to measure the engine PM emissions was a modification of the U.S. Environmental Protection Agency (EPA) Test Method 5; this method was originally developed back in the 1950s for measuring PM emissions from smoke stacks. Multiple sampling points traversing the cross-section of the stack is required. It is well known by engine manufacturers and certifiers that performing such a testing method is an expensive and time-consuming process. However, it is a recognized, but deficient, method for engine emission measurement. The EPA method is impractical and yields only limited results that are often been questioned on its usefulness in engine emission measurement.

Furthermore, ultrafine particles (defined as the diameter less than or equal to $100 \mathrm{~nm}$ or $0.1 \mu \mathrm{m}$ ) are the dominant population of the particulate matter of jet aircraft emissions. Quantitative measurement methods and instrumentation techniques must be developed for monitoring the complex jet engine exhaust streams. Advances of particle science and technology in the past two decades have produced techniques and instruments that are capable of real-time or continuous measurement of various properties of ultrafine particles in laboratory and field conditions. Some of the techniques and instruments may be ready for engine emission measurement, while some may need further development works. 
Thus, the goal of this project is to develop improved understanding of commercially available as well as research-grade instruments for characterizing military aircraft emissions. The techniques we applied were based on the established analytical principles for measuring particle properties. We anticipate that the uncertainties associated with the existing and future emissions inventories be reduced when the techniques are applied to aircraft emission measurement. The results and experience gained from this WP1401 program have advanced our understandings on the measurement reliability and field performance of these techniques.

\section{(II) MATERIALS AND METHODS}

The three field campaigns in 2005 - 2007 are described in details in Section (II). All tests performed during the campaigns were at military airfields under outdoor environmental conditions that an aircraft exhaust plume would encounter. Thus, the instruments and sampling techniques employed in the campaigns were subject to normal ambient conditions and no effort was made to perform the field test in extreme weather conditions.

\section{(II.1) Aircraft Arrangement, Test Cycle, and Field Configuration}

The first field emission-measurement campaign in October 2005 was conducted on a C-130H aircraft (shown in Fig. 1) operated by the Kentucky Air National Guard (KYANG). The test site was in Louisville, KY. The primary function of the $\mathrm{C}-130 \mathrm{H}$ aircraft is aerial transport of cargo and personnel.

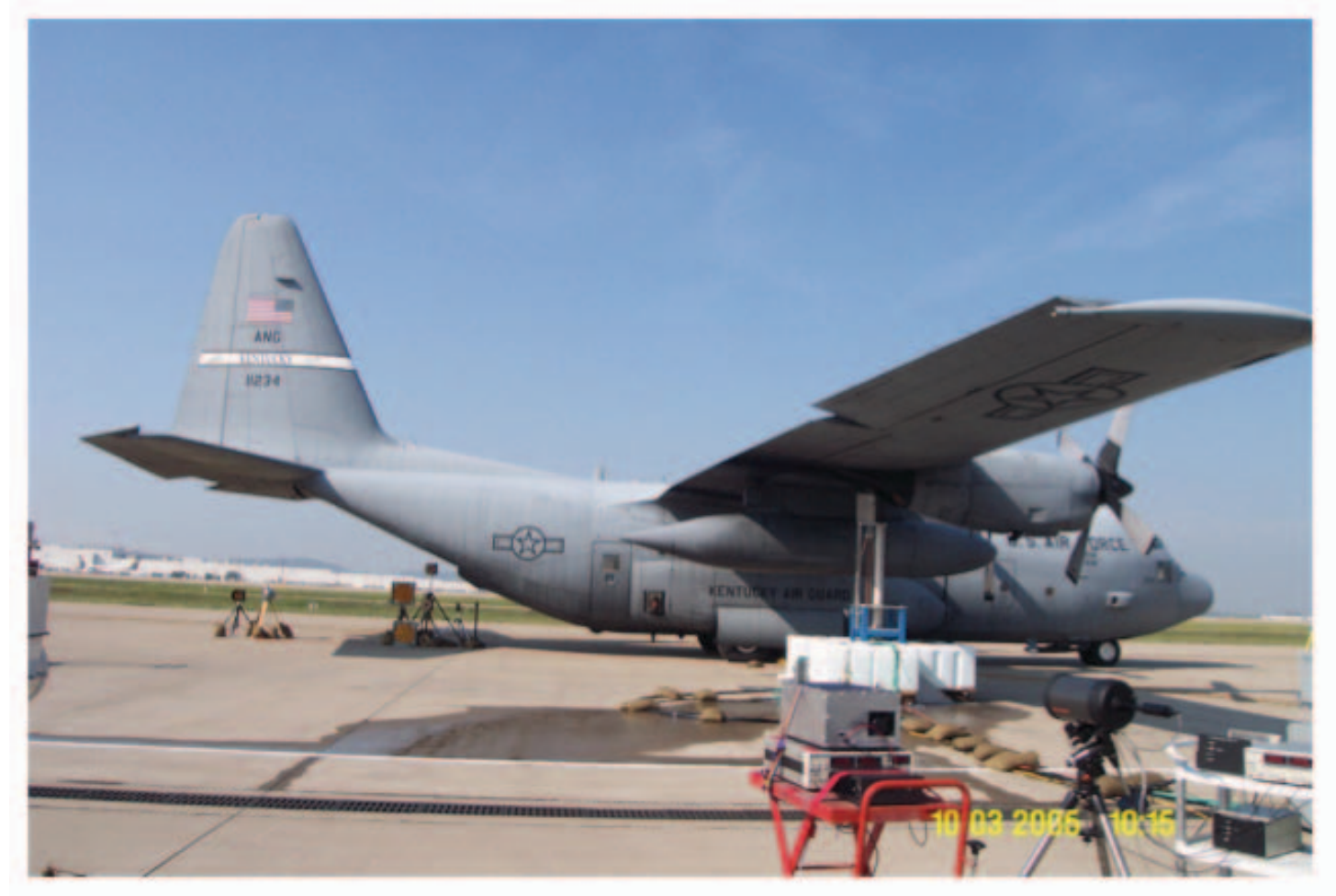

Fig. 1. A C-130H aircraft parked at the Kentucky Air National Guard air field 
The aircraft has four (4) Rolls-Royce Allison T56-A-15 turboprop engines, two on each wing, each engine delivering about 4,000 horsepower. The two engines on the aircraft's right wing (pilot's view) were used in this field test during the one-week campaign. They are designated as the inboard (\#3) (closer to the fuselage) and outboard (\#4) engines; the outboard engine was tested during the first two days, while the inboard engine was tested during the last two days. Five engine settings with increasing thrust levels were set and run for each cycle. These engine load settings are labeled as (1) low speed ground idle (LSGI), (2) high speed ground idle (HSGI), (3) flight idle (FI), (4) cruise, and (5) max power (Max). The aircraft operator maintained each engine setting approximately $20 \mathrm{~min}$ to allow all measurements using the different techniques, before they were instructed to move on to the next engine level. On average, three cycles were run per day resulting in a total of 11 cycles and 55 engine load settings. Two peer-reviewed journal publications were resulted from this campaign (Cheng et al., 2008; Corporan et al., 2008) and several presentations were made at technical conferences (see the list of publication in the Section of C130).

The second field campaign was executed on two TF-33 engines of a B-52 aircraft (as shown in Fig. 2) at the Barksdale Air Force Base in Louisianan in May 2006. The primary function of a B-52 aircraft is aerial bombardment in a war. The Boeing Military Airplane Co. manufactured the aircraft and eight (8) Pratt \& Whitney TF33-P-3/103 turbofan engines power each B-52 aircraft. Each engine has thrust power of up to 17,000 pounds (7,650 kilograms). The nearest inboard engines on each side of the fuselage were evaluated during this campaign. Four engine load levels were used in each test cycle. These engine load settings are labeled as (1) idle, (2) $80 \%$ (80\% of the max), (3) $90 \%$ and (4) $95 \%$ of the maximum engine power. Overall, three cycles were run on the first engine and five cycles on the second engine resulting in 39 test runs. There was in fact one additional run using $100 \%$ of the max engine power, which unfortunately resulting in unfavorable operating condition for the extractive and remotesensing sampling apparatus. The max engine power setting was removed from the test cycle during this campaign. This experience points to an engineering limitation of the extractive sampling strategy.

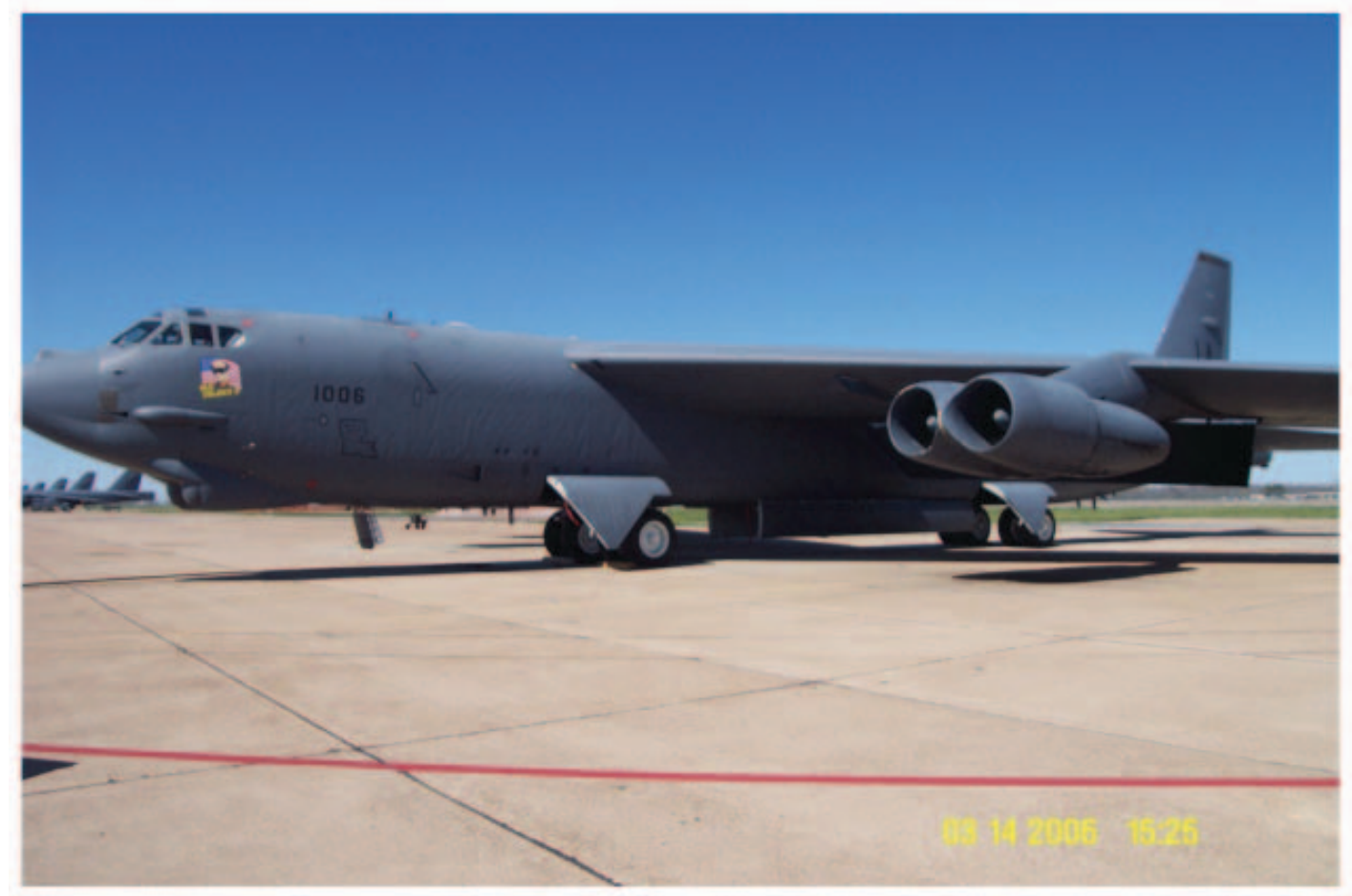

Fig. 2. A B-52 aircraft parked at the Barksdale Air Force Base 
The final campaign for this program was conducted at the Hunter Army Airfield in Georgia in June 2007 on a completely different turbine engine from those tested earlier. In this campaign, we used two turboshaft engines instead of turbofan engines. Rotating-wing aircraft like helicopters uses Turboshaft engine, while fixed-wing aircraft like B-52 uses turbofan engine. Due to the logistic and safety concerns of conducting emissions tests on a hovering helicopter, the emissions tests on the turboshaft engines were actually performed on a test stand at an engine-cell facility at the Hunter Army Airfield.

The three-turboshaft engines tested (i.e., T700-GE-700, T700-GE-701C, and another T700-GE701C) are used by Blackhawk and Apache helicopters (see Fig. 3). These engines all have a couple of thousand hours of operation, and the second T701C engine was just returned from the maintenance service. Three engine power levels were used in a test cycle: (1) idle, (2) $75 \%$ of the max, and (3) the max power. Each engine test followed the three-power-setting cycle about two to four times.

Emissions were characterized on the engines operated with JP-8 fuel, the same type of fuels used in the two previous tests. Additionally, on the second $\mathrm{T} 701 \mathrm{C}$ engine a synthetic fuel derived from natural gas using the Fisher-Tropsch (FT) process was also tested to explore the impacts of fuel formulation on engine emissions. Overall, a total of four test cycles were run on T700-GE-700 (or hereafter T700) on the JP-8 fuel, four test cycles on T700-GE-701C (or hereafter T701C) running the JP-8 fuel, and two test cycles on the second T701C operated with FT fuel

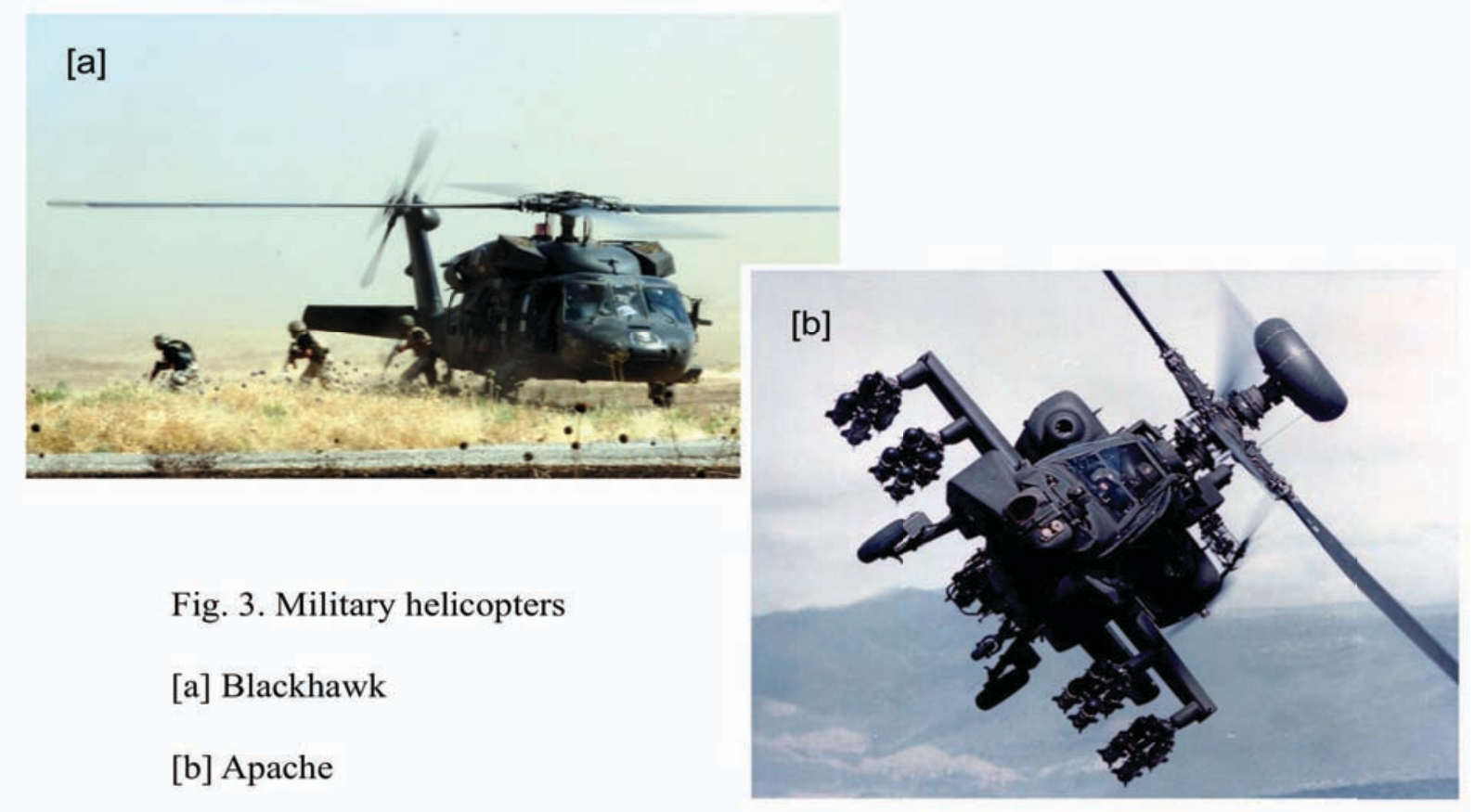

Image Sources:

[a] http://news.soc.mil/releases/News\%20Archive/2006/06JUL/060710-02.html

[b] http://en.wikipedia.org/wiki/File:Apache helicopter_in_flight.jpg 


\section{(II.2) Sampling Platform Configurations}

Two types of emission sampling platforms were applied in this research program: an extractive sampling platform and a remote-sensing platform. The former platform has been the choice by the aircraft emission measurement community, while the later one was new. The following sections describe in details the configurations of these two sampling platforms.

\section{(II.2.1) Extractive Sampling Platform}

Engine emissions are traditionally characterized by taking an one-point measurement from (generally at the center of) the exhaust plume or multiple points (for engine certification) pre-determined on a sampling grid mounted at the cross-section of the plume. Samples are extracted directly from the plume; thus, the sampling apparatus itself could disturb the exhaust flow. This type of sampling strategy is referred to as the "extractive sampling" in this report. The sampling setup is very labor-intensive and requires a team of experienced personnel. Extractive samples have to be carefully preserved and transported to instruments that are operated by personnel at a distance of $23 \mathrm{~m}$ (for safety reason) from the sampling apparatus. As an example, the extractive sampling used in the $\mathrm{C}-130 \mathrm{H}$ campaign is shown in Fig. 4, while the schematics in Fig. 5 shows the location of various sampling trailers, instruments, and supporting facilities relative to the location of the $\mathrm{C}-130 \mathrm{H}$ aircraft engines during the campaign.

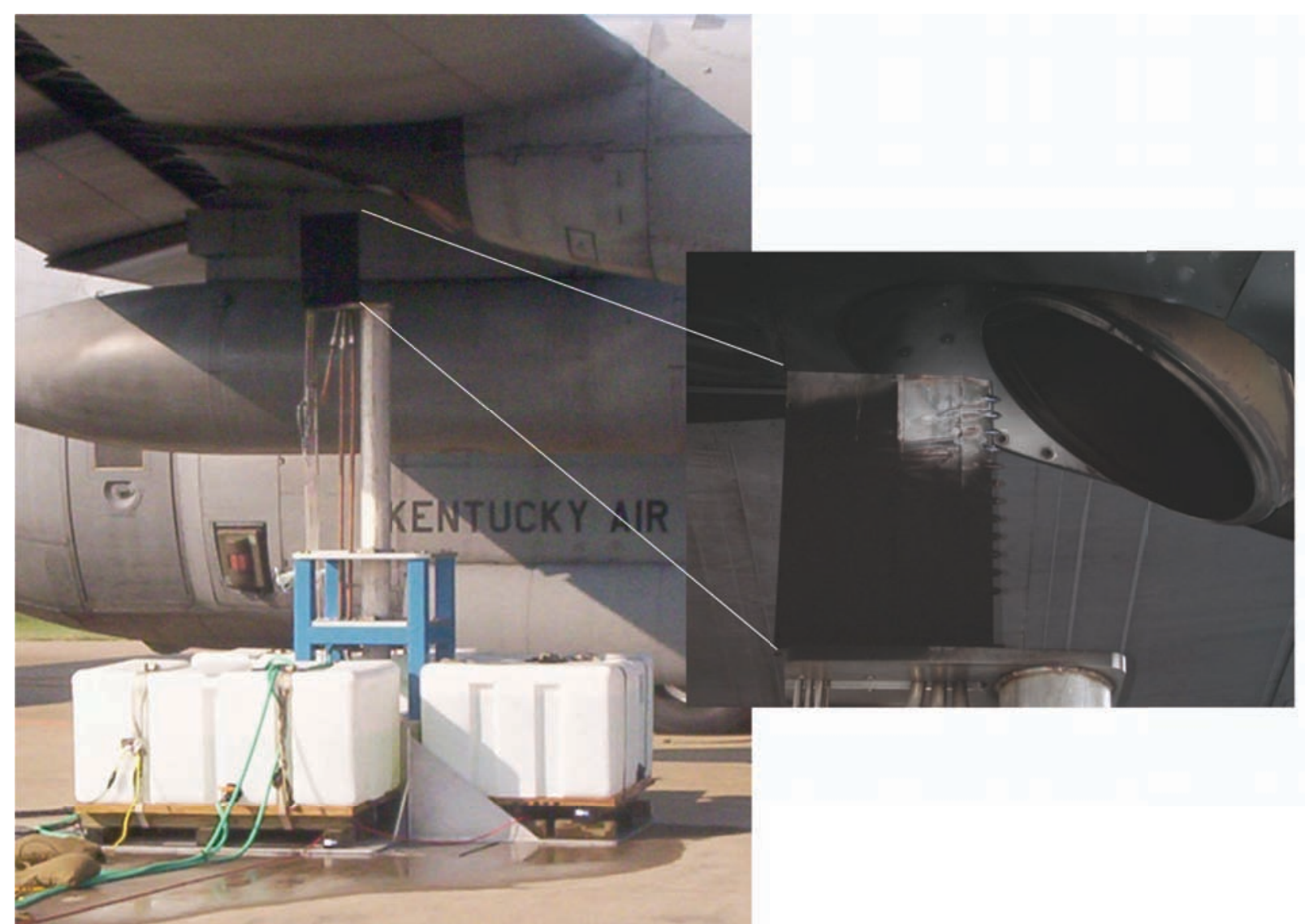

Fig. 4. Close-up photo of extractive sampling set up 


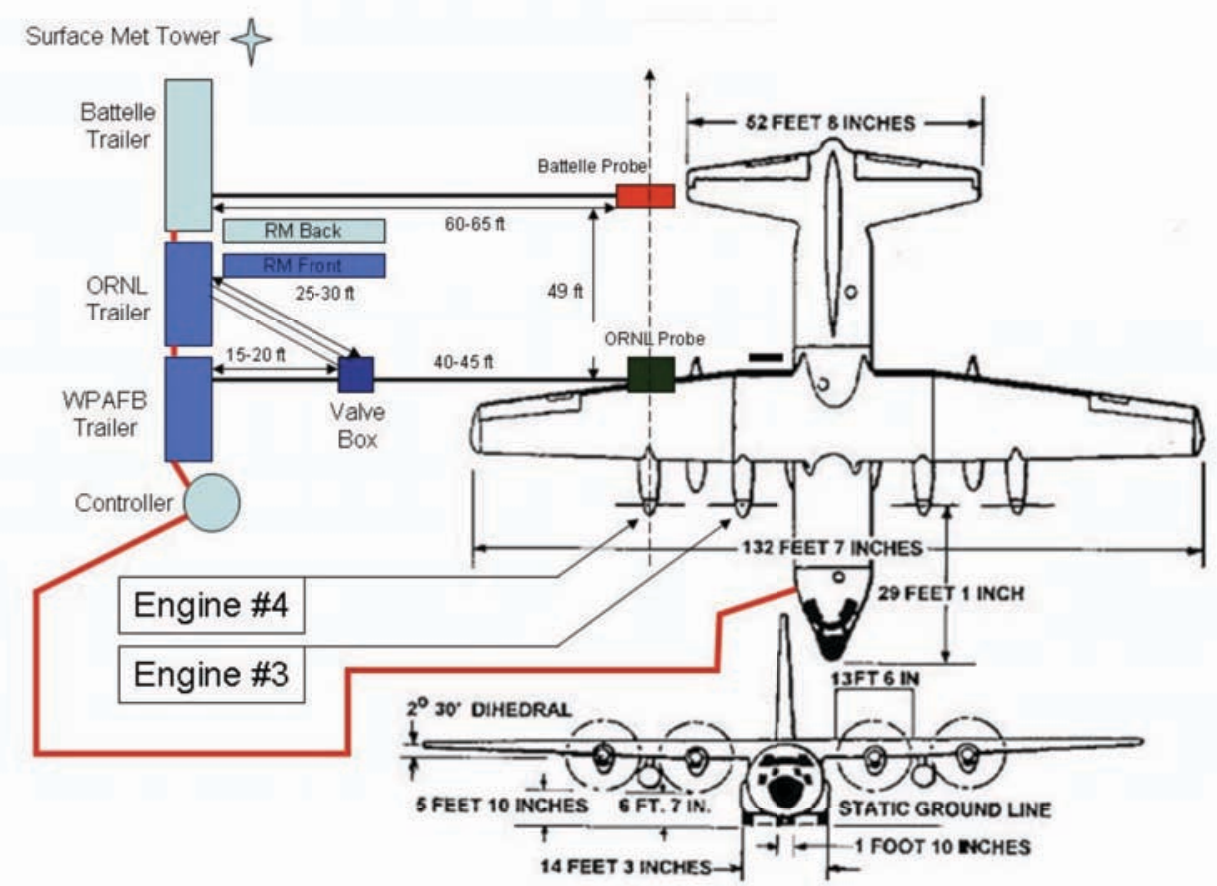

Fig. 5. Schematic of field setup for $\mathrm{C}-130 \mathrm{H}$ campaign

Samples extracted from the exhaust plume are transported to two different categories of instruments for analysis. These are (1) continuous on-line measurement or (2) time-integrated sample collection (typically on filters) for subsequent laboratory analytical determination. Extracting samples at the engine exhaust plane (EEP) from a high-temperature high-speed moving plume is challenging. The temperature and pressure of the exhaust plume at the max thrust of a B-52 engine actually boiled the cooling water used in the dilution probe rake causing it to leak. The thrust at the max engine power of a B-52 engine compromised the stability of the remote-sensing platforms even they were at distances of $19 \mathrm{~m}$ and $32 \mathrm{~m}$ downstream. The stability of the extractive sampling platform was secured, however, under a total weight of $3,280 \mathrm{~kg}$ from the three 300 -gal water tanks. The platforms hosted the ORS instruments on one side of the plume and retroflectors on the other side of the plume. The ORS platforms were in the perpendicular distance $16-22 \mathrm{~m}$ from the centerline of the plume.

The extractive sampling rake and probes used in this project were designed and fabricated by the Arnold Engineering Design Corporation (AEDC) at Tullahoma, TN. Twelve (12) probes can be mounted simultaneously on the rake; each probe is separated center-to-center by about $2.54 \mathrm{~cm}$. The probe tips were typically located at about $35 \mathrm{~cm}$ normal from the engine nozzle. These probes enable extractive sampling of gases and particulate matter directly at the EEP. For particulate sampling, probe-tip dilution using dry nitrogen gas is used to minimize any potential coagulation and wall lost due to high particle counts. Probe-tip dilution also serves to reduce the likelihood of water condensation in the sampling line. Sample dilution also prevented the saturation of the analytical instrumentation. The probes for gas species sampling were not diluted and so were those for measurements of total particulate mass, carbon, sulfur, sulfate, elemental composition, and smoke number. 
The sampling system was configured to allow for switching of sampling probes via fast-response ball valves to direct the sample from each probe to different instruments. The routing valves were installed in a heated box $\left(150^{\circ} \mathrm{C}\right)$ located between the aircraft and instruments. All sample lines from the probe stand base to the valve box $(16 \mathrm{~m}$ long $)$ were maintained at $150^{\circ} \mathrm{C}$.

The undiluted sample lines were maintained at $150^{\circ} \mathrm{C}$, and the diluted particle samples were maintained at $75^{\circ} \mathrm{C}$ from the valve box to the instruments $(8.3 \mathrm{~m}$ long) to help maintain sample integrity. Emissions samples were drawn into the individual instruments via vacuum pumps used by each instrument. The inner diameter of the sample lines was $4.6 \mathrm{~mm}$, unless specified otherwise, and the total length from the sampling point to the instruments was approximately $25 \mathrm{~m}$.

\section{(II.2.2) Optical Remote-Sensing (ORS) Platform}

A graphical representation of the remote-sensing instrument setup is illustrated in Fig. 6 in which an ORS platform is located at about $5 \mathrm{~m}$ and the second group about $15 \mathrm{~m}$ downstream from the EEP during the C-130H campaign. Sampling at several locations along a plume downstream allows the opportunity to obtain information on pollutant transformation. Similar configuration was used in the subsequent B-52 and T700 engine series campaigns in the year two and three of this program. Due to the space constraint at the Hunter facility, the remote-sensing configuration was modified. The space constraint shortened the beam lengths of several instruments forcing us to move the light sources and retroflectors of the open-path spectroscopy closer to the EEP. A shorter beam path would reduce the sensitivity of the instruments, but higher concentrations of pollutants at a distance closer to the engine nozzle could compensate for the reduction in detection sensitivity as we learned in this project.

The use of extractive measurements can provide detailed information regarding the characteristics of the engine exhaust as we had demonstrated in this program. However, the sampling conditions at the

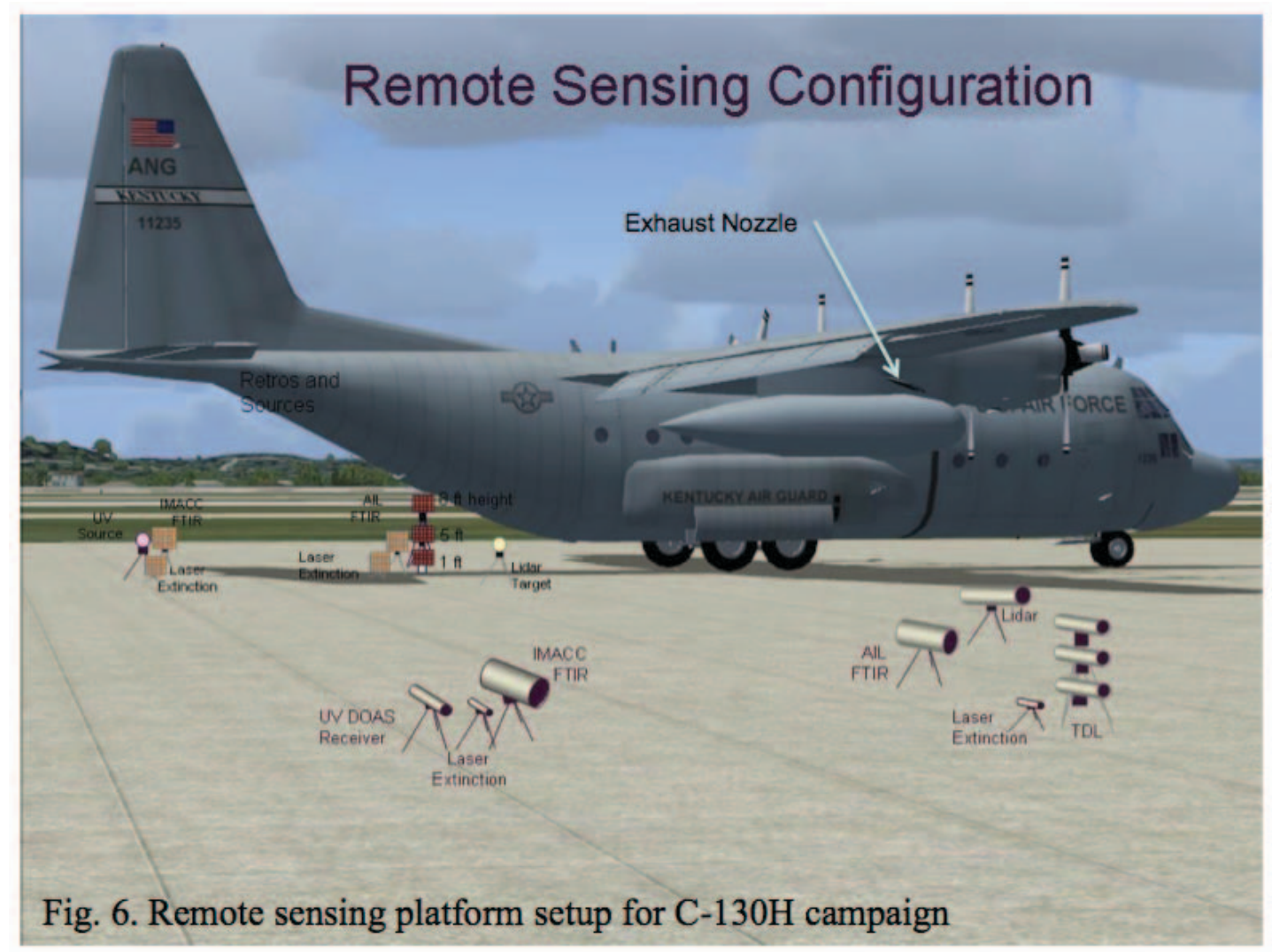


point of engine exhaust are harsh to instruments and dangerous to operators. Development of remotesensing methodologies could potentially provide information on the characteristics of engine exhaust and may complement the extractive measurements. The remote-sensing platform is unconventional and the techniques require developmental works to use for aircraft emissions-type applications. However, as the remote-sensing techniques are relatively fast compared to those mentioned above, they can be employed for measuring trace concentrations of target species and investigating the environmental fate of the exhaust constituents as they are diluted and cooled with the ambient atmosphere.

Instruments deployed for the remote sensing platform for this program were initially chosen for both gas-phase species and particulate matter. However, it was determined through the course of this research that currently available remote-sensing instruments are best suited for measurement of gaseous species. None of the remote-sensing techniques deployed for this project could provide the chemical composition and physical size distribution of particles smaller than a couple of hundred nanometers (i.e., the ultrafine fraction of the engine particle population), which is actually the size range for the majority of the engine particulate emissions. One would find most of particles emitted by the military aircraft engines are in the 40nm-size mode, which made it extremely hard to use optical sizing methods in the open-path configuration. In addition, to derive emission indices using the ORS data require a number of assumptions about the physics of the aircraft plume that are difficult to verify. At the minimum, the plume geometry has to be known to help derive the emissions indices. The geometry information was unavailable a priori for any of the three platforms; therefore, additional instruments were employed during the campaigns in an attempt to retrieve plume flow characteristics, such as stream velocity and plume boundary condition. Other assumptions include (1) no chemical transformation between the EEP and optical plane and (2) velocity and concentration profiles are Gaussian. These are strong assumptions and difficult to validate. The uncertainty embedded in those derived plume physics data propagates through our subsequent calculation for emissions indices.

\section{(II.3) Instrumentation}

To obtain an extensive properties of the engine emissions, a large array of instruments were employed. These instruments were listed in Table 1. For measurement of the properties of extracted samples at the EEP, the instruments include the followings: (1) condensation particle counter (CPC), (2) a laser particle counter (LPC), (3) scanning mobility particle sizer (SMPS) which consists of a differential mobility analyzer and condensation particle counter or electrometer, (4) tapered element oscillating microbalance (TEOM), (5) smoke sampler, (6) PM-1 samplers, (7) Fourier-Transform Infrared spectrometer (FTIR), and (8) heated total hydrocarbon analyzer (THC).

The CPC (TSI model 3022A) is used to obtain the count of the total particles per unit volume (PN) from $10 \mathrm{~nm}$ up to $1 \mu \mathrm{m}$, while the LPC (MetOne) provides total particle counts from $300 \mathrm{~nm}$ and up to $5 \mu \mathrm{m}$. Both require approximately 10 seconds for measurement. The SMPS (TSI Model 3936) system uses a long (TSI Model 3081) or nano (TSI Model 3085) differential mobility analyzer (DMA) with a butanol-based CPC. The DMA separates the polydisperse particle exhaust into a monodisperse stream and the CPC measures the corresponding concentration for each particle size. The CPC can be a TSI model 3022A for particles as small as 9nm or model 3025A for detection of particles as small as $3 \mathrm{~nm}$.

Accordingly, measurement over a range of particle sizes requires sampling at a constant engine condition. A single size distribution measurement requires between 100-200 seconds. Use of the long DMA allows measurement of size distributions in the mobility size range of $9 \mathrm{~nm}$ up to $640 \mathrm{~nm}$, while the nano DMA typically measures from $3 \mathrm{~nm}$ up to $250 \mathrm{~nm}$. The overlap size region from 9 to $250 \mathrm{~nm}$ was used to evaluate the consistency of the distributions obtained from each type of DMA. 
The 3085 DMA was also used with an electrometer during the Hunter campaign when the prototype fastscan particle sizer was ready for field test. This new configuration requires a custom-made control code written in the LabView ${ }^{\circledR}$ and executed on a laptop operated under Windows XP ${ }^{\circledR}$. Both DMA and electrometer are commercially available; however, an interface box between the DMA and electrometer was needed and developed. An example of the measured size distributions by this prototype instrument is discussed in the HAAF section. The advantage of this new fastscan prototype is that it can be used at a location close to $(<1 \mathrm{~m})$ the EEP; thus, the line-loss issue for engine particles was virtually eliminated with this instrumentation approach. In addition, the response time for this prototype is 5 to 10X faster than the commercial instrument making it suitable for probing transient emissions, although the transient conditions were insignificant for this project as all engine tests were done at the steady-state condition of various engine powers.

For particulate mass measurement, the TEOM (R\&P Model 1105) measures real-time particulate mass concentrations of the non-volatile particle emissions; the instrument requires approximately 5 minutes for a stable measurement to be obtained. A smoke sampler designed and fabricated at WPAFB is used to collect exhaust samples on paper filters to determine engine smoke numbers (per SAE ARP 1179) or on quartz filter for subsequent off-line analysis and characterization.

Two PM samplers equipped with 1- $\mu \mathrm{m}$ size cut are used to collect particles on different filter media. One set of filter media is TEFLO ${ }^{\circledR}$ for particulate metal content by X-Ray Fluorescence (XRF), while the other set of filters are quartz for measurement of particulate carbon content using a National Institute for Occupational Safety and Health (NIOSH) method with the Sunset OC/EC instrument (Birch and Cary, 1996). The ORNL OC/EC procedure follows the NIOSH method for the determination organic and elemental carbon on particulates collected on the quart filters for ambient and diesel soot particulate measurement. The sampling durations of the PM-1 carbon samples ranged from 5 to 20 min depending on the engine power setting. There was another set of carbon measurement by WPAFRL, which utilized LiCOR total carbon analyzer. These analyzers require sufficient sampling time in order to collect the desired quantity of exhaust particulate matter. Both analyzers gave similar measurements of total and elemental carbon.

During the third year, we also developed a prototype fastscan particle sizer. The prototype consists of commercially available hardware (i.e., a TSI 3080 Electrical Classifier, a nano-DMA, and an electrometer), which does not communicate with each other. However, a communication interface was developed and control software was developed on LabVIEW ${ }^{\circledR}$ to run on Windows platform. Using these two devices we operated the prototype device from a distance of $1 \mathrm{~m}$ sampling length from the engine exhaust, which we believe significantly reducing the problem of particle loss through the conventional $23 \mathrm{~m}$ sampling line required for the extractive platform. The measurement interval of the prototype was programmable up to hours, but was able to run as fast as 20 s per scan if needed. The results shown in the T700/T701C Section of this report demonstrates the utility of such a fast measurement capability in aircraft emission measurement.

For gas species measurement by the extractive platform, the FTIR (MKS Multigas 2030) was used to quantify $\mathrm{CO}, \mathrm{CO}_{2}, \mathrm{NO}, \mathrm{NO}_{2}, \mathrm{SO}_{2}$, and $\mathrm{H}_{2} \mathrm{O}$, while the unburned hydrocarbon concentration is determined using a THC monitor (CAI model 600 HFID); these instruments require less than 1 minute to obtain a stable reading.

Several remote-sensing measurement techniques were evaluated for feasibility earlier of this program and a short list of techniques were then implemented within this program for quantifying aircraft engine emissions. The basic instrumentation set for the ORS platform consists of two Open-Path FourierTransform Infrared Spectrometers (OP-FTIR; Kagann et al., 2002; Hashmonay et al., 1999a; 1999b), 
three Open-Path Tunable Diode Laser Absorption Spectrometers (OP-TDLAS; Nelson et al., 1998), two transsimometers, and one UV Differential Optical Absorption Spectrometer (UV DOAS).

During the first campaign, we also deployed a prototype Light Detection and Ranging (LIDAR) instrument (Simpson et al., 2005). This LIDAR was initially developed to detect the distribution of particles across an exhaust plume of a diesel truck, which in theory might be feasible to use for detect the edge or volume boundary of the cross section of an aircraft plume. This prototype LIDAR instrument measures particle number density across the plume uses a compact intensity-modulated, stepped frequency CW LIDAR operating on a blue $405-\mathrm{nm}$ diode of $3 \mathrm{~mW}$. A lock-in amplifier was used to drive the frequency modulation of the $\mathrm{CW}$ beam in discrete steps from 10 to $200 \mathrm{MHz}$ creating a chirped coherent light for probing distributed aerosol particles; the ranging resolution was on the order of $70 \mathrm{~cm}$ for this prototype. A 30.48-cm Smith-Cassigran telescope was used as the collection optics for return retrieval and the laser diode was center in the optics as the excitation source. Instrument control and data acquisition was done by custom-made software written by ORNL personnel. It is important to note that this prototype instrument was used only once in the first of the three campaigns due to technical problems involved in the hardware and software. We found that significant developmental work is required to make this technology field rugged and reliable; thus, we decided not to pursue this technology in the subsequent campaigns with the limited resources.

Gaseous species were measured by a twin, parallel plane tunable diode laser absorption spectroscopic (TDLAS; Nelson et al., 1998) system in addition to OP-FTIR (Kagann et al., 2002; Hashmonay et al., 1999a; 1999b) and UV DOAS. These remote sensing techniques cover several species ranging from the UV-active to Inferred (IR)-absorbing molecules. TDLAS makes continuous measurements of $\mathrm{CO}, \mathrm{CO}_{2}$; the measurements are based on the absorption of monochromatic light from tunable diode laser in the near infrared region of the spectrum (around $1.5 \mu \mathrm{m}$ ). Ratio of $\mathrm{CO}$ and $\mathrm{CO}_{2}$ to a pollutant concentration at one beam allows us to estimate cross-sectional flux of the pollutant, which may be expanded to calculate emission factors for other air pollutants and Hazardous Air Pollutants.

UV DOAS measures $\mathrm{SO}_{2}$ and $\mathrm{NO}_{\mathrm{X}}\left(=\mathrm{NO}+\mathrm{NO}_{2}\right)$, and OP-FTIR measures total hydrocarbons and speciated hydrocarbons concentrations. OP-FTIR is an established technique for measurement of gaseous species, such as acetaldehyde, acrolein, benzene, carbon tetrachloride, formaldehyde, and vinyl chloride. The OP-FTIR instrument passes an infrared light along an open beam path through the aircraft engine emission plume and identifies chemical contaminants from IR absorption spectra, while UV DOAS performs an absorption measurement, similar to OP-FTIR, but the absorption is done in the ultraviolet wavelength range. The use of both wavelength regions yielded data on an interval of several seconds/sample simultaneously for multiple chemical species typically with ppbv detection sensitivity. The aerosol extinction instrument was actually the OP-FTIR that was proven to be insensitive to the extinction of ultrafine particles of the engine emissions.

The characterization techniques used on the two sampling platforms throughout the three years of the life of this project, and the instruments are tabulated in Table 1. The instruments provided near realtime data about the particle size distribution, number and mass concentrations and gaseous emissions. 
Table 1. List of Instruments Used in Each Campaign

[Platform P = Extractive measurement; Platform R = Remote Sensing measurement

\begin{tabular}{|c|c|c|c|c|c|}
\hline & Instrument and Model No. & Measurement Parameter & T56 Test & $\begin{array}{l}\text { TF33 } \\
\text { Test }\end{array}$ & $\begin{array}{c}\text { T700 \& } \\
\text { T701C } \\
\text { Test }\end{array}$ \\
\hline$P$ & $\begin{array}{l}\text { Condensation Nuclei Counter } \\
\text { (CNC) CPC TSI Model 3022A }\end{array}$ & $\begin{array}{l}\text { Particulate number Density } \\
\qquad\left(\# / \mathrm{cm}^{3}\right)\end{array}$ & $\mathrm{X}$ & $\mathrm{X}$ & $\mathrm{X}$ \\
\hline $\mathrm{P}$ & $\begin{array}{l}\text { Tapered Element Oscillating } \\
\text { Microbalance (TEOM), Rp } \\
\text { Series } 1105 \text { Particle Monitor }\end{array}$ & $\begin{array}{c}\text { Particulate mass } \\
\text { concentration }\left(\mathrm{mg} / \mathrm{m}^{3}\right)\end{array}$ & $\mathrm{X}$ & $\mathrm{X}$ & $\mathrm{X}$ \\
\hline $\mathrm{P}$ & Laser Particle Counter (LPC) & $\begin{array}{l}\text { Particulate count for particles } \\
\text { larger than } 300 \mathrm{~nm}\end{array}$ & $\mathrm{X}$ & $\mathrm{X}$ & $\mathrm{X}$ \\
\hline $\mathrm{P}$ & $\begin{array}{c}\text { On-line Gas Analyzer, MKS } \\
\text { Multigas } 2030\end{array}$ & $\mathrm{NO}_{\mathrm{x}}, \mathrm{CO}, \mathrm{CO}_{2}, \mathrm{SO}_{2}$ & $\mathrm{X}$ & $\mathrm{X}$ & $\mathrm{X}$ \\
\hline $\mathrm{P}$ & ORNL Fastscan & $\begin{array}{l}\text { Particle number distributions } \\
\qquad(1-250 \mathrm{~nm})\end{array}$ & & & $\mathrm{X}$ \\
\hline $\mathrm{P}$ & $\begin{array}{c}\text { Nano and Long SMPS TSI } \\
\text { 3936NL25 }\end{array}$ & $\begin{array}{c}\text { Particle number-size } \\
\text { distribution }(4-640 \mathrm{~nm})\end{array}$ & $\mathrm{X}$ & $\mathrm{X}$ & $\mathrm{X}$ \\
\hline $\mathrm{P}$ & $\begin{array}{c}\text { Aerodynamic Particle Sizer } \\
\text { TSI } 3320\end{array}$ & $\begin{array}{l}\text { Particle number-size } \\
\text { distribution } \\
(530-10,000 \mathrm{~nm})\end{array}$ & $X$ & $\mathrm{X}$ & $\mathrm{X}$ \\
\hline $\mathrm{P}$ & Integrated PM-1 sampler & Metals and carbons & $\mathrm{X}$ & $\mathrm{X}$ & $\mathrm{X}$ \\
\hline $\mathrm{R}$ & ORNL LIDAR & $\begin{array}{l}\text { Particle number-size } \\
\text { distribution }\end{array}$ & $X$ & & \\
\hline$\overline{\mathrm{R}}$ & OP-FTIR & IR-absorbing species & $\bar{X}$ & $\bar{X}$ & $\mathrm{X}$ \\
\hline $\mathrm{R}$ & OP-TDLAS & $\mathrm{CO}, \mathrm{CO}_{2}, \mathrm{NO}_{\mathrm{x}}, \mathrm{HC}$ & $\bar{X}$ & $\mathrm{X}$ & $\bar{X}$ \\
\hline $\mathrm{R}$ & UV-DOAS & UV-active species & $\mathrm{X}$ & $\mathrm{X}$ & $\mathrm{X}$ \\
\hline $\mathrm{R}$ & Aerosol Extinction Instrument & Aerosol extinction & $\mathrm{X}$ & $\mathrm{X}$ & $\mathrm{X}$ \\
\hline
\end{tabular}




\section{(III) RESULTS AND DISCUSSION}

The three-year results are summarized in this chapter. Some of the results are published in open literature (see Appendix) or presented in technical conferences, while some are still in review as this report is being prepared in 2009. Results from testing on C-130H, B-52, and the T700/T701C engines campaigns are presented sequentially in Section (III). The results are divided into particulate matter and gaseous species.

\section{(III.1) C-130H T56 Turboprop Engines}

The military aircraft tested in the first campaign of this program was a $\mathrm{C}-130 \mathrm{H}$ aircraft. The field study was conducted at the Kentucky Air National Guard (KYANG) in Louisville, KY in October 2005. Throughout the week, the sky conditions were clear to partially cloudy. The ambient temperatures ranged from $10^{\circ} \mathrm{C}$ during early morning hours to $24^{\circ} \mathrm{C}$ during the afternoon to early evening hours. Wind was breezy but not gusty.

During the test, emissions from each of the two engines on one wing of the aircraft were independently sampled and characterized by a number of instrumentation placed at various locations along and across the exhaust plume from the exhaust exit plane outward. The outboard engine (further from the fuselage) was tested first in the first two days of the campaign, while the inboard engine (closer to the fuselage) was tested during the last two days. When testing the outboard engine, the inboard engine was not operating, although the similar engine (e.g., inboard or outboard) on the opposite wing was operated simultaneously to balance the aircraft.

For each test cycle, five separate engine settings with increasing thrust levels were tested. These engine load settings are labeled as (1) low speed ground idle (LSG idle), (2) high speed ground idle (HSG idle), (3) flight idle, (4) cruise, and (5) max power. For all conditions except LSG idle, the engine was operated at $100 \%$ of the maximum engine speed. Changing the torque to the propeller changed the thrust of the engine and subsequently the engine load. The power settings given below are based on the torque for that setting relative to the maximum engine torque.

1) Low speed ground idle - $4 \%$ of the max engine speed

2) High speed ground idle - 7\%

3) Flight idle - $20 \%$

4) Cruise $-41 \%$

5) Maximum power - $100 \%$

For each engine power setting, the aircraft crew increased the thrust until the appropriate level was achieved. The engine condition was maintained stable for approximately 20 minutes to provide sufficient sampling time for all measurement techniques. After all the measurements were completed at a given engine power setting, the crew was instructed to increase/decrease the thrust level to the next engine setting.

During the campaign, sampling was typically undertaken for three replicate cycles of five engine power settings during each testing day, resulting in data for a total of 11 cycles and 55 engine load settings. 


\section{(III.1.1) Particulate Matter Emissions}

\section{Particle Number and Size Distributions}

The averaged particle size distributions were obtained at EEP and dilution-corrected by using measured $\mathrm{CO}_{2}$ concentrations at raw and diluted particle samples, and averaged geometric mean diameters for both engines are shown in Fig. 7 and Fig. 8, respectively. These results are the averaged curves taken at a 64-bin resolution every 120 seconds. The modal diameters for all engine power settings were smaller than $70 \mathrm{~nm}$ and the peak number concentrations corrected for probe-tip dilution were above $1 \times 10^{7}$ particles per $\mathrm{cm}^{3}$. It is important to note that the dominant sizes of these engine particles were all less than $100 \mathrm{~nm}$ in the range of "ultrafine" particles. The concentrations produced by the three idle conditions were between those obtained for the max and cruise conditions.

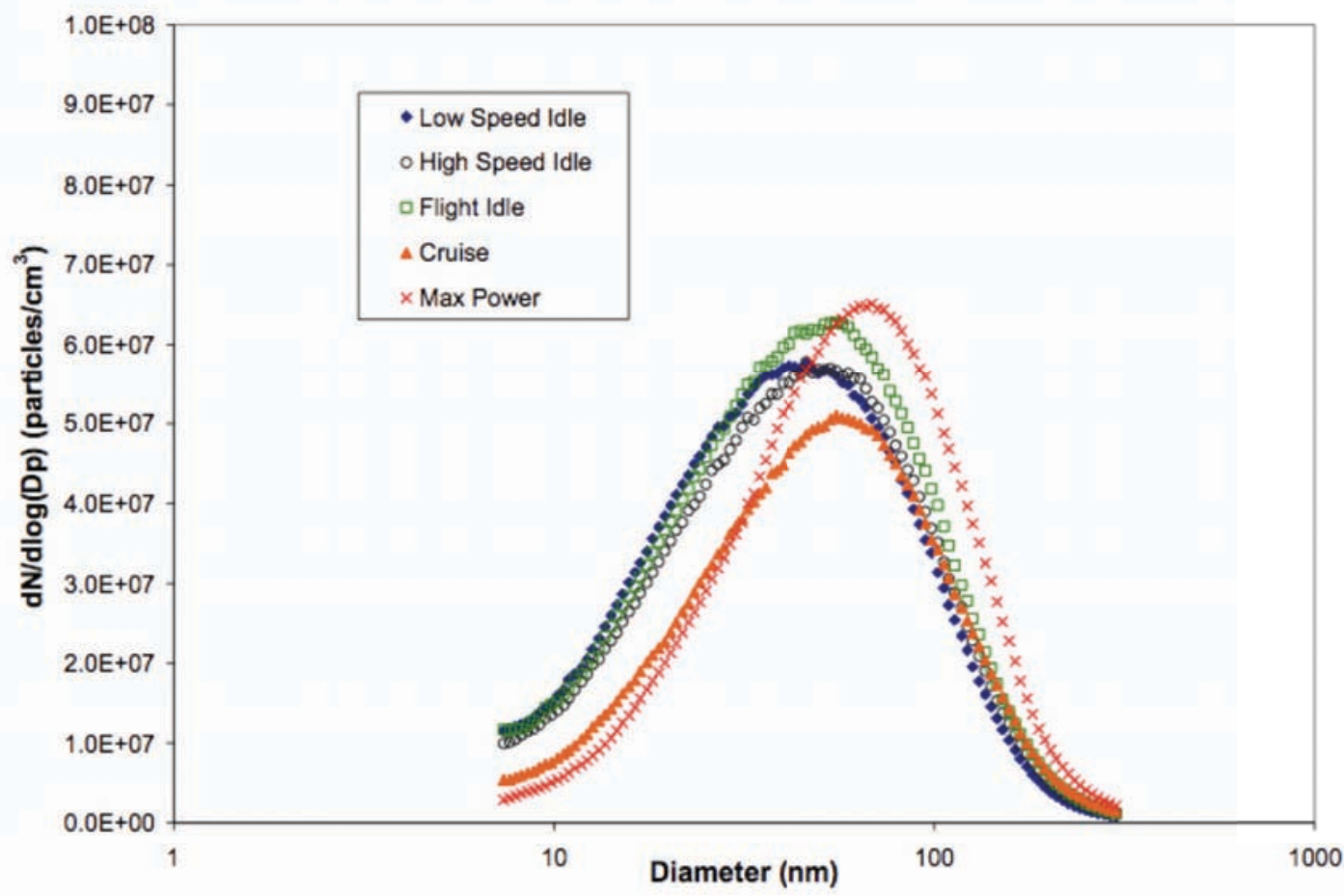

Fig. 7. Averaged dilution-corrected particle size distributions for the T56 engines

The difference of the modal particle sizes between the two engines were found to be negligible for the cruise and max engine power conditions, while statistically different particle sizes were found in the three idle power conditions and the sizes of the outboard engine were found to be consistently larger (Fig. 8). There are many possibilities of what the causes might be, but the exact reason for the inboard engine to generate consistently smaller-size particles than those produced by the outboard engine at idle conditions was unclear. We don't think this is an instrument issue as collocated instruments were observing similarly. Pursue of the causes appears to be beyond the scope of this work and was decided not to. Note that the downstream size distributions obtained with another SMPS equipped with a nanoDMA were similar to those shown in Fig. 8 after the distributions were corrected for plume dilution [Cheng et al. (2008)]. 


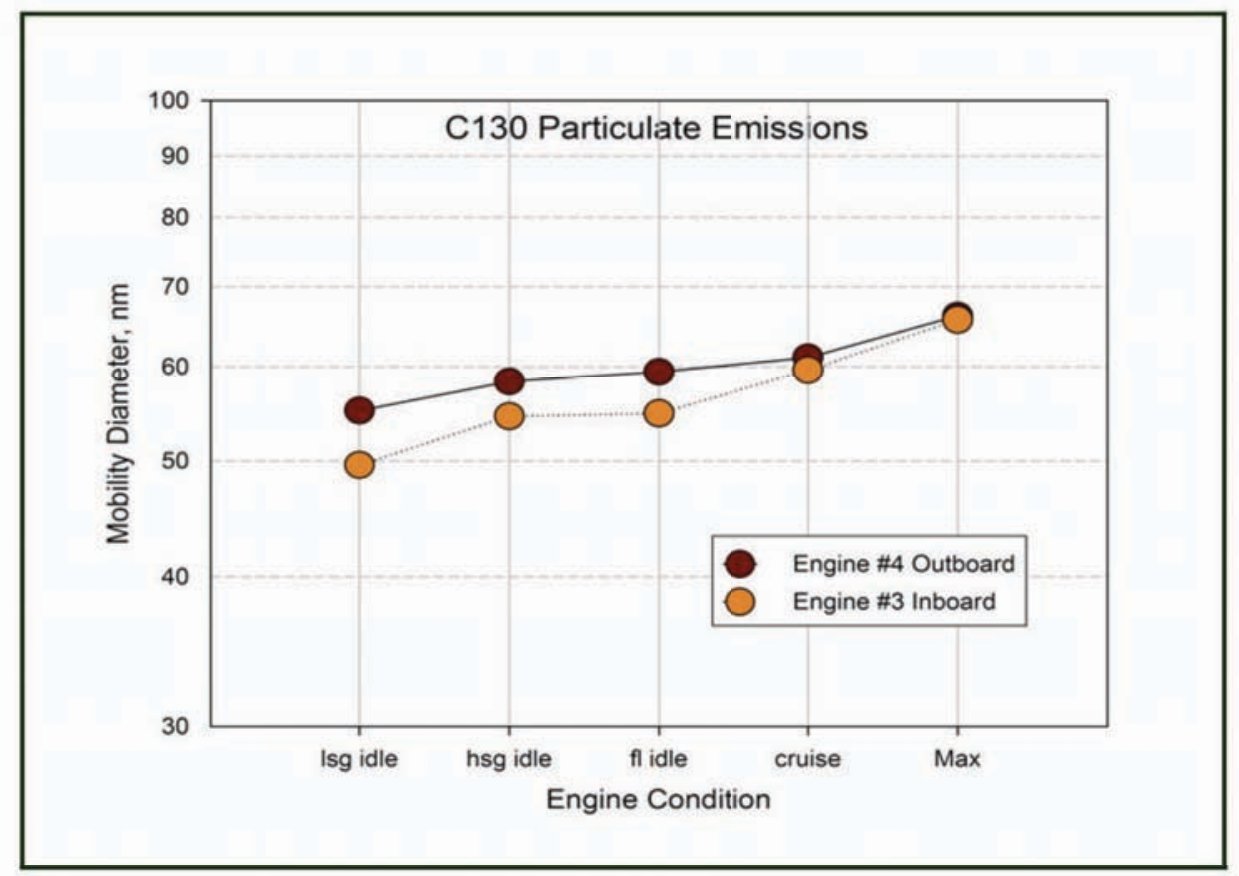

Fig. 8. Plot of mobility diameter of $\mathrm{C}-130 \mathrm{H}$ particles versus engine power level

Small variations in the engine fuel-to-air (F/A) ratios could have a significant impact on the PM emissions, the emission index based on the particle number concentration (EI; number particles per kgfuel), EI_pn, is especially sensitive to the variation. The particle number concentration data used for EI_pn calculation were obtained by using a condensation particle counter of non-scanning version (TSI 3022). EI_pn was calculated by using the following equation derived from the fluid flow fundamentals and the assumption that the molecular weight of the exhaust gases averages that of air $(28.96 \mathrm{~g} / \mathrm{g}$ mol $)$ :

$$
\text { EI_pn }=2833 * \mathrm{PN}_{\text {corrected }} *(1+\mathrm{F} / \mathrm{A}) /(\mathrm{F} / \mathrm{A}) * \mathrm{~T}_{\text {sample }} / \mathrm{P}_{\text {sample }}
$$

where EI_pn is in number particles per kg-fuel, $\mathrm{PN}_{\text {corrected }}$ is the corrected $\mathrm{PN}$ in no. $/ \mathrm{cm}^{3}, \mathrm{~T}_{\text {sample }}$ is the sample temperature at the instrument in Kelvin $(\sim 293 \mathrm{~K}) . \mathrm{P}_{\text {sample }}$ is the sample pressure at the instrument in atmospheres $(\sim 1 \mathrm{~atm})$, and $\mathrm{F} / \mathrm{A}$ is the engine fuel-to-air ratio.

The F/A ratios were calculated based on the stoichiometry of the reactants and the primary gaseous products $\left(\mathrm{CO}\right.$ and $\left.\mathrm{CO}_{2}\right)$. Excellent agreement was observed between the F/A ratios for each condition for both engines and probes with ratios ranging from 0.0085 at high-speed idle to 0.021 at maximum power. The EI_pn are averaged to be $1.8 \mathrm{E}+16,1.4 \mathrm{E}+16,1.4 \mathrm{E}+16,1.0 \mathrm{E}+16$, and $1.2 \mathrm{E}+16$ particles/kg-fuel burned for the five engine power settings, respectively.

The EI_pn was 40-50\% higher for the three idle conditions than for the two high power cases, which suggests improved combustion of soot particles and precursors (semi-volatiles) at higher power settings. A significant concentration of particles formed at the idle is believed to be semi-volatile species. As observed, the EI_pn were $\sim 25 \%$ lower for the inboard engine at the low-speed ground idle. This power 
setting was the only condition in which the particle emissions between the two engines were significantly different, which we think it might explain the difference in the modal mobility diameter shown in Fig. 8. Particle Mass

A TEOM was used to directly quantify the total PM mass emissions of the T56 engines on a semi-continuous basis. The $\mathrm{CO}_{2}$ dilution-corrected PM mass concentrations of $10-25 \mathrm{mg} / \mathrm{m}^{3}$ were observed for the conditions tested. The total PM mass concentrations were lower for low-speed ground idle and relatively similar for all other conditions. Excellent agreement was observed for the measurements between probes and each engine except for the low-speed ground idle. Overall, the data reproducibility for each engine setting was between 5 and 15\%, with the largest deviation observed for the maximum power condition. This is likely because of extensive instrument vibration inherent at this condition.

Dilution-corrected PM mass EI were determined using a similar correlation as described above for the EI_pn. The PM mass EI ranged from $0.9-2.2 \mathrm{~g} / \mathrm{kg}$-fuel. Considering the estimated losses in the sample transfer line, the corrected PM mass EI averaged 1.6-3.5 g/kg-fuel, which are in excellent agreement with those reported by Wade (2004) of 1.2 and $3.6 \mathrm{~g} / \mathrm{kg}$-fuel for a similar range of engine conditions. The agreement between these and previous results increase confidence that the techniques and instrumentation used in this study are viable for the measurement of PM mass emissions from turbine engines.

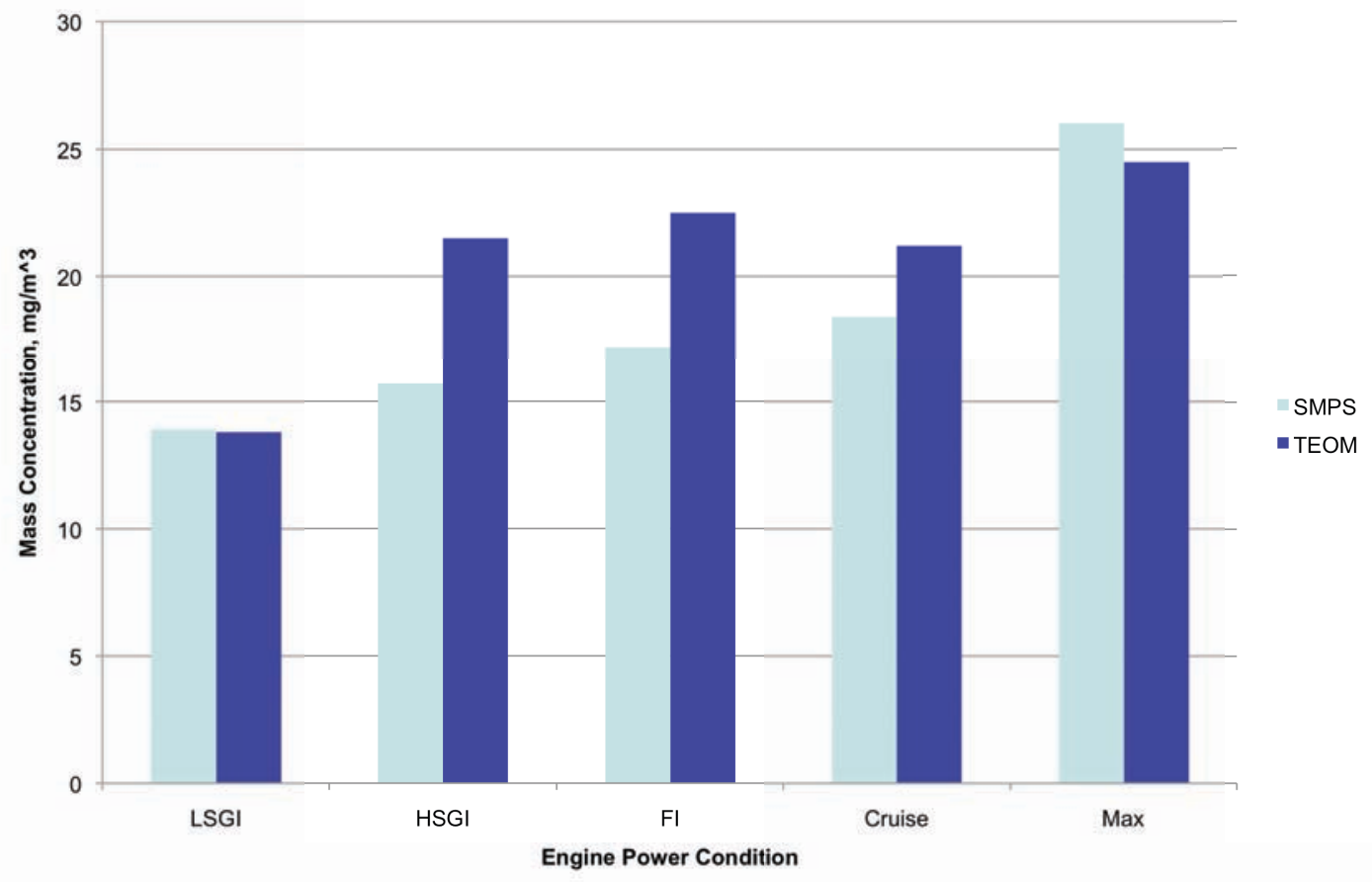

Fig. 9. Comparison of $\mathrm{C}-130 \mathrm{H}$ particle mass concentrations obtained by SMPS and TEOM

PM mass emissions could also be estimated using the aerosol size distribution data collected with the SMPS. The calculation requires assumptions for the soot particle geometry and density. Diesel soot particles within the submicrometer size range are considered to have a density value of $1.2 \mathrm{~g} / \mathrm{cm}^{3}$ (Maricq 
and $\mathrm{Xu}, 2004$ ), and the same value was used herein. The average PM mass was calculated using the size distribution data (corrected for dilution and line losses) multiplying the total particle count for each bin size by the density to yield particle mass (see Fig. 9). Relatively good agreement (better than $\sim 30 \%$ ) was observed between the averaged mass concentrations measured with the TEOM and estimated with the size distribution.

However, the SMPS data was greater than that for the TEOM as shown in Fig. 9. Although good agreement was observed in these test results between the TEOM and SMPS-derived PM mass, the assumptions of particle geometry and density could have produced significant error in the calculated mass based on SMPS data. The particle density could be measured (e.g., Kelly and McMurry, 1992), but the team did not have the instrument nor such an instrument is ready for major field experiment such as this one. Further development of aerosol density measurement may help solve the issue. However, with an additional instrument needed in order to "calculate" particle mass, it is rather that direct mass measurement techniques (e.g., TEOM, gravimetric) be recommended for more accurate and reliable measurements of PM mass if it is possible.

It is also relevant at this point to mention however that the mass measurement by TEOM or gravimetric method may fail as the newer fighter jet engines, F-35 and F-22 for instance, have improved that leads to very low particle emissions. With extremely small particle size and low particle concentration of the new jet emission, low mass concentration may present a significant challenge to current mass measurement technique for aircraft emission measurements. This could potentially lead to a paradigm change in measurement metrics of engine-emitted particles using particle counts instead of particle mass, for example.

\section{Smoke Number}

The smoke numbers (SN) determined for the emissions of the $\mathrm{C}-130 \mathrm{H}$ aircraft at KYANG were averaged to be 31, 41, 43, 41, and 45 for the five engine power conditions. Excellent agreement between the SN was observed for the two engines. In general, the SN was very similar for all engine-power conditions, except LSGI. The smaller particles generated at LSGI appeared contributing little to the mass (by TEOM) and SN. The SN values for the higher-power conditions (i.e., two higher-power idles, cruise and max) were approximately the same; the differences among them were statistically insignificant.

\section{(III.1.2) Gaseous Emissions}

Emissions of gas species from T56 engines were measured using an FTIR-based MKS Type MultiGas 2030 analyzer on the extracted samples taken by the gas sampling probes at EEP. Three primary combustion species of interest $\left(\mathrm{CO}, \mathrm{CO}_{2}\right.$ and $\left.\mathrm{NO}_{\mathrm{x}}\right)$ are shown in Fig. 10 as a function of engine condition. At the low-speed ground idle, the $\mathrm{CO}$ concentrations were approximately seven (7) times higher than those observed at the other engine conditions, evidence of this being the least efficient condition. This result mirrors those reported earlier in the mass-based indices like SN and TEOM mass, but not in the count-based index as SMPS size distribution or CPC total counts.

The carbon dioxide $\left(\mathrm{CO}_{2}\right)$ concentration ranging from 1.5 to $4.5 \%$ shows a convex curve pattern where the lowest power setting (LSGI) was recorded with a higher $\mathrm{CO}_{2}$ value than the other two idling conditions. The $\mathrm{CO}_{2}$ emissions at the cruise and max power conditions were 1.5 to 3 times higher than those at the idle conditions because of the increased combustion efficiency at higher power conditions. However, the outlying $\mathrm{CO}_{2}$ value observed for the LSGI condition could be suggestive of the extraordinarily high $\mathrm{CO}$ value at the same power condition indicating incomplete combustion. 
The concentrations of $\mathrm{NO}_{\mathrm{x}}$ appear similar for the three idle conditions, and increased as the F/A increased during the cruise and maximum power conditions. This behavior was expected because the primary route for $\mathrm{NO}_{\mathrm{x}}$ formation is via the combustion pathways. As the engine power increased, the combustion temperature will increase that leads to higher NO production and emission than that would be produced at the lower-temperature idle power condition.

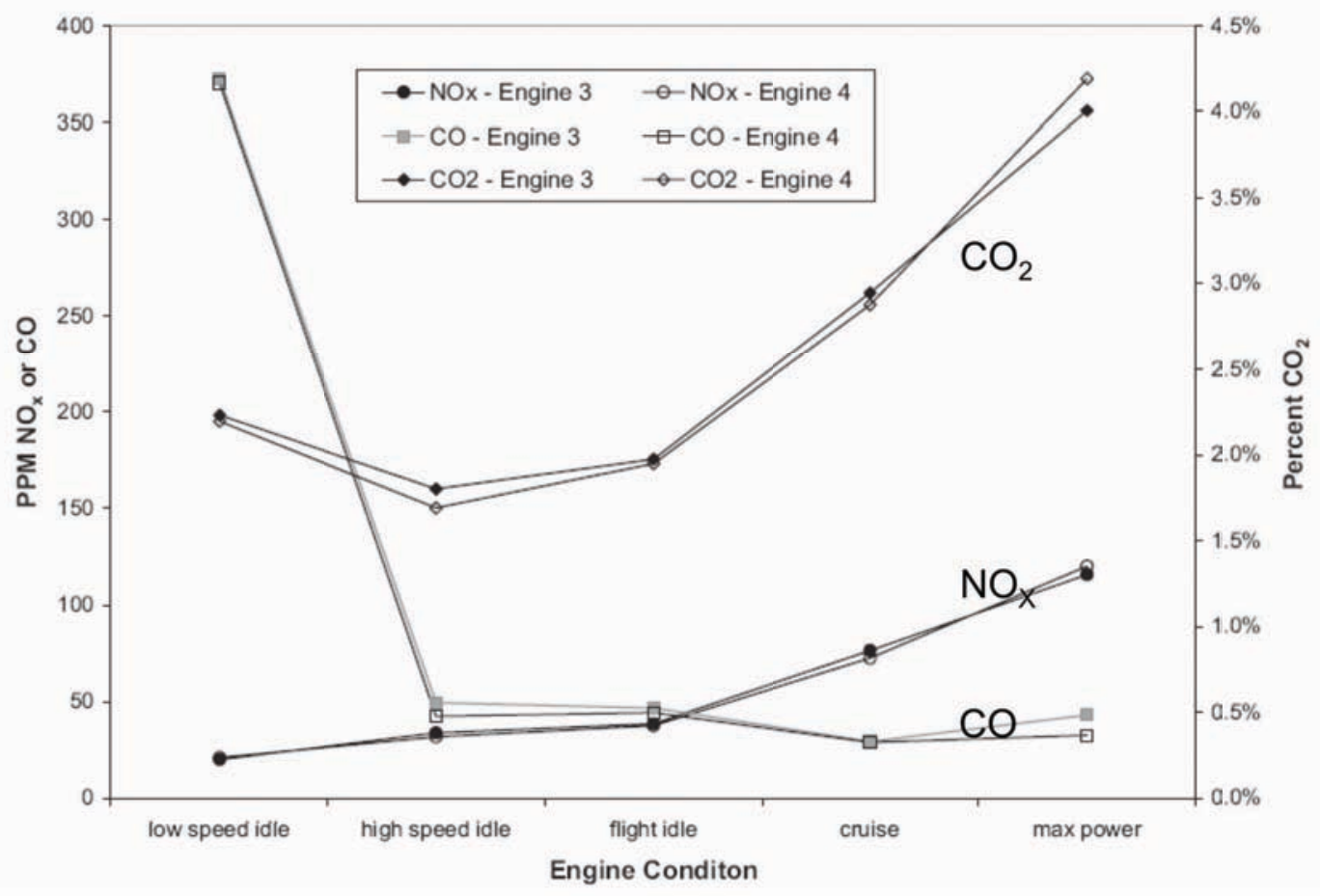

Fig. 10. Plot of $\mathrm{CO}, \mathrm{CO}_{2}$, and $\mathrm{NOx}$ versus engine power condition. Gases measured by MKS FTIR.

The trends and values of the emission indices for $\mathrm{NO}_{\mathrm{x}}$ and $\mathrm{CO}$ are in good agreement with those reported by Wade (2004) for the range of engine conditions. As expected, the absolute $\mathrm{SO}_{2}$ emissions were observed to vary directly with the fuel flow because of the increased concentration of fuel bound sulfur reacting in the engine combustor. Unburned hydrocarbon species, inferred from the FTIR spectra showed the highest concentrations at low-speed ground idle and negligible concentrations for all other conditions. The total unburned hydrocarbons were not quantified in this campaign because of problems with the flame-ionization detector (FID)-based hydrocarbon analyzer.

Gaseous concentrations measured at $5 \mathrm{~m}$ downstream from the EEP by OP-FTIR and OP-TDLAS are shown in Fig. 11. The CO emission, measured by FTIR, decreased when the engine was run at higher powers as shown in Fig. 11a (indicated by later time interval). Note that from the Y-axis the CO concentration in Fig. 11 was approximately ten (10) to 40 times lower at this distance than that measured at EEP as shown in Fig. 10. $\mathrm{CO}_{2}$ emissions registered on a second FTIR and three TDLAS instruments located at three different heights (each separated by about 1 meter) show consistently decreasing trends as a function of time (from 1330 to 1730 of the date). These measurements were made at the front plane located approximately $3 \mathrm{~m}$ from the EEP. The consistency of the $\mathrm{CO}_{2}$ data pattern from the three TDLAS heights (Fig. 11a) indicates that the mixing process in the plume was rigorous and the stream was relatively homogenous vertically (ground up to $3 \mathrm{~m}$ ). 


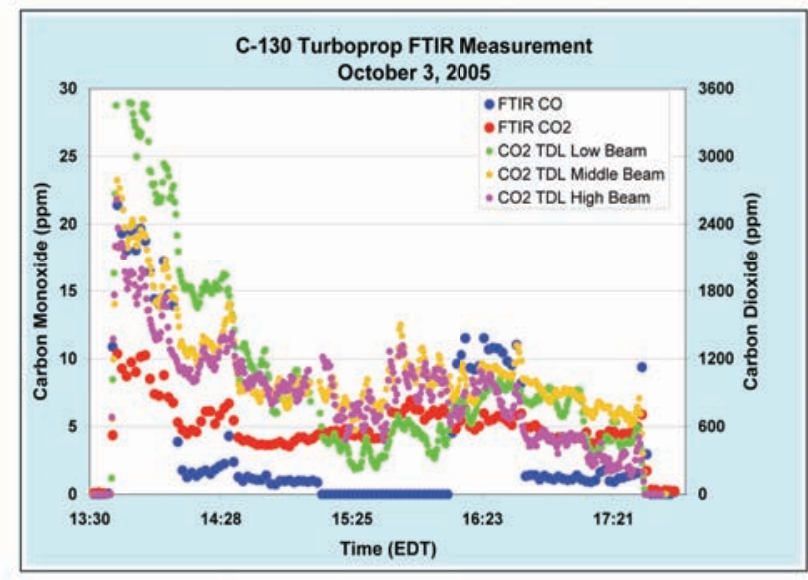

[a]

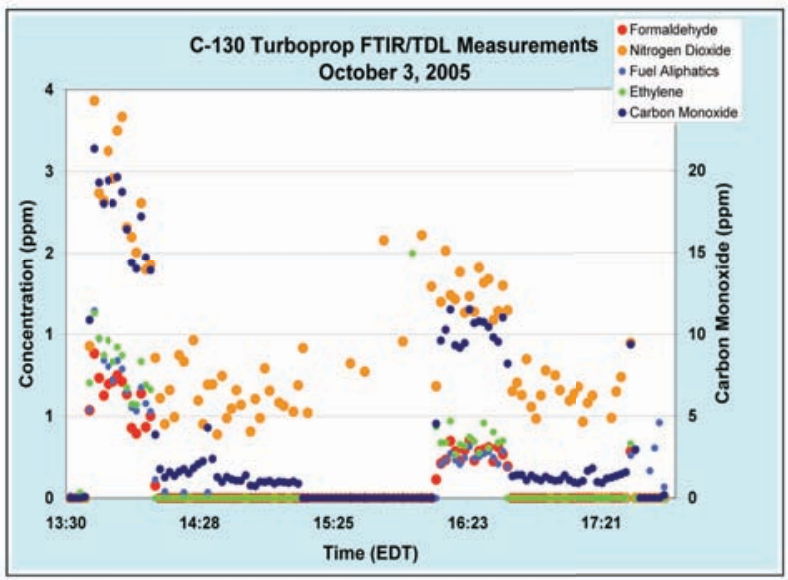

[b]

TDL is TDLAS used in the report

Fig. 11. Time-series plots of OP-FTIR and TDLAS measurements of formaldehyde, NO, fuel aliphatics, ethylene, and $\mathrm{CO}$

Fig. $11 \mathrm{~b}$ shows the time series of selected chemical species measured by the same OP-FTIR and OP-TDLAS systems as those used in $\mathrm{CO}$ and $\mathrm{CO}_{2}$ measurements shown in Fig. 11a. Formaldehyde ( $\mathrm{HCHO})$, nitrogen dioxide $\left(\mathrm{NO}_{2}\right)$, fuel aliphatics, and ethylene data are plotted in comparison to that of the measured $\mathrm{CO}$. The organic compounds such as HCHO, aliphatics and ethylene were below detection during high power operation and not reported. During the idle conditions, the emissions of organic compounds were generally highest among all power conditions that are consistent with the trend of $\mathrm{CO}$ concentration. This occurs since the reduced combustion efficiency would result in concurrent increases in the emissions of hydrocarbons (unburned or thermo chemically converted). $\mathrm{NO}_{2}$ emission was detected throughout all engine settings.

Overall, the results indicate ORS instruments were responsive to engine emissions of major gases and could detect the change in the emission patterns in near real time. There were however relatively few air toxic compounds that could be detected by the ORS instruments in the C-130 campaign due to low concentration at the downstream locations. This problem was exacerbated at higher engine-power conditions, because the engine would be operated close to the stoichiometry of JP-8, which would emit carbon in the predominant $\mathrm{CO}_{2}$ form.

The $\mathrm{C}-130 \mathrm{H}$ data set is the first data set for this research program and as such it provided an opportunity for us to identify sampling and measurement problems regarding the sampling train, probes, and instruments that we used in subsequent campaigns. It also provided an opportunity for us to intercompare the reliability of the instruments we used and made a go/no-go decision about each of the instruments deployed for this program. 


\section{(III.2) B-52 TF33 Turbofan Engines}

The field setup for the B-52 campaign was similar to the one for the $\mathrm{C}-130 \mathrm{H}$ study. A photo of the extractive sampling setup at EEP is displayed in Fig. 12, while the schematics of the ORS sampling setup is drawn and shown in Fig. 13. The ORS setup was slightly modified from that used in the C-130H campaign with the expectation that the emission would travel a lot farther and faster due to the larger and more powerful TF33 engines used on B-52. Thus, the individual open-path instruments were located further downstream from the engine exhaust plan (EEP) at two pre-determined distances - one at $19 \mathrm{~m}$ behind EEP and the other at $32 \mathrm{~m}$. Besides the relocation was made based on safety concerns, lack of available high-temperature spectroscopy data for the section of the plume close to EEP also contributed to the logistic decision. Thermo-imaging visualization were made to visualize the plume structure; these were shown during the Spring IPR briefing in 2007. A time slice of the plume visualization is shown in Appendix D.

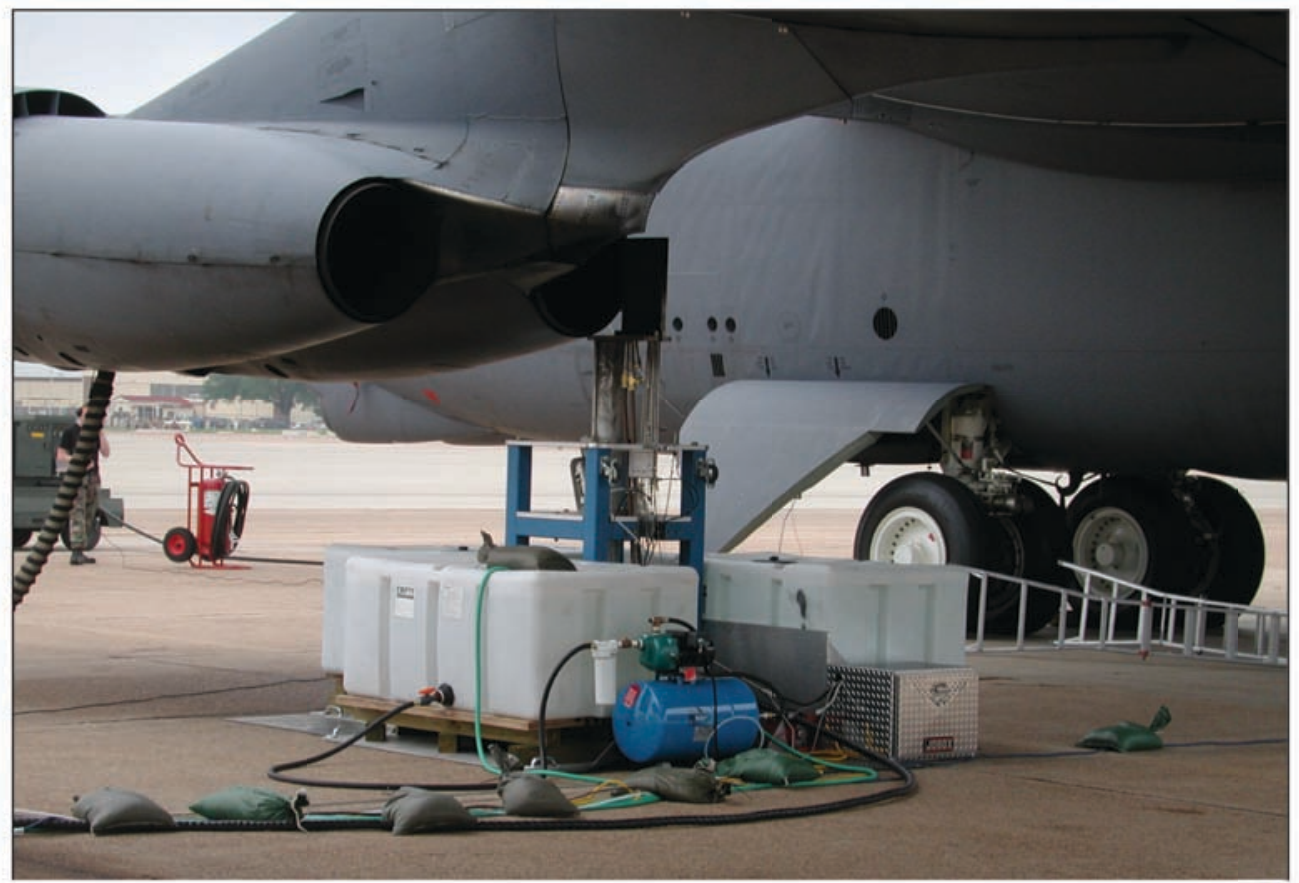

Fig. 12. Close-up photo of extractive sampling setup for the TF33 engine on a B-52 at Barksdale AFB 


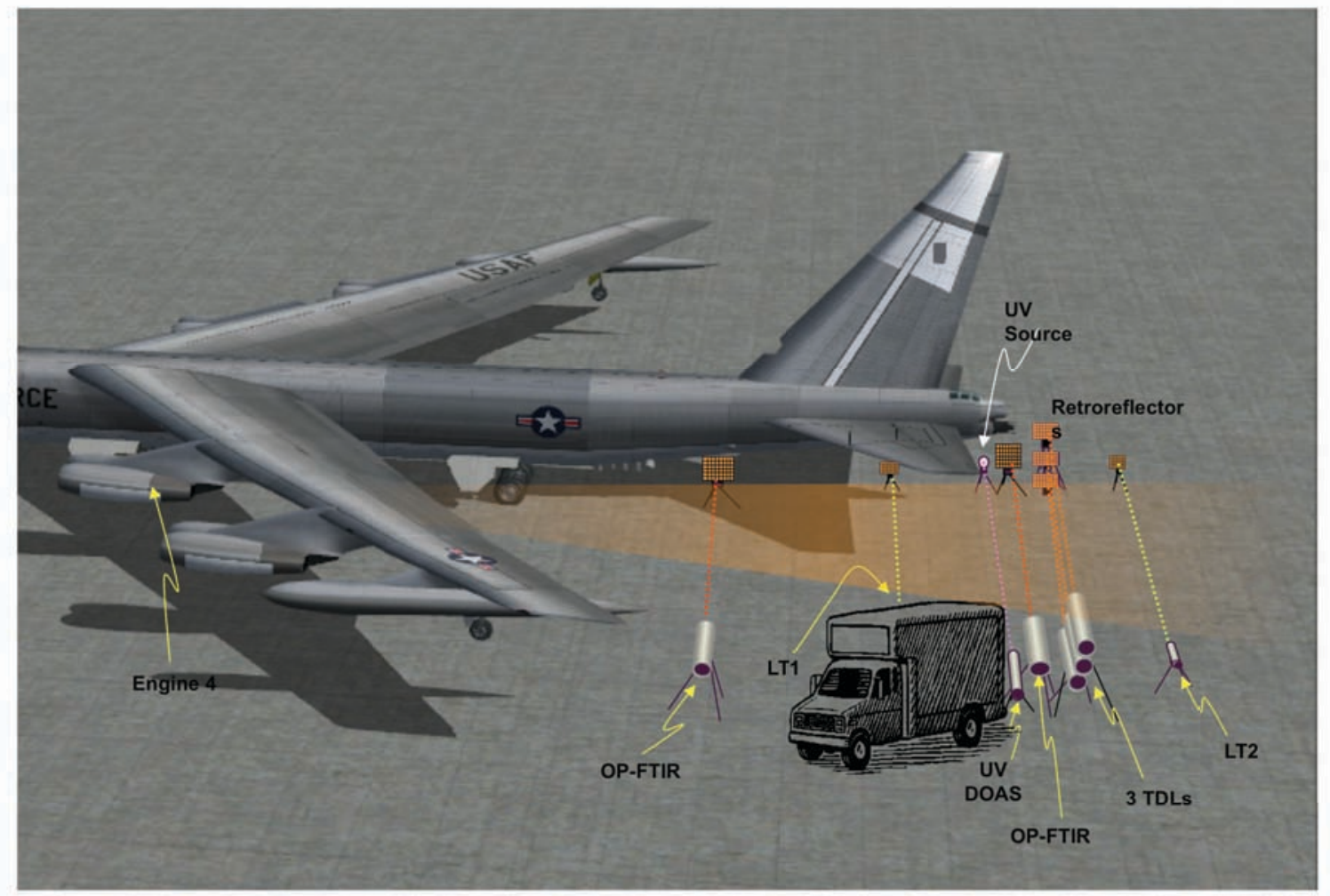

Fig. 13. Drawing of ORS instruments setup for the B-52 test at Barksdale AFB

\section{(III.2.1) Particulate Matter Emissions}

The fuel-to-air (F/A) ratios at the four (4) engine power settings for the two TF33 engines tested are displayed in Fig. 14. The F/A ratio was found to increase from the idle ( $\sim 60 \%$ of the max power setting) to the $95 \%$ of the maximum power indicating more fuel was consumed as the engines went into higher power. The trend was nearly linear that is in contrast to that of the $\mathrm{C}-130$ engines tested in FY2005, which was exponential (data not shown here). The engine F/A ratio is a strong function of the engine operating characteristics; the difference in the F/A curves between a TF33 turbofan engine and a TF-56 turboprop is a clear example. The F/A ratios for both TF33 engines were reasonably close to each other indicating consistent engine performance. 


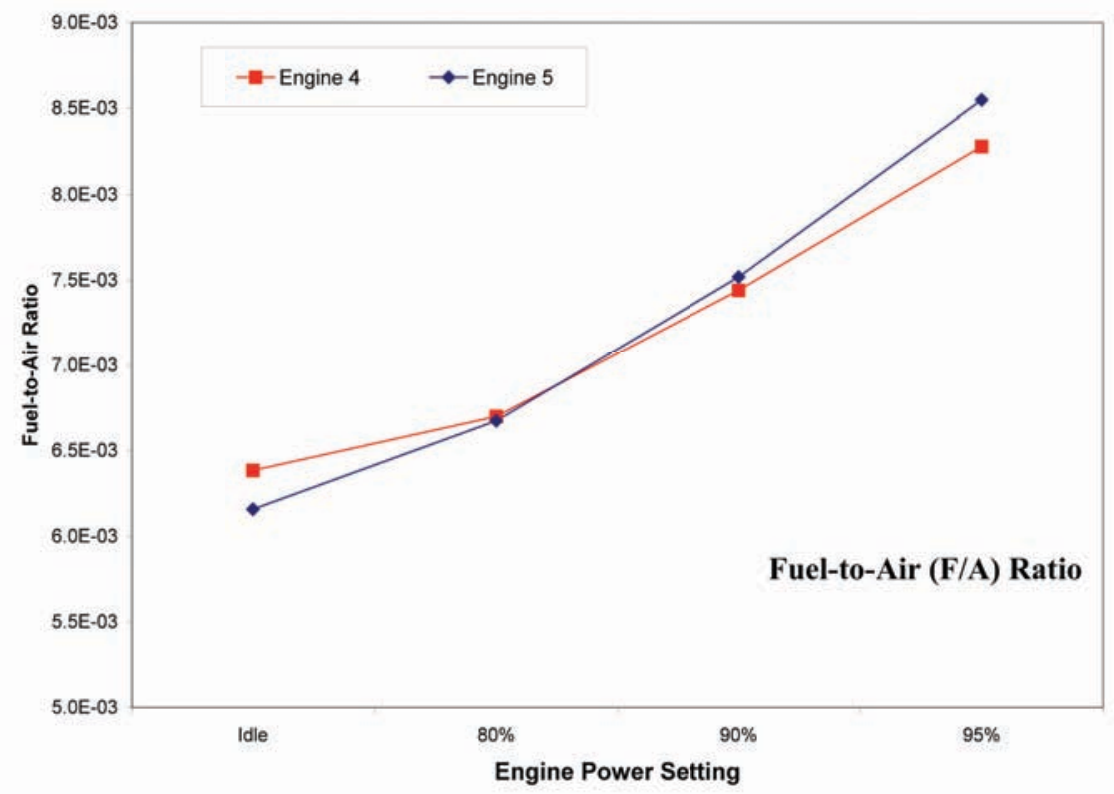

Fig. 14. Plot of TF33 fuel-to-air ratio versus engine power setting

\section{Particle Mass}

The emission index by particle mass concentration measured by TEOM, EI_mass, is calculated by knowing the particulate mass concentration in the exhaust corrected for dilution, line loss, temperature of exhaust, and $\mathrm{F} / \mathrm{A}$ ratio as did for the $\mathrm{C}-130 \mathrm{H}$ data. The emission index for particle mass has a unit of $\mathrm{g} / \mathrm{kg}$ of fuel burned. The averaged mass-based emission indices for the two TF33 engines were ranging from $0.90 \mathrm{~g} / \mathrm{kg}$ of fuel burned for the $80 \%$ setting to $3.0 \mathrm{~g} / \mathrm{kg}$ of fuel burned for the $95 \%$ power setting. As shown in Fig. 14, an upward trend of the F/A ratio determined for both TF33 engines suggests more fuel was consumed at a higher power; thus, more particulate matter was expected to be produced and higher mass concentration emitted as the engine was at a higher power. The EI_mass values derived for the two TF33 engines are $1.5,0.9,2.5$, and $3.0 \mathrm{~g} / \mathrm{kg}$-fuel burned for the four engine power settings, respectively. The EI_mass is increased as the engine power level increased. The general trend of the EI_mass follows that of the F/A ratio shown in Fig. 14 and that of the SN values shown in Fig. 15. It is noticed that SN values obtained for the two engines vary somewhat for the $80 \%$ max power condition, but were virtually identical for the other three conditions. The dip at the $80 \%$ max power condition might also explain why the EI_mass at that power setting was an outlier. 


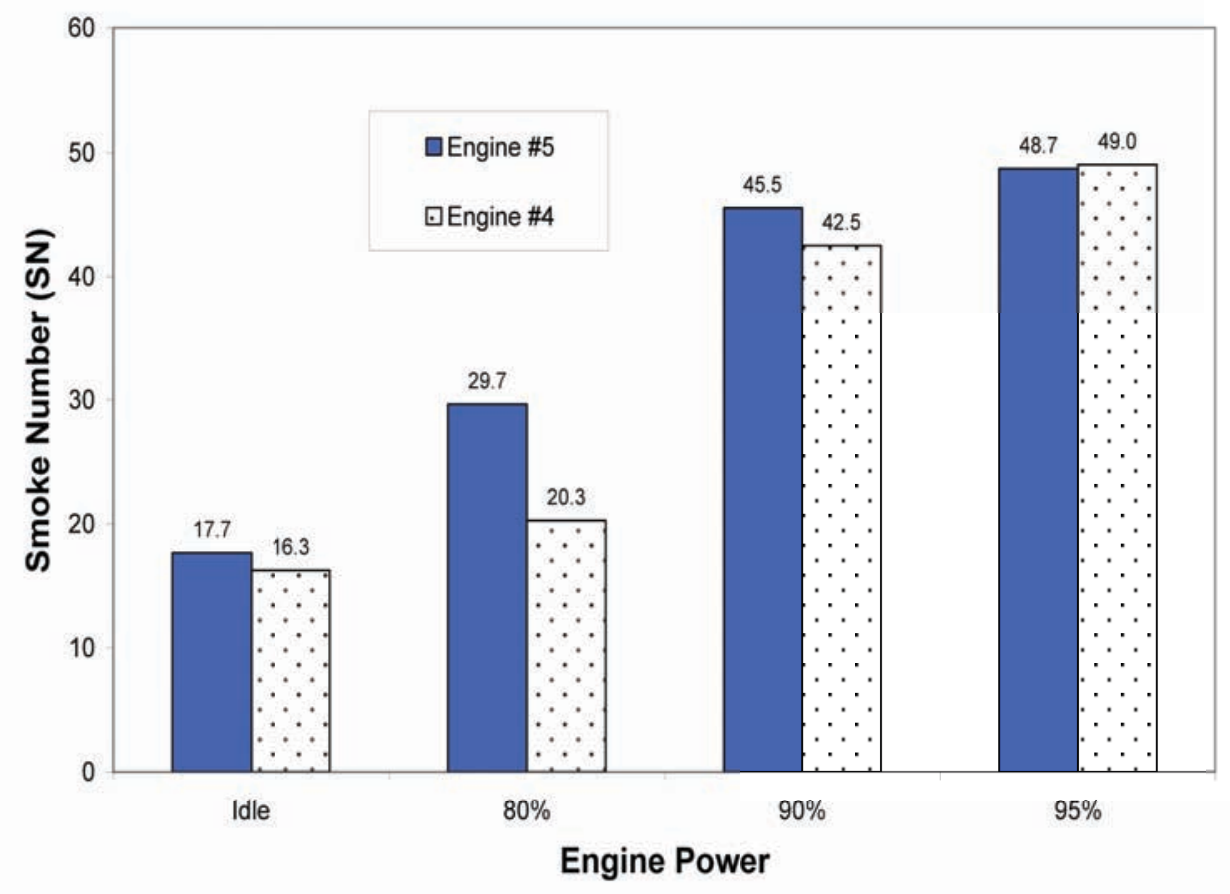

Fig. 15. Plot of smoke number of TF 33 engine exhaust versus engine power

\section{Particle Number}

The emission indices based on the particle number concentration, EI_pn, were calculated by the same formula used in the $\mathrm{C}-130 \mathrm{H}$ case. The particle number concentration was measured by a condensation particle counter (TSI 3022, non-scanning version). The EI_pn has a unit of \# of particles $/ \mathrm{kg}$ of fuel burned. The averaged EI_pn for the two TF33 engines are 5.5E15, 5.3E15, 9.6E15, and 8.9E15 for the four engine power settings, respectively. Again, the EI_pn for the 80\% power level was found less than that for the idle, and the EI_pn for the $95 \%$ is less than that of the $90 \%$. The results suggest that higher number of particles was emitted as the engine power setting was increased. A large gap in the EI_pn values was found between $80 \%$ and $90 \%$ of the TF33 engines; a similar observation was also found earlier in the EI_mass pattern. The results appear to be uniquely characteristic of the TF33 engine emissions as such patterns did not exist in the T56 engine emissions reported in the earlier section for T56.

\section{Modal Size of TF33 Particles}

In the analysis of particle-size data obtained by SMPS, the size distributions were described by a lognormal distribution. The results from the parametric fit were used only when the fit has a $\mathrm{R}^{2}$ value greater than 0.9 . The geometric mean diameters (GMD) determined for the four (4) TF33 engine power settings at idle, $80 \%, 90 \%$, and $95 \%$ are $55,63,80$, and $85 \mathrm{~nm}$, respectively. The trend is similar to that of T56 engine reported earlier. The increase in GMD as the engine power increased is significant, particularly from the $80 \%$ max power condition to the $90 \%$ max condition. This observation again is 
similar to those in the emission indices based on particle mass and number concentrations that were reported previously in the last section.

Note that for each kg JP-8 fuel burned, at the max power condition TF33 engine emits some 30\% less particles (in number) but $200 \%$ more particle (in mass). Also, note that the modal diameter of the TF33 particles is about $18 \mathrm{~nm}$ larger than that of T56 particles. Taking the results of TF33 and T56 all together, it is important to note that the modal size of the particles emitted by the T56 and TF33 engines are all in the "ultrafine" size range - less than $100 \mathrm{~nm}$ or $0.1 \mu \mathrm{m}$ by US EPA definition. There is no known regulatory standard for such small particles. It is most likely that such small particles may present challenges for regulatory agency to implement effective monitoring and control strategies of aircraft emitted particulate matter in the near future.

\section{Sulfur Species on Particles}

Sulfur is an important ingredient of lubricant in fuel so the lower the sulfur content, the poor the lubricating property. Sulfur in various forms is commonly found in aircraft emissions. The combustion process of a turbine engine converts fuel sulfur into sulfite, which is highly hygroscopic; sulfite then is rapidly converted into sulfate when it combines with water molecules to form sulfuric acid vapors. Once the vapor exceeds its saturation ratio, the molecules condense onto the primary engine exhaust, the nonvolatile soot particles, and surrounding surfaces. Given sufficient vapor pressure, homogeneous nucleation could occur leading to the production of small particles as we saw in the case of T56 emissions [Cheng et al. (2008)].

Depending on the environmental conditions, the condensation could add mass to existing particles and increase particle size as well as changing the surface chemistry of the particles making the soot particles hygroscopic. The particles would be capable of attracting more water vapor than a fresh non-volatile soot particle, and also it is likely to adsorb or absorb other organic compounds, possibly polar, thus increasing its potential to become cloud condensation nuclei. On the other hand, this chemical transformation could make the particles carrying molecules that are more toxic and posing higher threat to human health.

The sulfate coating can change the refractive index of the particles making the soot particles a better light scatter for altering atmospheric radiation balance and potentially inducing the engine particles to become effective cloud condensation nuclei. The added particulate mass contributes to a fraction of the secondary particulate matter that does not exist at the EEP condition, but was found in the far field of an aircraft plume and was "originated" from the aircraft emissions. Such mass belongs to what is called "volatile particulate matter". Other portion of the secondary particulate matter in the ambient might be resulted from condensation of semi-volatile carbon species in the exhaust.

Since in our tests, data were taken only when engines reached a steady state, we collected timeintegrated filter samples for chemical composition analysis. This alleviates the complexity of using an insitu real-time instrument such as a time-of-flight mass spectrometer. We thus analytically determined the elemental sulfur and ionic sulfur species as in sulfate associated with the particulate matter collected on the Teflo ${ }^{\circledR}$ particulate filters for each individual engine power settings. The filter samples for sulfur and sulfate measurements were taken from the same unheated larger-bore sampling line described earlier at a volumetric flow rate of 23 liters per minute each by the two PM1 samplers. These samplers are two-stage $1.0-\mu \mathrm{m}$ sharp-cut impaction samplers meaning they are high-efficiency $1.0-\mu \mathrm{m}$ size-selective samplers. Each sampler was equipped with an impactor at the inlet to remove incoming particles greater than 1- $\mu \mathrm{m}$ in aerodynamic diameter; thus, particles greater than $1 \mu \mathrm{m}$ were not collected on the filter. 
Particulate sulfur was analyzed after the campaign in a laboratory by using an X-Ray

fluorescence (XRF) spectrometer on particles collected on the Teflo® filters, while particulate sulfate was analyzed by ion chromatography (IC) on separate Teflo ${ }^{\circledR}$ filters. Shown in Fig. 16 is a plot of the mass concentration ratio of sulfur calculated from the measured sulfate to total elemental sulfur, and associated error bars at each power setting. The error bars are calculated from individual runs so the bar reflects the variation among the runs NOT the analytical precision of the chemical analysis. The sulfur-in-sulfate was obtained from converting the measured sulfate mass concentration by multiplying the atomic weight ratio of sulfur to that of sulfate (i.e., 32/96). There was only one (1) sample taken at the max power level due to the harsh condition discussed in the previous sections; the data point at the max power condition is displayed in Fig. 16 for completeness.

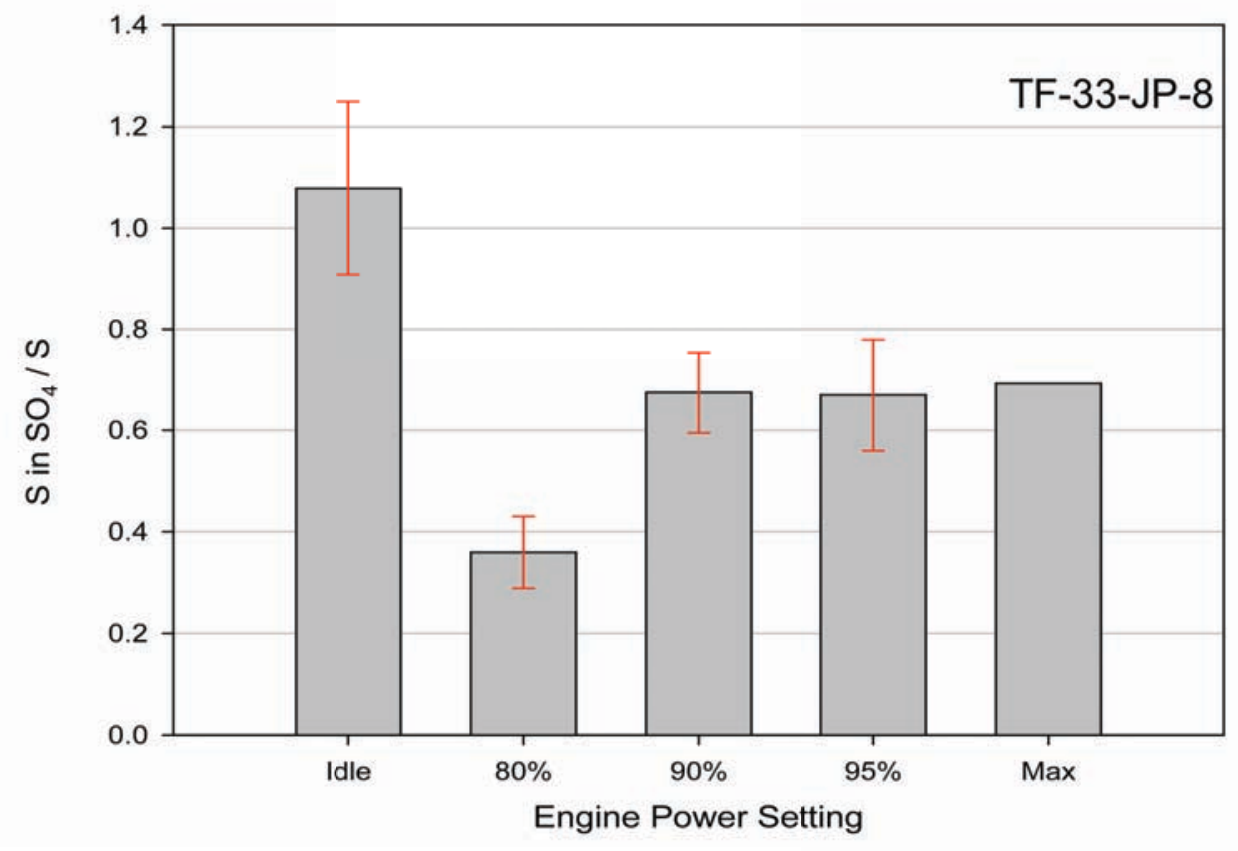

Fig. 16. Plot of sulfur-in-sulfate to total sulfur on TF33 particles

The ratio calculated for the idle condition is statistically equal to one indicating all the particulate sulfur was in the sulfate form. A dramatically lower ratio (a mean ratio of 0.38 ) was found at the $80 \%$ max power setting than that at the idling condition. The ratios for the three higher power settings $(90 \%$, $95 \%$, and max power) then increased from 0.38 to 0.65 and their mean values remained relatively stable across the three power conditions. Once again, the dip in the ratio at the $80 \%$ max power condition appears to be consistent with all other observations for this type of engine. The percentage of sulfate production seems to level out when the engine power reached the $90 \%$ of the max power even the F/A data in Fig. 4 show otherwise.

\section{Particulate Carbon Content}

Particulate carbon is a major component in the composition of the aircraft engine exhaust particles. However, the carbonaceous component of the engine particles is much more complex than the 
sulfur ones, and not all the carbon species in the engine emissions have been identified and quantitatively determined even today. Thus, we consider evaluating the analytical techniques for measuring operationally defined carbon contents; i.e., the elemental and organic carbons that are operationally separated by a pre-programmed temperature profile using established NIOSH protocol described earlier.

Filter samples for particulate carbon were collected by one of the two PM1 samplers discussed in the sulfur section above; the particles were filtered through quartz filters for carbon analysis instead of Teflo filters used for sulfur. Prior to the field use, the quartz filters were baked in an oven at $350^{\circ} \mathrm{C}$ for 2 hours to ensure removal of organic carbon contamination. The NIOSH protocol was followed in the analysis (Birch and Cary, 1996). The outcome of the analysis is divided into organic carbon (OC) and elemental carbon (EC), the method of separating these two categories of carbon is detailed in the protocol. Most EC is empirically known to be non-volatile at the engine exhaust conditions, as soot or graphitic material, while OC could represent a large class of semi-volatile organic molecules adsorbed onto the engine exhaust particles via condensation at the downstream. Semi-volatile organic carbon (OC) is a collective class of carbonaceous materials for many organic compounds that are adsorbed onto the engine particles in the ambient conditions or in the un-heated line as in the case of the B-52 campaign.

A gas-phase analysis of total unburned hydrocarbons (THCs) extracted from the TF33 engine emissions is shown in Fig. 17[a] below.

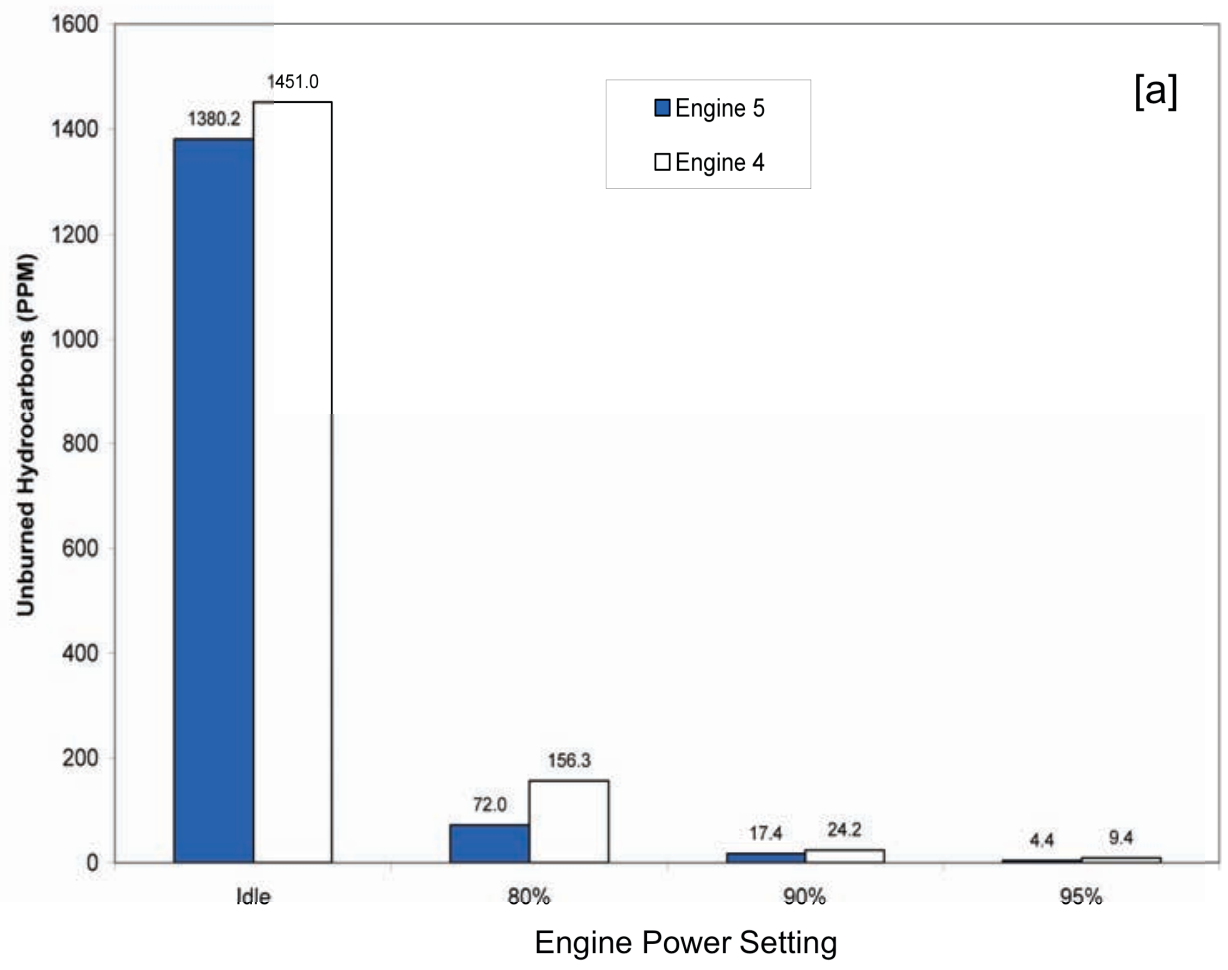



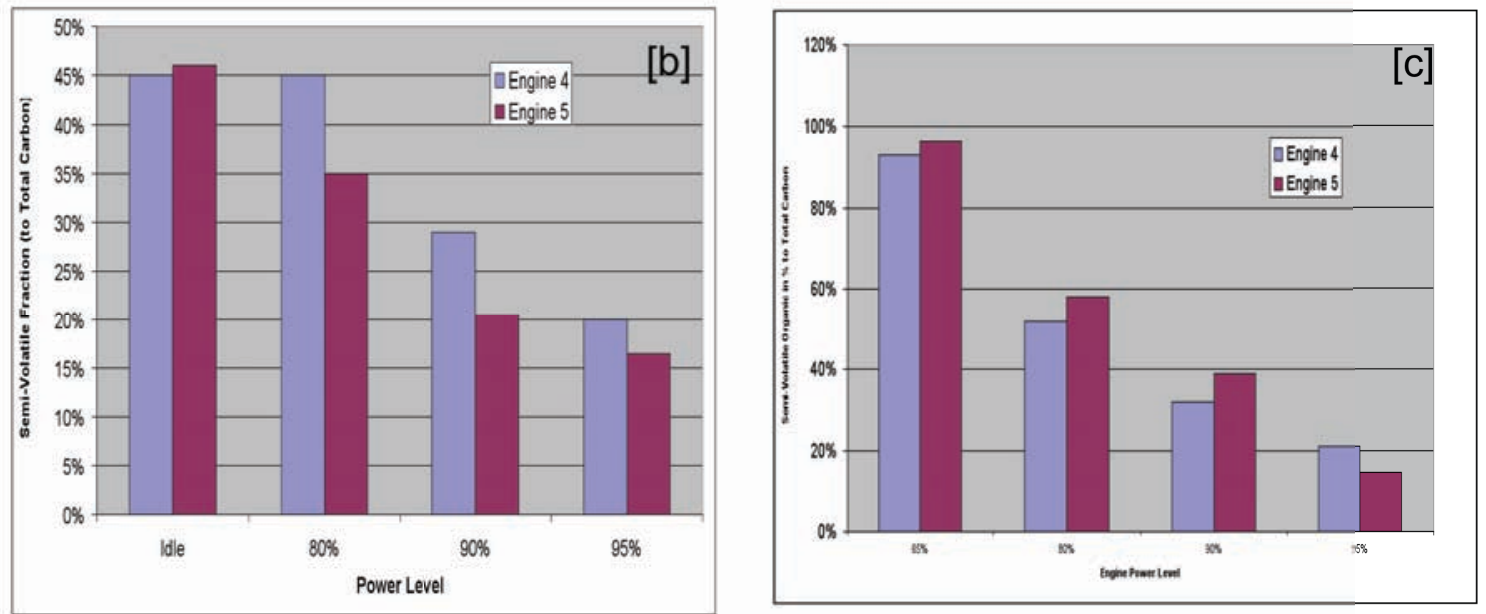

[a] Total Unburned Hydrocarbons in ppm

[b] Heated Line, LECO Carbon Analyzer

[c] Unheated Line, Sunset Lab Analyzer + NIOSH Proc.

Fig. 17. Plot of THCs and $\mathrm{OC} / \mathrm{TC}$ versus TF33 engine power

The THCs in Fig. 17[a] decreased dramatically from the idle condition to the $80 \%$ of max power level by a factor of seven (7) and by almost 2 orders of magnitude at the $90 \%$ and $95 \%$ of max engine power conditions. The result indicates organic species in TF33 engine emissions could be found at a significant quantity mostly at the idle condition. The concentrations of THCs at higher engine power conditions are relatively low to that at the idle.

Further investigation on analytical techniques for measurement of particulate carbons, WrightPatterson AFRL performed measurement using the LECO analyzer where the total carbon and soot content were measured, and the OC was inferred from TC and soot (or EC). ORNL on the other hand follows the NIOSH procedure to determine OC and TC, using the sum of these two to obtain TC. The result of the particulate OC fraction (i.e., semi-volatile carbon to total carbon) was shown in Fig. 17. Fig. $17[\mathrm{~b}]$ shows percentage of organic to total carbon (TC) on samples obtained through the heated line and measured by LECO, while Fig. 17[c] shows similar data but they were obtained through the unheated line and measured by the NIOSH method. Note that both were extracted samples obtained by the tipdilution probes located at EEP.

The OC fraction decreased with the engine power condition increased as expected for both heated and unheated samples. At the idle condition, we found $45 \%$ of carbon was in the OC fraction, while through the unheated sampling line we saw close to $90 \%$, a factor of two differences from that of heated line. At the $80 \%$ max power condition, the fraction decreased a little to some $40 \%$ averaged for both engines, but that by the unheated line was about $50 \%$. The OC fraction was approximately $24 \%$ by heated and $32 \%$ by unheated for the $90 \%$ max, and $18 \%$ by the heated and $17 \%$ by the unheated line. Thus, we saw that as the engine power conditions go to $90 \%$ and $95 \%$ max power conditions, the difference in the 
OC fraction between those measured by the heated and unheated lines diminishes. It is important to note that the sampling line length for the heated and unheated lines was identical and so was the line geometric dimension (i.e., ID and make of material, etc.). Therefore, we attributed the large difference in the OC fraction at the idle condition to condensation of volatile molecules in the unheated (thus cool) line.

\section{(III.2.2) Gaseous Emissions}

Fig. 18 shows the ratio of $\mathrm{CO}$ to $\mathrm{CO}_{2}$ measured by the OP-FTIR at both locations -19 and $32 \mathrm{~m}$ behind the EEP. The data taken at $19 \mathrm{~m}$ are referred to as those from the Front Plane in the figure, while those from $32 \mathrm{~m}$ are referred to as from the Back Plane. This is a self-consistency check for the OP-FTIR measurement. In general, the ratios (in the 4-color group) decrease exponentially as the engine power setting increases. Also, note that the Back-Plane data from both engines were consistently higher than that of the Front Plane. The uncertainty bars associated with the Front Plane are also larger than that of the Back Plane. Everything being equal, the larger uncertainty in the Front-Plane data could be because the plume was narrower at $19 \mathrm{~m}$ behind the EEP. The general pattern in this figure indicates that the CO emission was significantly higher at the idle condition than at the higher power settings, which was consistent with the $\mathrm{CO}$ data taken by the extractive method (not shown).

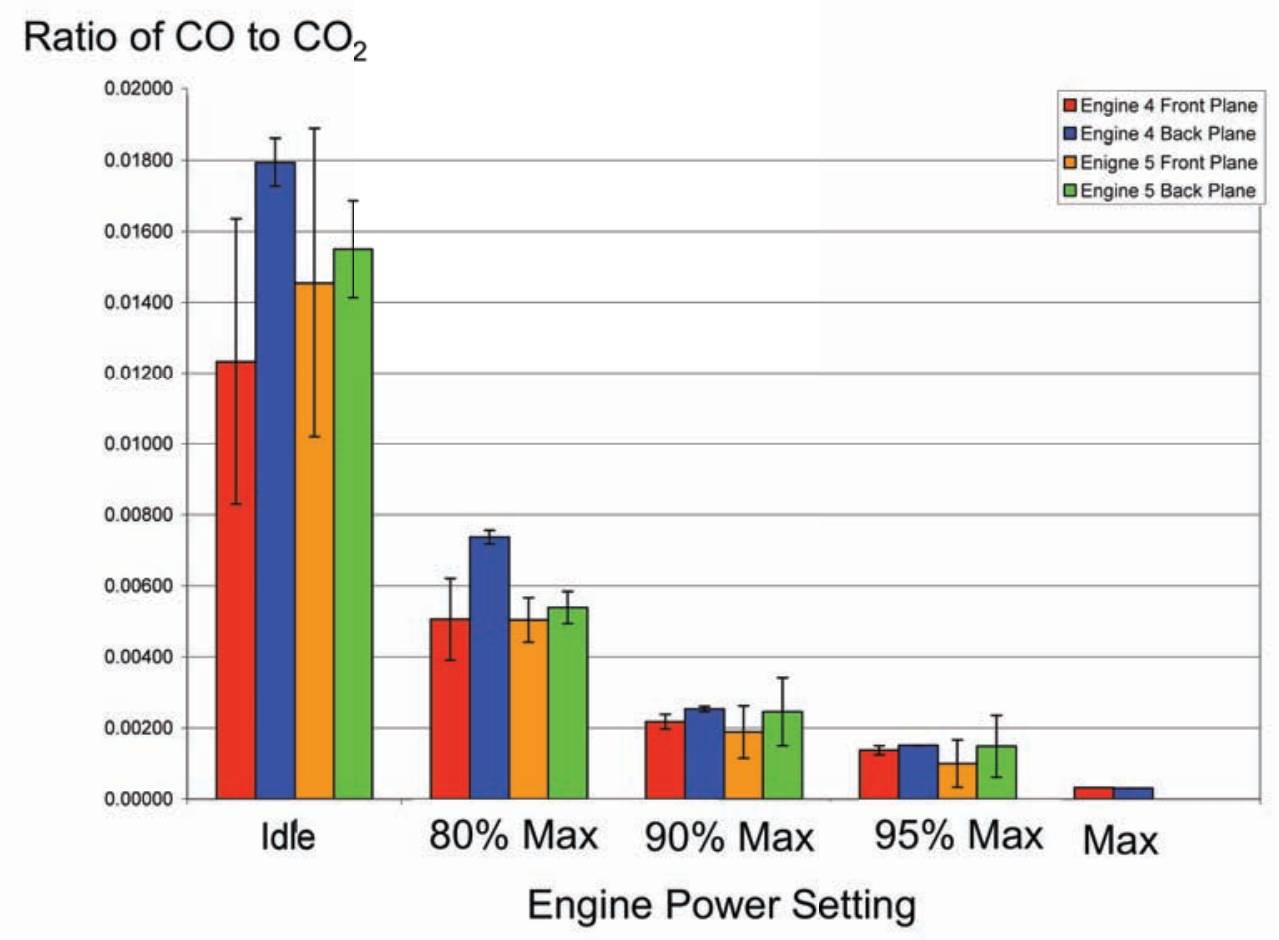

Fig. 18. Plot of $\mathrm{CO} / \mathrm{CO}_{2}$ ratio obtained by $\mathrm{ORS}$ at various TF33 engine power settings

The 30-second averaged OP-FTIR measurements of acetylene, ethylene, propylene (in the right panel), and $\mathrm{CO}_{2}$ (in the left panel) were shown in Fig. 19. Both panels in Fig. 19 show plots of the OPFTIR measured concentrations versus time for the engine \#4. As expected the $\mathrm{CO}_{2}$ patterns clearly track the engine power conditions; the higher the engine power, the higher the $\mathrm{CO}_{2}$ level. The concentrations of the four species were substantially lower at the high power conditions than at the idle condition as seen in the figure. Again, the reduction in the emissions of the four gas species as the engine power increased 
reflects the increase in combustion completeness at the high power conditions. The reduction was dramatic for the air toxic species at the higher power levels, at which the concentrations were below the detection limits of OP-FTIR. This indicates that air-toxic emission by aircraft engines may only be significant during the idle condition. The variations of the ORS measurements were large relative to the extractive data.
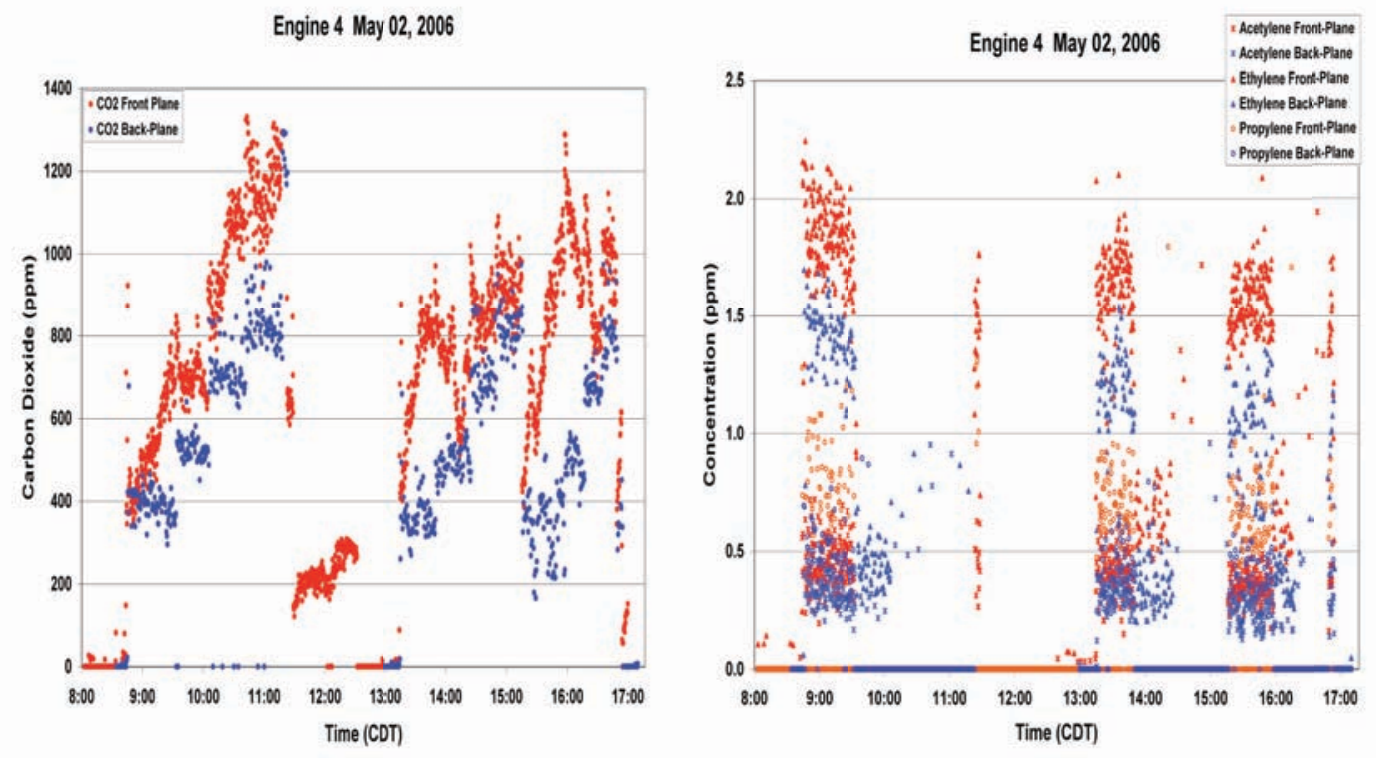

Fig. 19. Time-series plots of ORS data on acetylene, ethylene, and propylene emitted by TF33 engines

\section{(III.2.8) Emission rates derived from the ORS measurements}

To derive the emission index using the ORS measurements is an interesting and challenging task for this program, because not only it has never been done before but also it requires several important assumptions to be made. Remember that ORS measurement is line-integrated across the plume. In other words, an ORS data point is produced for a given detected species along a line (1 dimensional or 1D) that intercepts the plume cross-section (2D) at a given downstream distance. One needs to know exactly the volume of the plume that was sampled during the measurement interval to be able to derive the emission index. The procedure we used to perform this derivation is described below.

The vertical of the plane, which intercepts the exhaust plume normally, is divided into three sections as shown in three solid colors - red (top), green (middle), and blue (close to the ground). The left panel of Fig. 20[a] shows this drawing. Each section is of 1-m height. Each of the three TDLAS light beams is assumed to pass through the center of a layer. A gas species in each section is assumed to be homogeneously mixed and thus the OP-TDLAS measured in this section is used to represent the concentration in that section. Also assumed is the flow velocity is identical for the first and third layer and half of the middle layer based on the idea the plume has a core flow which has a higher flow velocity. In other words, the velocity profile across the plume is assumed Gaussian, which may not hold because from 
the thermal imaging we knew the plume was turbulent and the profile was unknown but definitely not like Gaussian or a bell-shape.

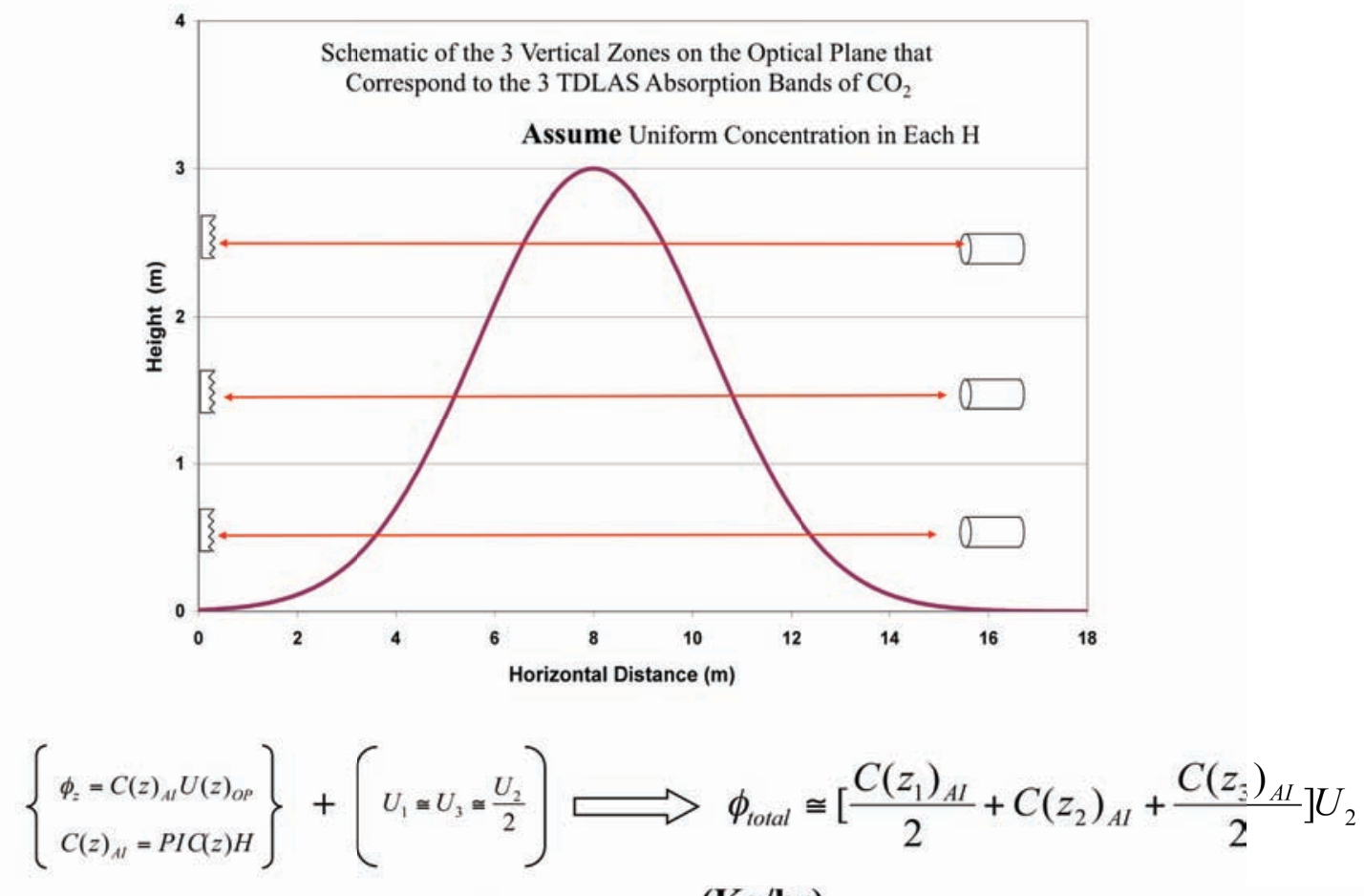

Assumption

$(\mathrm{Kg} / \mathrm{hr})$

Fig. 20[a]. Graphical description of the model used to derive ORS emission rate

Assuming no chemical transformation occurred between the EEP and optical measurement plane, the emission rate would be equal to the total flux of the plume at the optical plane. The basic equation for deriving the emission index using ORS data is shown in Fig. 20[a] and described here:

Emission flux has a unit of $\mathrm{kg}$ of pollutant per hour across a unit area. To compute the total flux, $\Phi_{\text {total }}$, is calculated as the sum of the flux through all three zones shown in the left panel of Fig. 20[a].

The flux through each zone, $\phi_{z}$, is given as

$\Phi z=C(z){ }_{A I} U(z) O P$

where $\mathrm{C}(\mathrm{z})_{\mathrm{AI}}$ is the measured area-integrated concentration at the surface of the zone and $U_{O P}$ is the average frontal flow velocity in units of $\mathrm{m} / \mathrm{sec}$ through the optical plane. Each area-integrated concentration, $C(z)_{A I}$, is equal to the corresponding path-integrated concentration (PIC in units of $\mathrm{g} / \mathrm{m}^{2}$ ) times the vertical height $(\mathrm{H})$.

$$
C(z)_{A I}=\operatorname{PIC}(z)_{A I} H .
$$

Since each zone is defined to be one meter high, value of $C(z)_{A I}$ is equal to the value of $\operatorname{PIC}(z)_{A I}$. The plane-integrated concentrations are in units of $\mathrm{g} / \mathrm{m}$ : 


$$
C(z)_{A I}[g / m]=P I C(z)_{A I}\left[g / m^{2}\right] *[1 m]
$$

Thus, the total mass flux becomes

$$
\Phi_{\text {total }}=\left[C\left(z_{1}\right)_{A I}+C\left(z_{2}\right)_{A I}+C\left(z_{3}\right)_{A I}\right] U_{o p}
$$

Assuming $\mathrm{U}\left(\mathrm{z}_{1}\right)=\mathrm{U}\left(\mathrm{z}_{3}\right)=\mathrm{U}\left(\mathrm{z}_{2}\right) / 2$ are the flow velocity at the first, second and the third layers, the total flux of a species is given as the linear additive sum of the products of PIC value times the flow velocity. The mass flux is in units of g/s/plume cross-sectional area. Fig. 20[b] represents a time-series plot of $\mathrm{CO}_{2}$ measured by TDLAS and FTIR at the Back plane, which is similar to the left panel of Fig. 19 but for different dates. The colors represent the measurements at different heights.

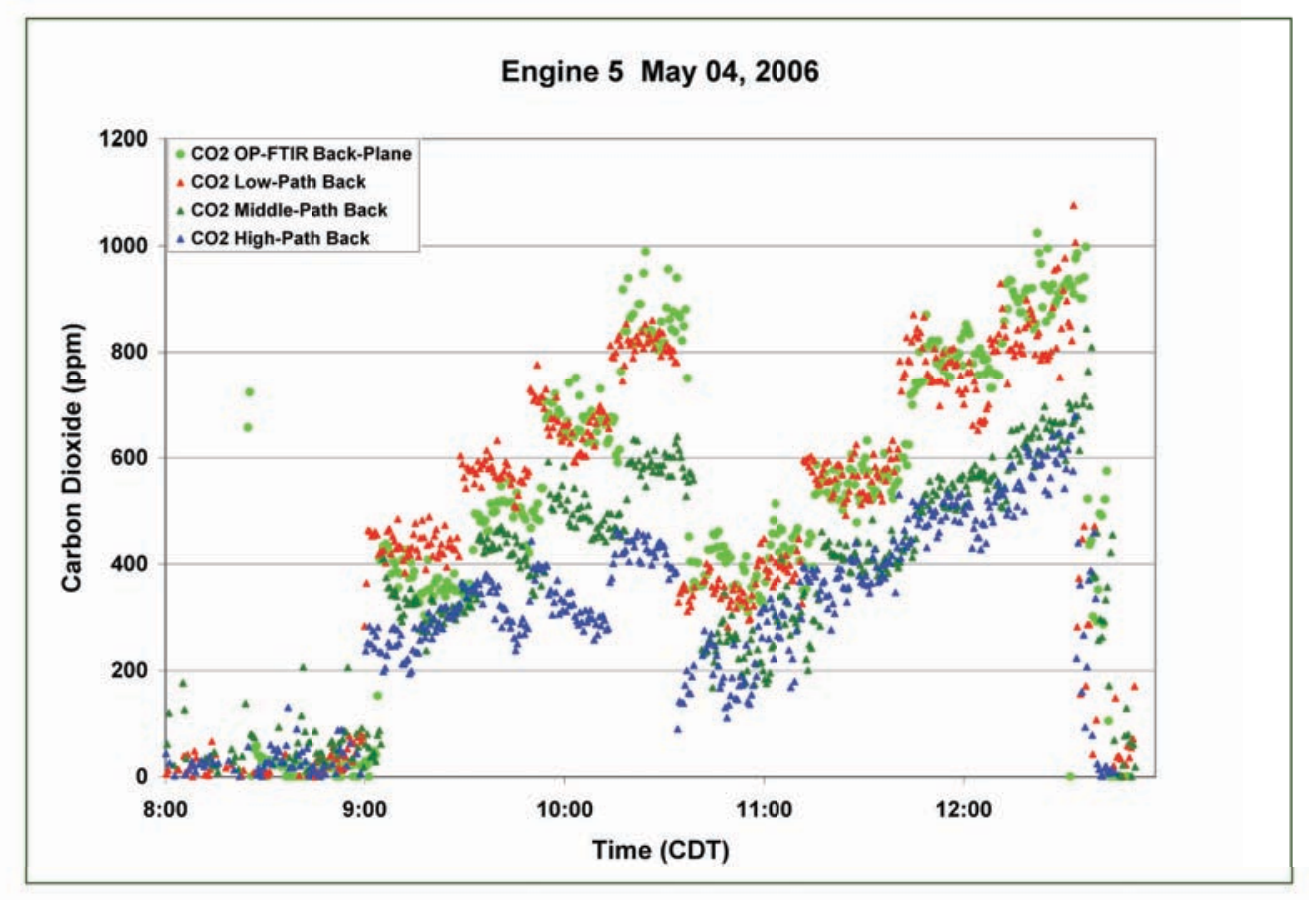

Fig. 20[b]. Carbon Dioxide Data Measured at Three Height Zones

TDLAS data for air toxics, NO, and other detectable gas species were used to extract $\mathrm{C}\left(\mathrm{z}_{\mathrm{i}}\right), \mathrm{i}=1,2,3$. Thus, $\varnothing_{\text {total }}$ is the ORS-derived emission rate or emission flux in units of $\mathrm{kg}$ of pollutant/hr/unit area. Figs. 21 to 23 show the calculated emission rate in $\mathrm{kg} / \mathrm{hr} / \mathrm{unit}$ area for $\mathrm{CO}_{2}$ (Fig. 21), NO (Fig. 22), and $\mathrm{HCHO}$ (Fig. 23), respectively.

If ORS-derived $\mathrm{CO}_{2}$ emission flux (in $\mathrm{kg} / \mathrm{hr}$ ) is plotted against the fuel flow of the engine power settings as in Fig. 21, the emission factor or index of $\mathrm{CO}_{2}$ can then be estimated as the slope of the plotted linear regression lines. The estimated emission factor (in units of $\mathrm{kg} / \mathrm{kg}$ of fuel burned) for $\mathrm{CO}_{2}$ was 4.22 $\mathrm{kg} / \mathrm{kg}$ of fuel for Engine \#4, and 4.88 for Engine \#5 on average. The line plotted in red was obtained assuming the stoichiometric combustion of JP-8 and was added just for reference. The TF33 engines 
obviously emitted higher $\mathrm{CO}_{2}$ than that estimated by the stoichiometric method indicating the model carbon compound $\left(\mathrm{C}_{11}\right)$ used in the stoichiometric calculation was probably low.
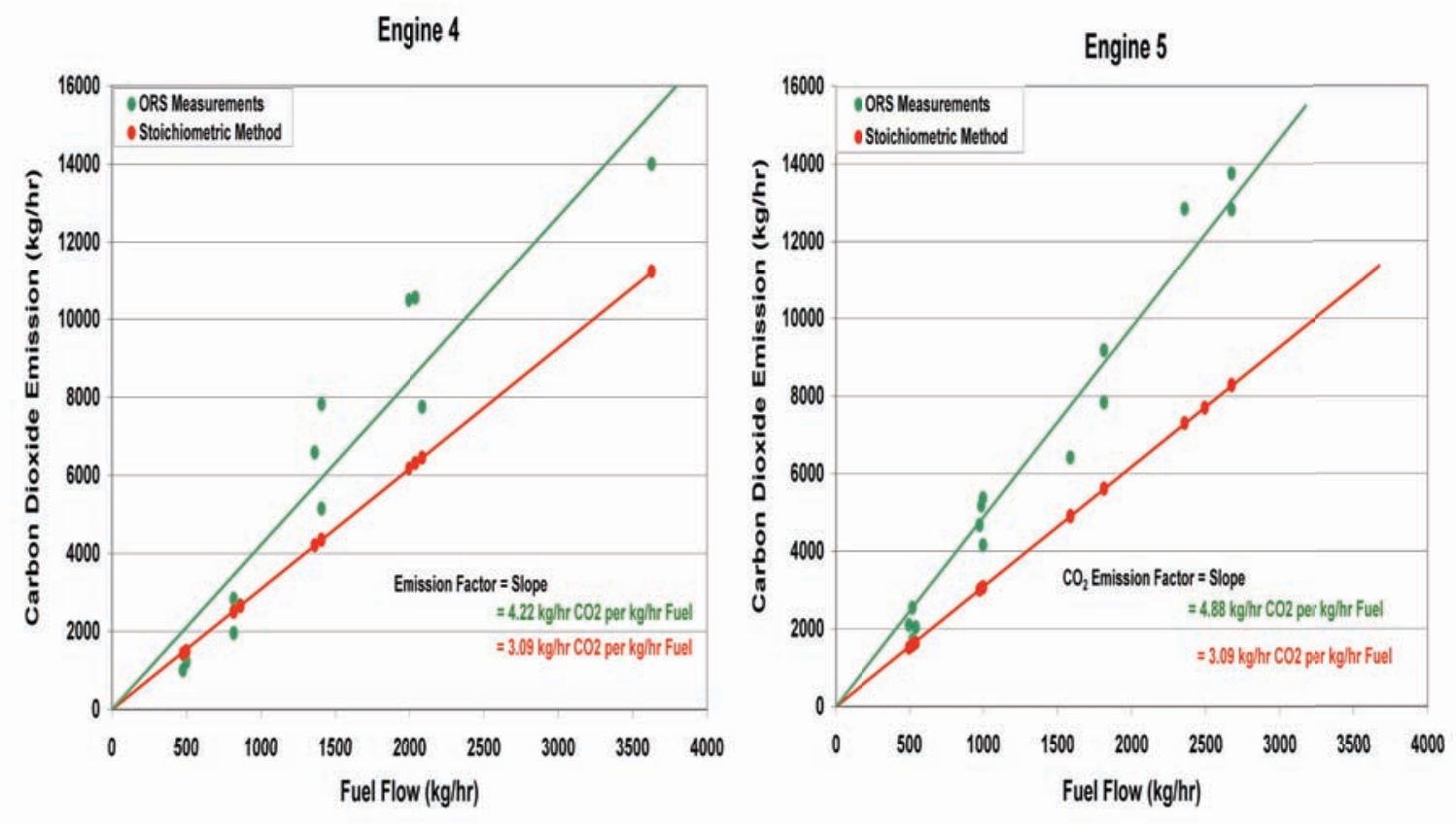

Fig. 21. Plot of ORS $\mathrm{CO}_{2}$ versus TF33 engine fuel flow for both engines 

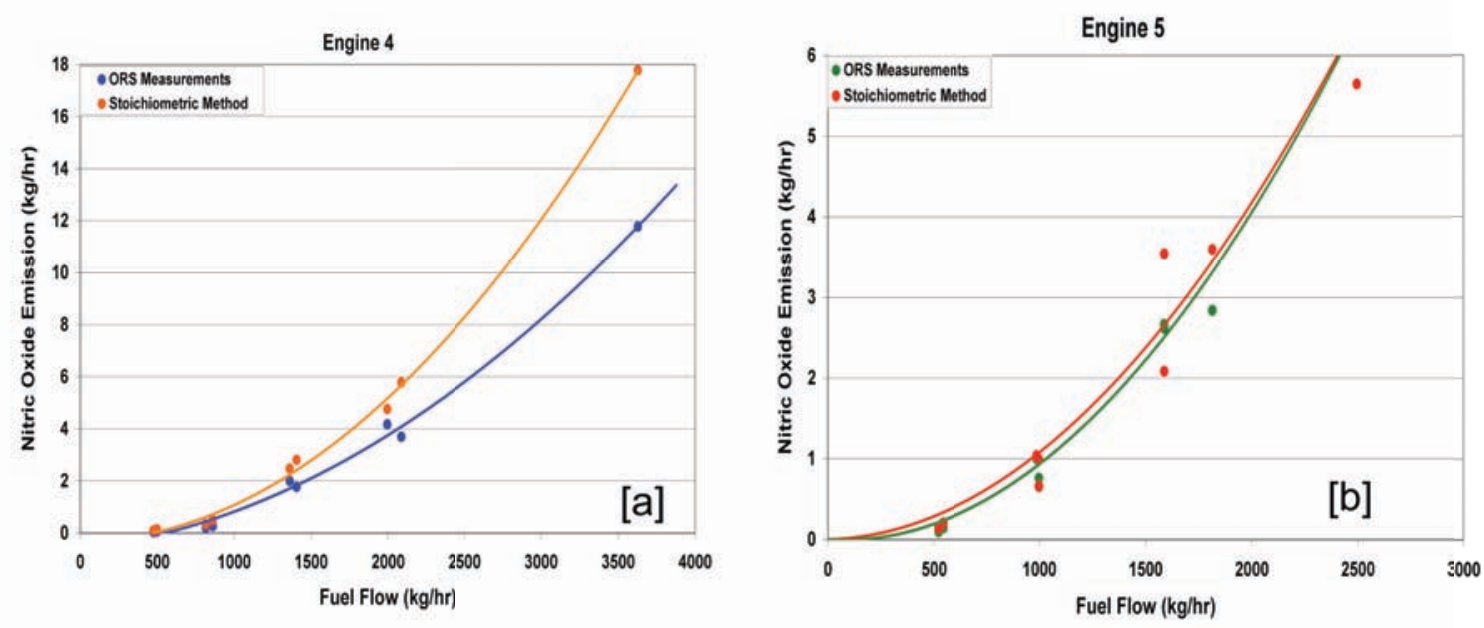

Fig. 22. Plot of NO emission rates versus TF33 engine fuel flow

Fig. 22 shows the plot of derived NO emission fluxes versus fuel flow for the engines \#4 [a] and \#5 [b]. Insignificant scatter was found in the plots for both engines indicating the operational stability of the engine combustion. Engine \#5 appears to be operated close to the stoichiometric operation, while the engine \#4 was not. Fig. 23 shows the plots of formaldehyde (HCHO) emission to $\mathrm{CO}_{2}$ ratio versus the fuel flow for both engines by OP-FTIR measurements at both Front and Back Panels. Again, the curve pattern is consistent with such as THC (Fig. 17) observed by the extractive approach that is the HCHO concentration decreased significantly when the engines were in the higher power settings than the idle condition. The result further supports our conclusion earlier that air toxic issue may be important only at the idle condition. 


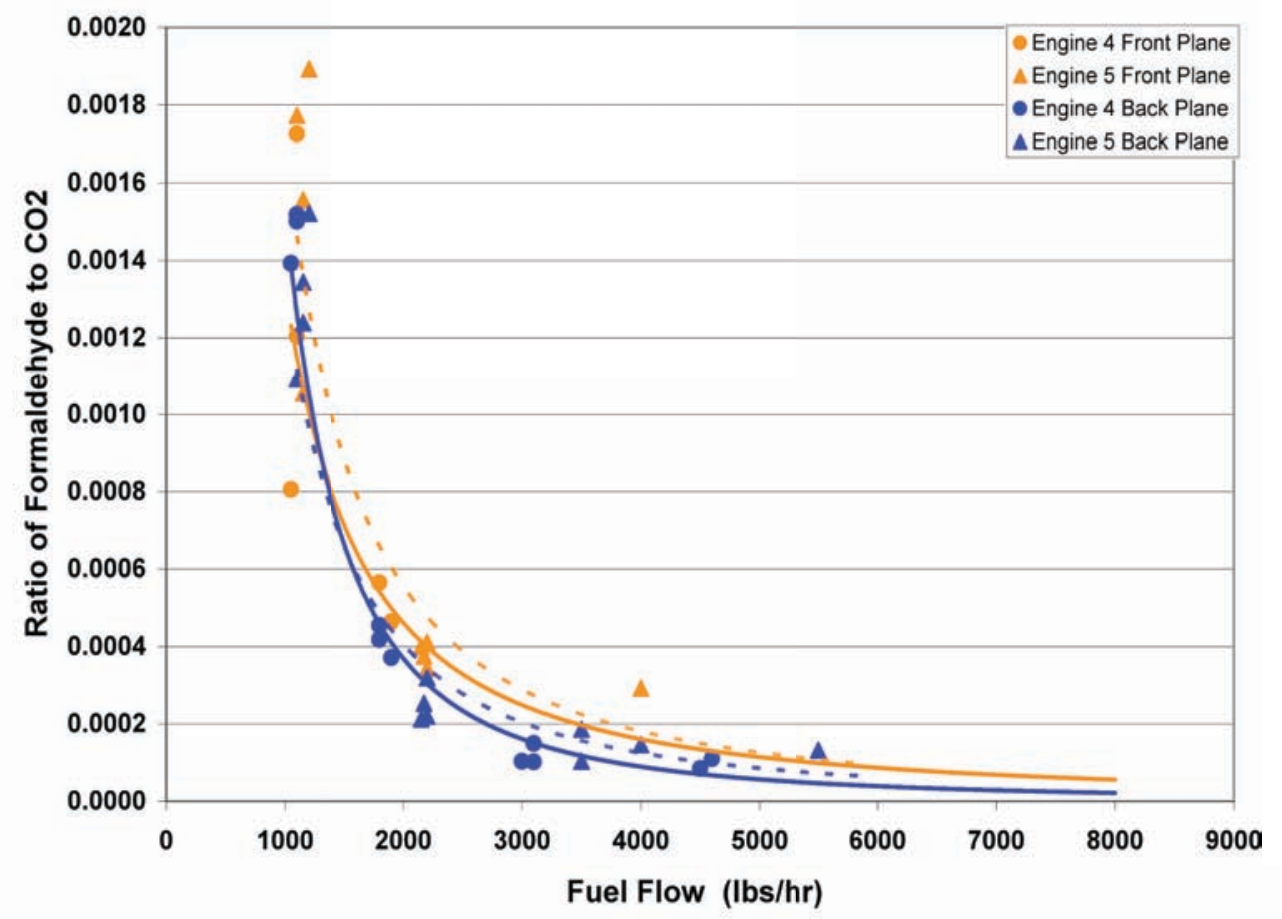

Fig. 23. Plot of formaldehyde to $\mathrm{CO}_{2}$ ratio versus TF33 engine fuel flow

\section{(III.3) Helicopter T700/T701C Engines}

Helicopters are heavily used by the US Army for a wide range of missions such as transporting troops in and out of battlefield, delivering cargo for supply and medicines, conducting surveillance, and engaging in war fighting. A large fleet of helicopters is located at the Hunter Army Air Field (HAAF) in Savannah, GA where we conducted the last emission measurement campaign in June 2007 for this program. The engines tested in this campaign were those used in Blackhawk and Apache aircraft, and are designed as T700-GE-700 or T700-GE-701C. We identify them as T700 for the former engine type and $\mathrm{T} 701 \mathrm{C}$ for the latter in this report.

T700 and T701C belong to a class of turbine engines called turboshaft engine, in which the energy is transferred to rotate the blades that uplift and propel the helicopter. This is a very different turbine engine from that used by B-52 (TF33), example, in which the energy was transfer to the propulsion from the emission nozzle to move the aircraft forward. Thus, the thrusts from the nozzles of T700/T701C type of engines are significantly lower than that of the TF33. This leads to a very different residence-time distribution for chemical reactions in the turboshaft engine plume from those in the TF33 engine plume. It has a significant implication to the formation of secondary particulate matter, for example, in a downstream location.

During the campaign, for logistics and safety concerns, both T700 and T701C engines were tested on an engine test stand at HAAF. The basic field sampling configuration at HAAF was similar to those at KYANG and Barksdale AFB except the distance of sampling locations relative to the EEP was much shorter due to the space constraints at HAAF. Photo of a close-up of the extractive sampling rake about 
$30-\mathrm{cm}$ in front of the engine exhaust nozzle is displayed in Fig. 24, while the photos in Fig. 25 displays the setup of the ORS instruments inside the fence of the test facility and relative location to the engine.

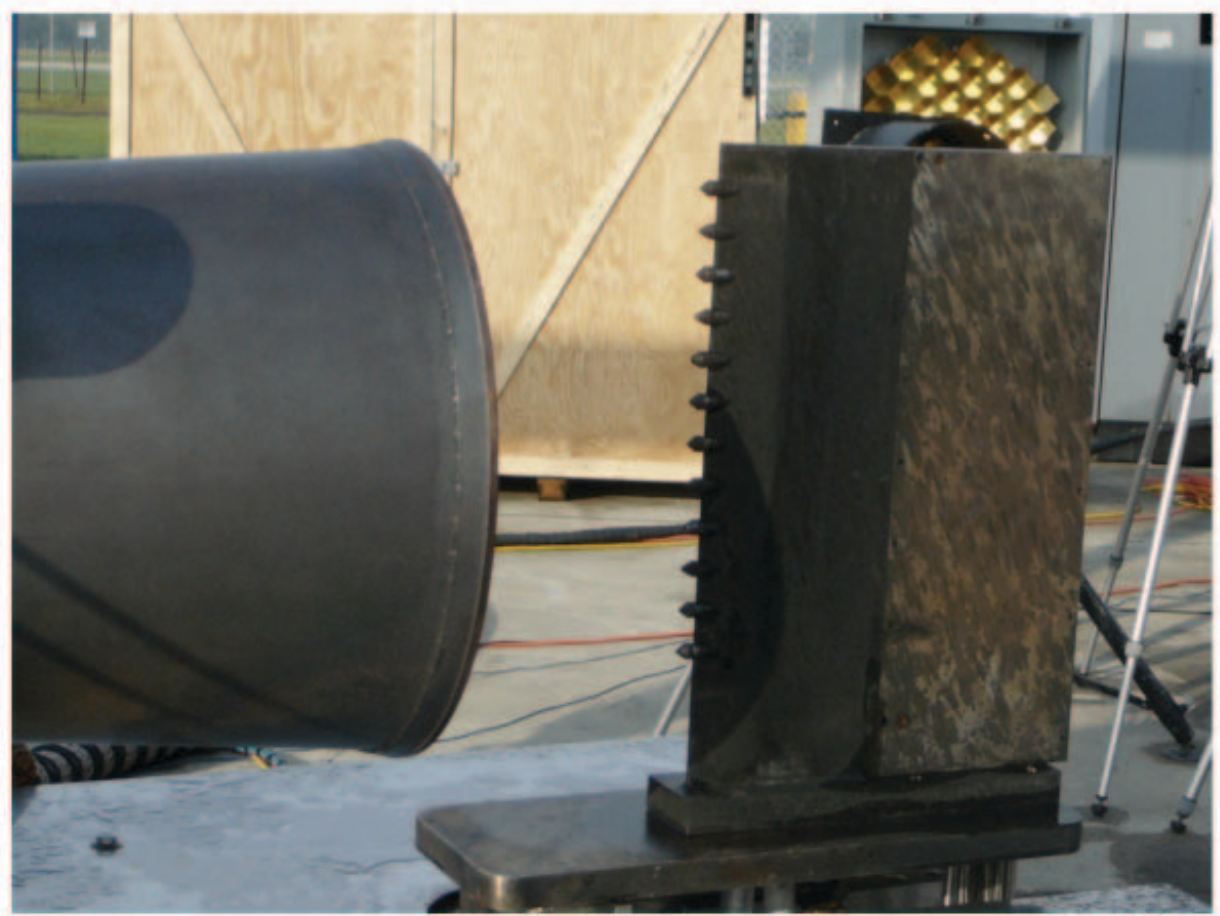

Fig. 24. A close-up photo of the extractive sampling probes for T700/T701C experiments at HAAF

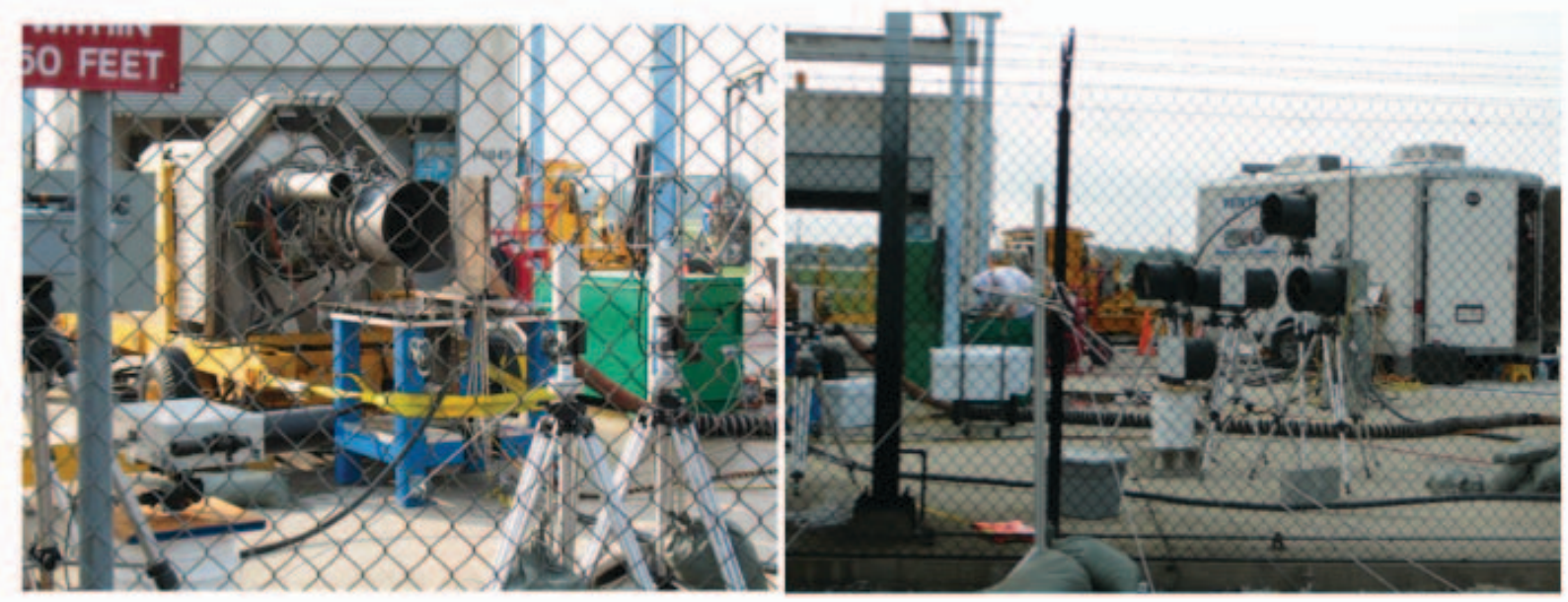

Fig. 25. [a] Relative location of instruments in the fence, [b] ORS instruments setup at HAAF

A schematic drawing of the locations of individual ORS instruments in relation to the engine exhaust nozzle (EEP) is shown in Fig. 26. The new notation "SA" stands for sonic anemometers; they are meteorological instruments adapted by the team for the first-time use in the program to measure the plume flow velocity. There were three of them installed for this campaign. Since the T700/T701C plumes 
were not as hot as those of TF33 were, there was no danger to the anemometers immersed in the plume at a few meters from the EEP. In addition, the T700/T701C plumes were not as momentous as that of TF33; the safety of the anemometers was not compromised.

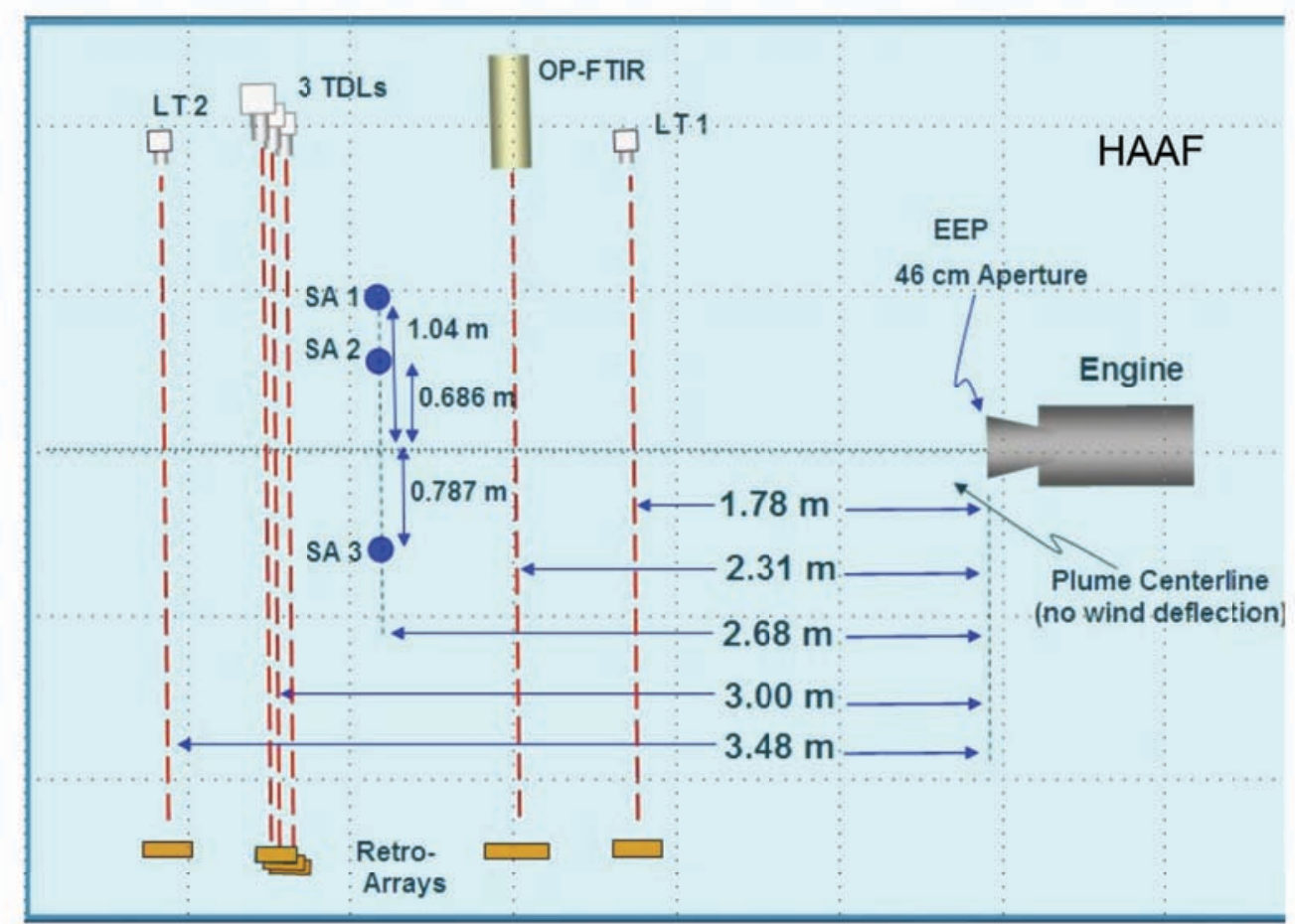

Fig. 26. Relative distance of various remote sensing instruments to the engine nozzle

In addition to the tests of the engines running the JP- 8 fuel, we also ran a natural gas-derived Fischer-Tropsch (FT) fuel on one of the second T701C engines. Both JP-8 and FT fuels used in the engine test were sampled and analyzed after the campaign by the team members at the Wright-Patterson AFRL. The fuel analysis results are shown in Table 2. It is noticed that the aromatic and sulfur contents in the FT fuel are zero in contrast to the conventional JP- 8 fuel that has $19 \%$ by volume of aromatics and $0.14 \%$ of sulfur. Other indices of these two fuels are similar.

For the helicopter engines running on JP-8 fuel, the smoke numbers were determined to be 2,16 , and 40 for the T700 engine operated at idle, $75 \%$ of the max, and max power level, respectively, while the numbers were $<1,8$, and 27 for T701C engine for the corresponding power level. The differences in the $\mathrm{SN}$ values of the two engines operated with the same fuel were significant and could only be attributed to the difference in the design and maintenance of the engines. The T701C engine was newer than the T700 engine and was tuned right before our test. For the T701C engine operated with the FT fuel, the smoke numbers were $<1,2$, and 12 for the three engine power levels, respectively. The smoke number results thus indicate the importance of engine maintenance. It is clear that the use of the neat FT fuel substantially reduced the smoke number of the T701C engine emission. 
Table 2. Engine Fuel Analysis Results (HAAF)

\begin{tabular}{|c|c|c|}
\hline ASTM Test Standard & JP-8 & Neat FT Fuel \\
\hline Aromatics, \% vol (D1319) Max. 25. 0 & 19.2 & 0 \\
\hline Total Sulfur, \% wt (D4294) Max. 0.30 & 0.14 & 0 \\
\hline Initial Boiling Point (IBP), ${ }^{\circ} \mathrm{C}$ (D86) Report & 173 & 150 \\
\hline $10 \%$ Recovered, ${ }^{\circ} \mathrm{C}(\mathrm{D} 86)$ Max. 205 & 189 & 173 \\
\hline $20 \%$ Recovered, ${ }^{\circ} \mathrm{C}(\mathrm{D} 86)$ Report & 192 & 181 \\
\hline $50 \%$ Recovered, ${ }^{\circ} \mathrm{C}$ (D86) Report & 207 & 208 \\
\hline $90 \%$ Recovered, ${ }^{\circ} \mathrm{C}$ (D86) Report & 234 & 245 \\
\hline Final Boiling Point, ${ }^{\circ} \mathrm{C}$ (D86) Max. 300 & 248 & 258 \\
\hline Distillation-Residue, \% vol (D86) Max. 1.5 & 1.3 & 1.5 \\
\hline Loss, \%vol (D86) Max. 1.5 & 1.5 & 0.50 \\
\hline Freeze Point, ${ }^{\circ} \mathrm{C}$ (D5972) Max. -47 & -51 & -49 \\
\hline Existent Gum, mg/100mL (D381) Max. 7.0 & 1.1 & 0.6 \\
\hline Viscosity @ $-20^{\circ} \mathrm{C}, \mathrm{cSt}$ (D445) Max. 8.0 & 5.0 & 4.9 \\
\hline FSII (DiEGME), \% vol (D5006) 0.10-0.15 & 0.12 & 0.05 \\
\hline Smoke Point, mm (D1322) Min. 19.0 & 25 & 35 \\
\hline Flash Point ${ }^{\circ} \mathrm{C}$ (D93) Min. 38 & 62 & 63 \\
\hline Specific Gravity @ $15.5^{\circ} \mathrm{C}$ (D4052) 0.775-0.840 & 0.806 & 0.756 \\
\hline Heat of Combustion, BTU/lb (D3338) Min. 18400 & 18500 & 18980 \\
\hline Hydrogen content, \% mass (D3343) Min. 13.4 & 13.7 & 15.3 \\
\hline
\end{tabular}

\section{(III.3.1) Particulate Matter Emissions}

\section{Size and size distributions based on number concentration}

The averaged particle size distribution obtained at EEP for the T700 engine operated with JP-8 fuel is displayed in Fig. 27 with respect to the engine power setting. The size distributions were probe-tip dilution corrected. The variation associated with each averaged particle size distribution shown in Fig. 27 was about $\pm 10-15 \%$ of the average. The distributions in Fig. 27 were those obtained by using a SMPS equipped with a long DMA and UCPC. The exhaust samples were transported through a 23-m heated sampling line to the SMPS located in the sampling trailer. As shown in Fig. 27 the peak height of the size distributions increased as the engine power increased. This observation is consistent with the other two tests (i.e., the C-130H and B-52 tests) discussed earlier where a larger peak was found to be also associated with a higher-power engine setting. In other words, more fuel burned leads to higher particulate emission. 


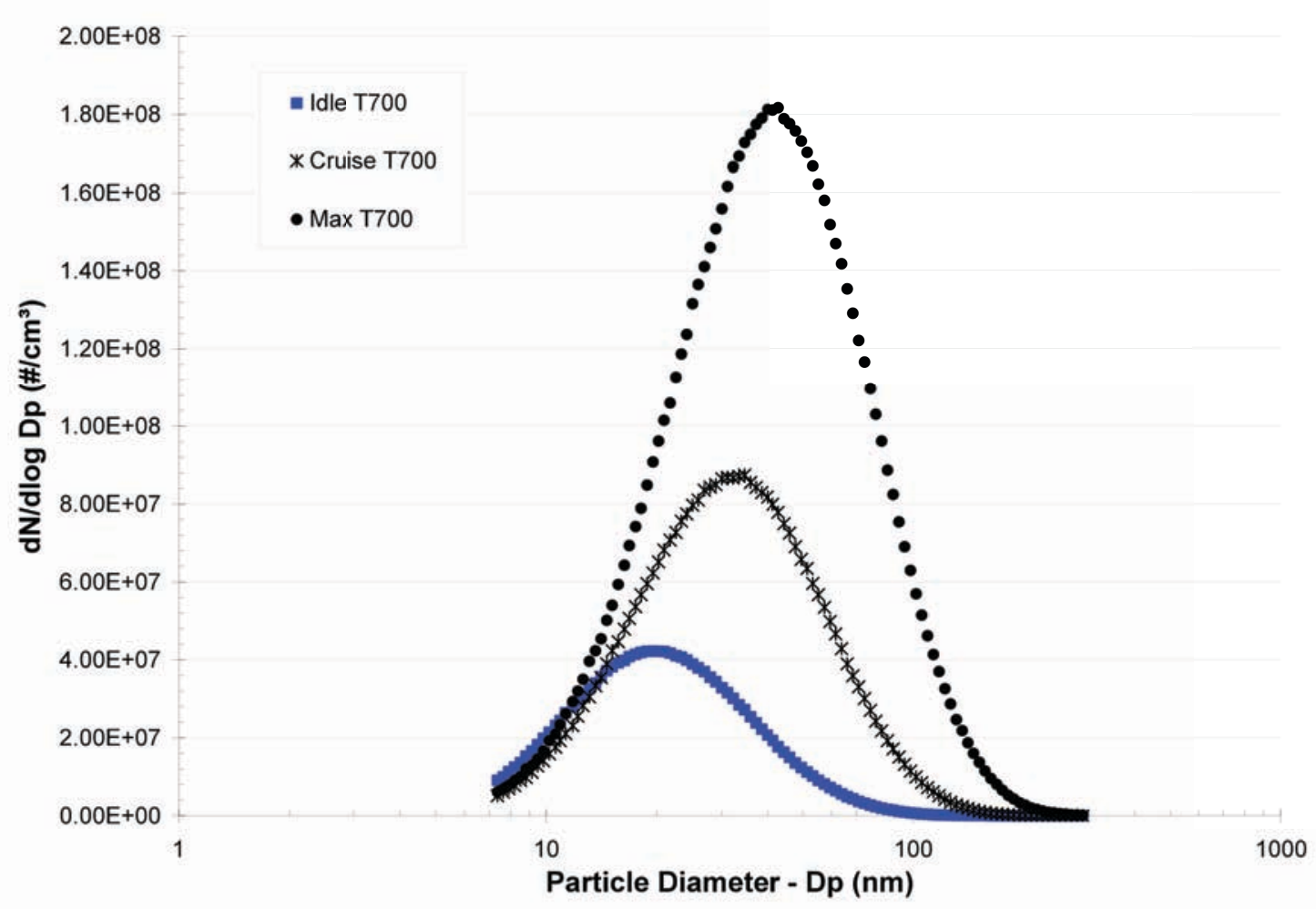

Fig. 27. Averaged size distributions of T700 engine particles observed at EEP

The modal diameter of the particles increased as the engine power setting increased (20nm at idle, $31 \mathrm{~nm}$ at the $75 \%$ of max, and $41 \mathrm{~nm}$ at the max power), which is also consistent with what we have seen in the two earlier tests. Thus, generally for turbine engine PM emission, it seems that larger particles and higher particle number concentrations are produced at higher power settings. In other words, the particulate emission is expected to reach its maximal concentration and largest particle size during the take-off, for example, when the max power is required to lift the aircraft off the ground. In comparison, an idling engine would not produce as much particulate matter.

The three averaged particle size distributions taken in the plume at the fence location about $4 \mathrm{~m}$ from the EEP are shown in Fig. 28. The probes at this sampling location were actually located inside the fence; this is to prevent any potential contamination from blowout of any particles previously deposited on the fence. For the same reasoning, we decided not to place any probes beyond the fence boundary. The three size distributions were averaged from the distributions taken by the SMPS equipped with a nanoDMA (instead of a long-DMA used for the data shown in Fig. 27); a nano-DMA equipped with a UCPC enabled characterization of particles as small as $4 \mathrm{~nm}$. 


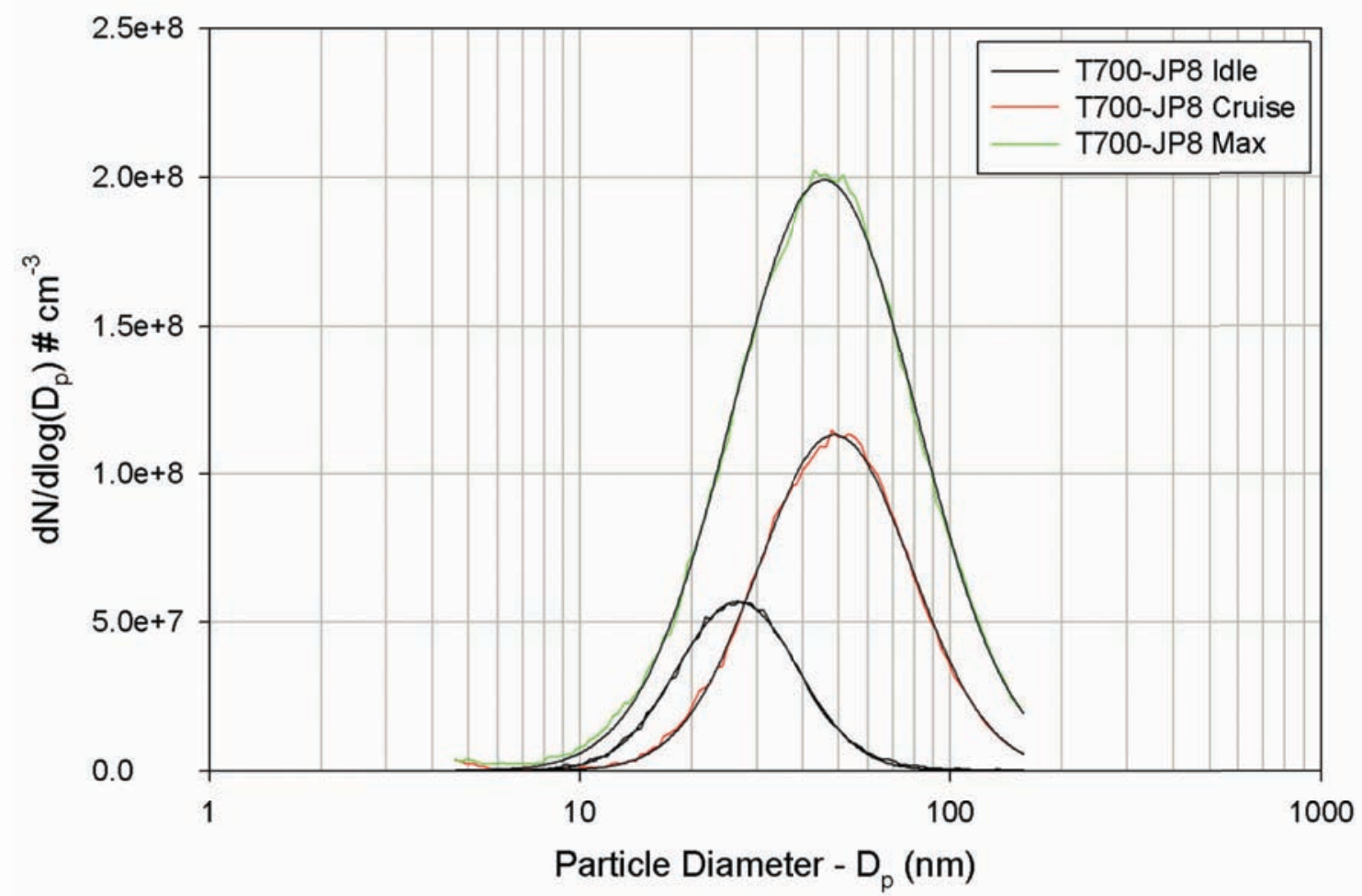

Fig. 28. Averaged size distributions of T700 engine particles at the 4-m distance from the EEP

The size distributions were corrected for plume and probe-tip dilutions. The $\mathrm{CO}_{2}$ measured at the EEP was divided by the $\mathrm{CO}_{2}$ determined at the 4-m distance to yield the plume dilution ratio for correcting the number concentration for each of particle size distribution curves. The dilution-corrected distributions are shown in Fig. 28; the dilution correction does not affect the shape or location of the peak of a particle size distribution (also called the mode diameter). It simply adjusted the particle number concentration upward. We are confident that the data are credible and the overall patterns and the similarity of the size distribution curves shown in both figures (Figs. 27 and 28) are valid. Moreover, the probe-tip dilution technique used in sampling engine particles appears to be working satisfactorily.

Note that the modal diameters are larger for particles measured at the 4-m location (Fig. 28) than that measured at the EEP (Fig. 27). If the larger diameters found at the 4-m downstream location was attributed to particle growth, one finds that the growth in the mode diameter decreased as the engine power increased. 


\section{Particulate sulfur}

The measured concentrations (in units of $\mathrm{mg} / \mathrm{m}^{3}$ ) of the particulate sulfur $(\mathrm{S})$ and sulfate $\left(\mathrm{SO}_{4}\right)$ for the T700 engine running on JP-8 fuel are summarized in Fig. 29. Note that the sulfur in sulfate was calculated by multiplying 0.33 with the sulfate concentration determined by IC. This again is to obtain the sulfur mass that was detected in the sulfate form, and this would make both sulfur data comparable on the same chemical footing. Statistically, all the sulfur mass in the particles appears to be in the form of sulfate for all engine power conditions, except for the $75 \%$ max power condition that only about $82 \%$ of the particulate sulfur was in sulfate form. The difference was statistically weak. However, recalled the results shown in Fig. 16 earlier where not all-particulate sulfur was in the sulfate form at higher power conditions. The abundance of sulfate appears to be lowest also at the middle power conditions (e.g., the $75 \%$ max in the case of T700 engine and $80 \%$ in the case of TF33). The total sulfur and sulfate content increased when the engine power increased. In other words, the conversion of sulfur to sulfite and or sulfate that then were condensed onto non-volatile soot particles appears to be more prevalent at the idle condition than the higher power conditions.

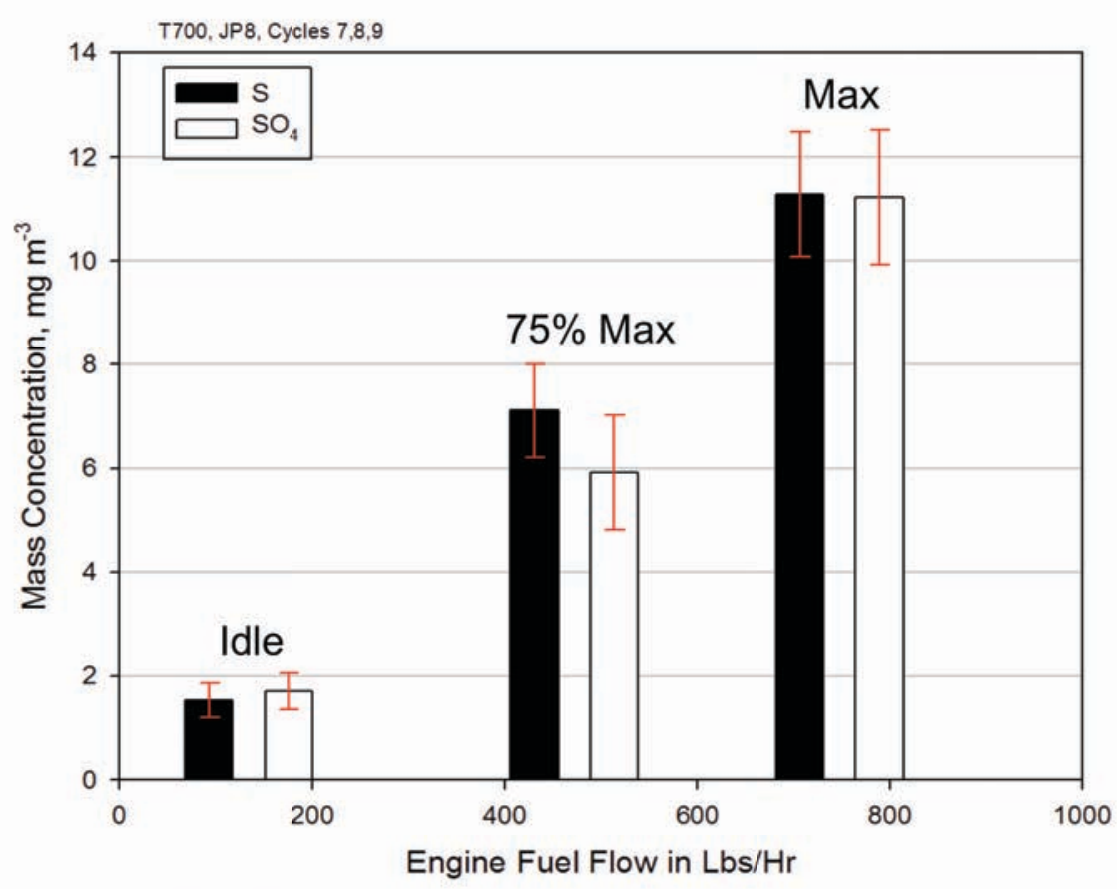

Fig. 29. Plot of engine particulate sulfur and sulfate versus T700 engine power setting

Two curves were plotted in Fig. 30. The blue curve is another graphical illustration of the sulfur conversation result discussed in the previous paragraph, while the red curve shows the ratio of $\mathrm{SO}_{4}$ to elemental carbon (EC) for the same engine emissions. The red curve has a downward trend indicating the ratio of $\mathrm{SO}_{4}$ to $\mathrm{EC}$ decreased as the engine power increased. We know that both sulfate (from Fig. 29) and element carbon (see next section) increased as the engine power increased. Thus, the reversed trend of $\mathrm{SO}_{4} / \mathrm{EC}$ could be resulted from the following mechanism. 
Fuel sulfur is oxidized into $\mathrm{SO}_{2}$ or $\mathrm{SO}_{3}$. The conversion of $\mathrm{SO}_{2}$ into $\mathrm{SO}_{3}$ or $\mathrm{SO}_{4}$ in the gas phase is a slow process in the atmospheric condition unless other catalyst like $\mathrm{Fe}$ or $\mathrm{Mg}$ is involved. So to find sulfate on particles condensation of sulfuric acid molecules onto soot particles is a more likely process. Condensation is a surface-driven process. Higher engine power leads to the formation of larger particles (thus more EC mass) but less reactive surface area per unit mass. As the engine power increased, the production of particulate sulfate would slow down if sulfate were adsorbed onto the surface of larger soot particles by condensation process. That would lead to a smaller $\mathrm{SO}_{4} / \mathrm{EC}$ ratio at the higher power setting like reported here in Fig. 30. Thus, it is likely that sulfate was formed on TF33 engine particle surfaces where the precursor vapors condensed on.

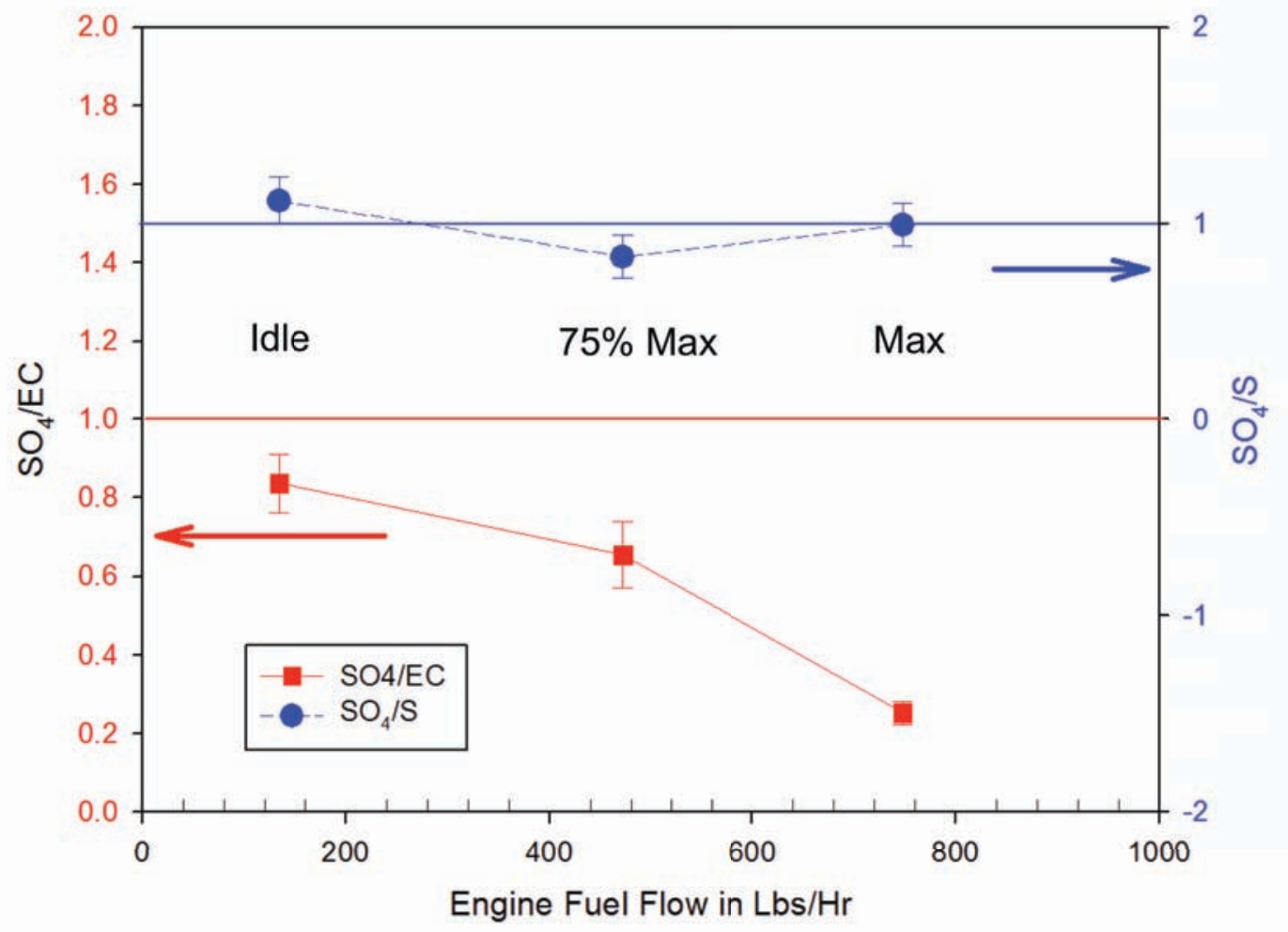

Fig. 30. Plot of $\mathrm{SO}_{4} / \mathrm{S}$ ratio and $\mathrm{SO}_{4} / \mathrm{EC}$ ratio against $\mathrm{T} 700$ engine power setting

\section{Particulate carbon}

The particulate carbon analysis data for T700/T701C test are shown in Fig. 31. The carbon data plotted in Fig. 31 were obtained based on the NIOSH protocol for diesel soot that was discussed earlier for TF33 engine data. Again, the organic and elemental fractions of carbon were produced by applying the analytical protocol. Fig. 31[a] displays the ratio of OC to TC, while Fig. 31[b] shows the ratio of EC to TC. Shown in this figure are data for samples taken at the 4-m distance from the EEP. 

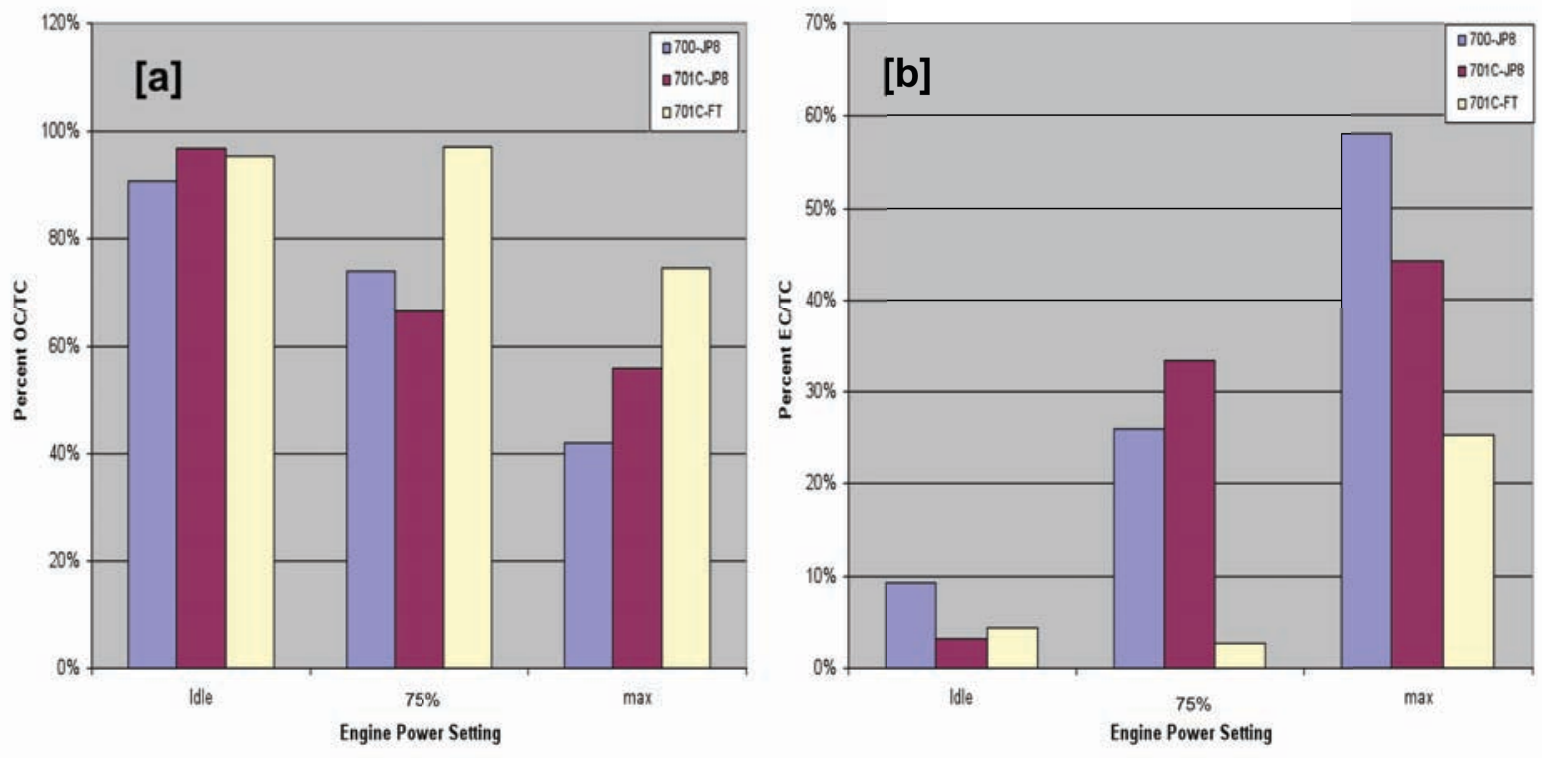

Fig. 31. Plots of particulate carbon contents measured at 4-m downstream [a] OC/TC, [b] $\mathrm{EC} / \mathrm{TC}$

Note that the TC increased as engine power increased (the plot not shown here). In addition, the use of the FT fuel significantly reduced the total particulate carbon emission as compared to the use of JP8 fuel. It is noticed that the $\mathrm{OC} / \mathrm{TC}$ decreased as the engine power increased for both engines operated with JP-8 and FT fuel as expected; the negative trend of OC/TC is similar to that reported in Fig. 17 for the TF33 engine emissions. The EC/TC trend is the opposite of the OC/TC slope where the higher engine power conditions led to emissions of higher EC or EC fraction.

As shown in Fig. 31[a], the use of the FT fuel appears not significantly reducing the volatile organic component as expected; instead, the OC/TC ratio seems to be larger for T701-FT than for T701JP-8 at the max power and $75 \%$ of max power setting (Fig. 31[a]). The ratios for the idle were about the same. This is a data artifact; however, remember as EC/TC goes down due to the use of FT fuel that minimizes the formation of engine soot, the $\mathrm{OC} / \mathrm{TC}$ ratio that is associated with the case of FT fuel burning would naturally increase because $(\mathrm{OC} / \mathrm{TC}+\mathrm{EC} / \mathrm{TC})$ is equal to 1 .

The plot shown in Fig. 32 is the ratios of OC/EC for various engine-fuel cases tested at HAAF. The error bars associated with the ratios were resulted from performing Taylor series expansion for error propagation using errors associated with the carbon measurements. In Fig. 32 the light brown shade represents typical OC/EC values found in the metropolitan areas around the world, while the light blue shade represents typical OC/EC values found in the forest areas where biogenic emissions contribute significantly to the OC component. As the engine power increased, the emitted OC/EC by T700 operated with JP-8 decreased as expected; however, from highly OC enriched regime in the blue shade to below the brown shade at the max power condition. This result indicates that the aircraft emission has its own unique $\mathrm{OC} / \mathrm{EC}$ signature at the max engine power condition from that of urban or rural aerosols. The 
signature is difficult to distinguish from those in the environment at the $75 \%$ max or idling power condition. The carbon results are published in Cheng et al. (2009).

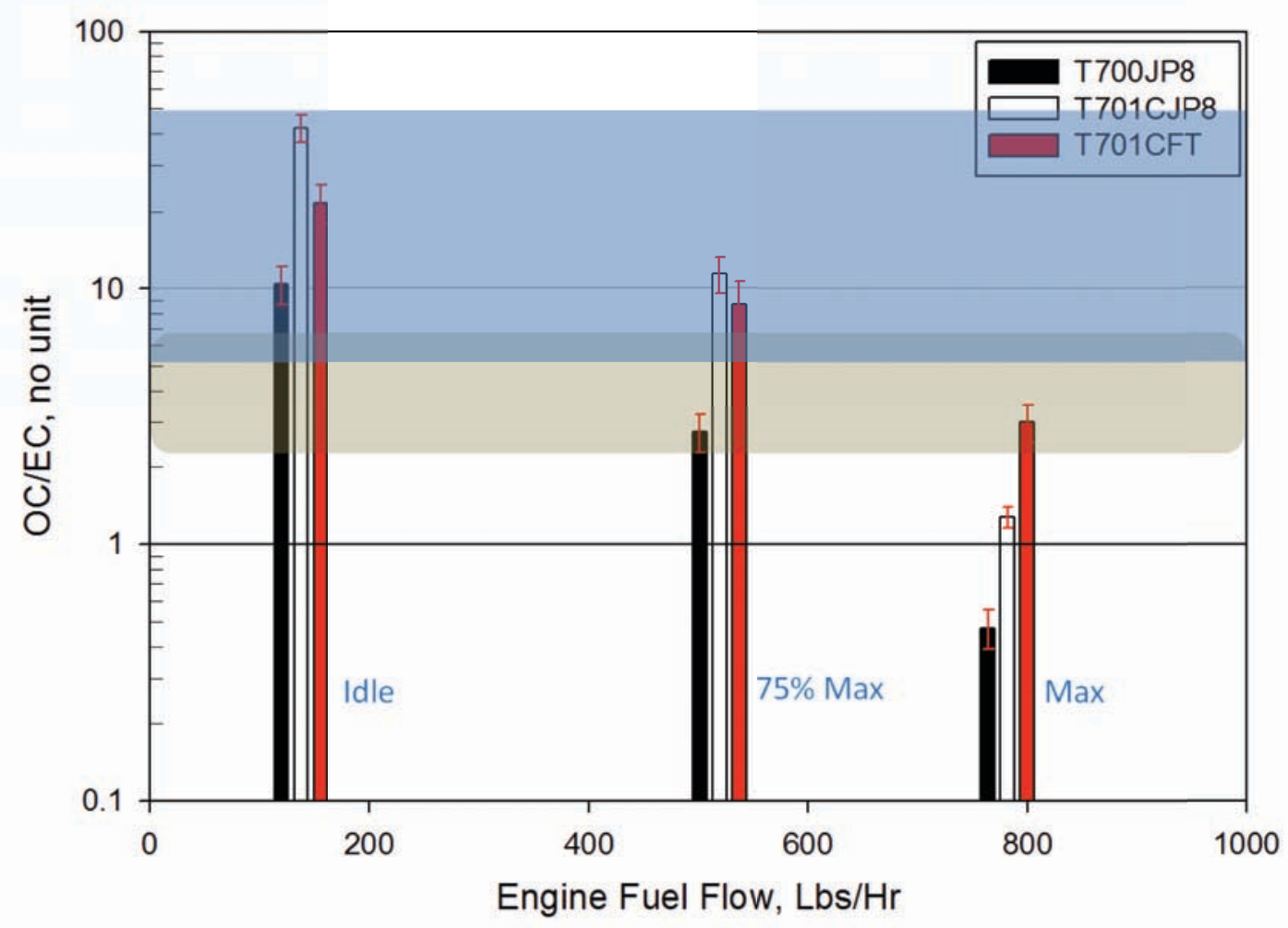

Fig. 32. Plot of OC/EC ratio of T700/T701C particles vs. engine power setting

\section{Particulate Emission Indices and Smoke Number}

The emission indices based on the particle number concentration were derived and plotted against the engine power settings in Fig. 33. The calculation was based on the same formula used previously for T56 and TF33 engine emissions and were discussed earlier in this report. The particle number concentration was measured by using the TSI 3022 device mentioned previously and corrected for dilution as well as line loss. 


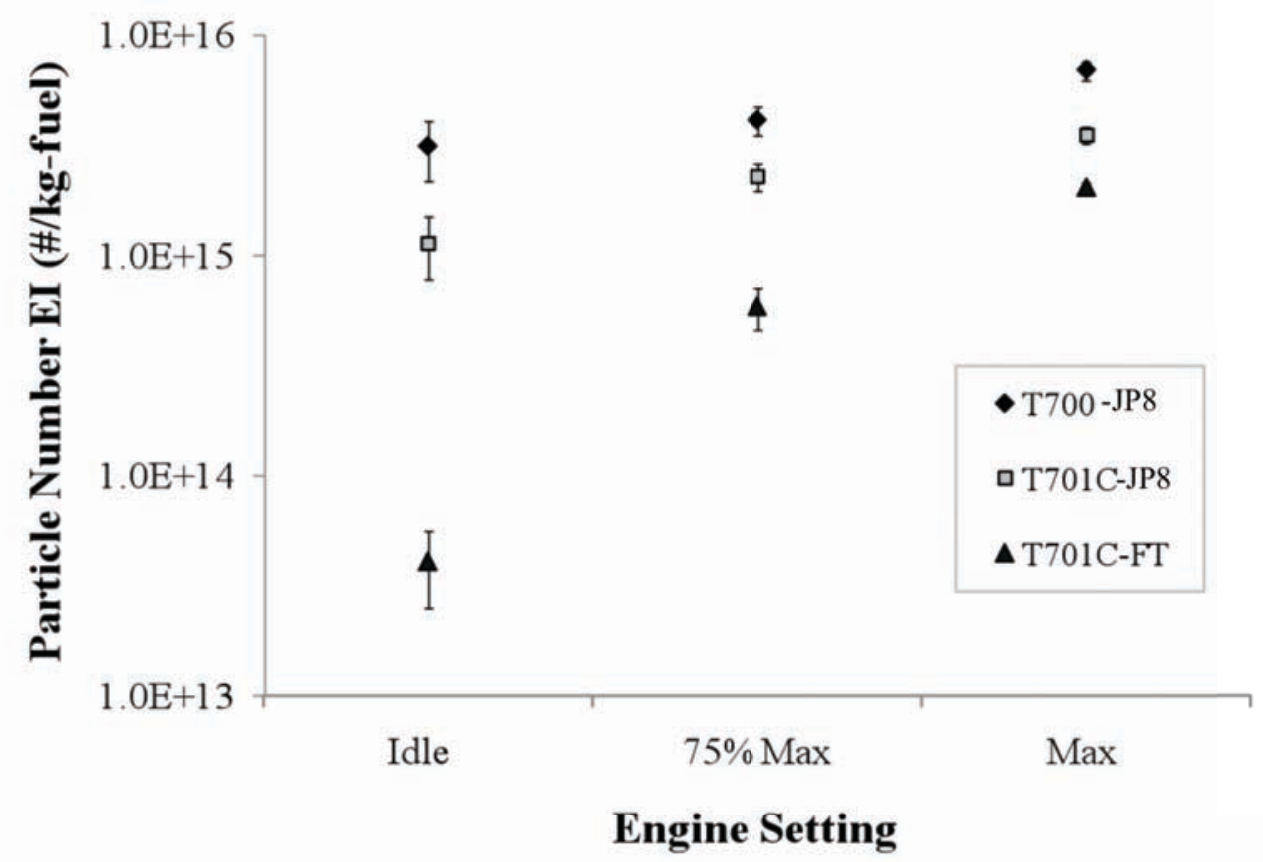

Fig. 33. Plot of EI_pn versus T700 and T701C engine power setting

In general, the higher the engine power, the larger the emission index and therefore the higher the particulate emission. The T700 engine operated with the JP-8 fuel produced the highest number of particles compared with the T701C operated with JP-8 or the second T701C engine operated with the FT fuel at each engine power condition. During the ground idle condition, the second T701C engine operated with the FT fuel produced very little particles as compared to the other two engine-fuel combination cases. However, the emission index of T701C-FT increased rapidly approaching the other two cases as the engine power increased, the change was dramatic ranging from 3 orders of magnitude at the idle condition to a factor of 4 at the max engine power condition.

This is interesting because the FT fuel reduced substantial mass concentrations of the particulate sulfur and carbon contents as we reported in the previous sections, and we expected the reduction of particle number concentration would be proportional. Thus, the emission index curves for the three engine-fuel cases should be at least parallel to each other. The two JP-8 cases certainly do parallel with each other, but the FT case does not. This result raises the question about the predictability on the emitted particle number concentration as a function of the engine power when the engine is operated with an alternative fuel like the FT.

The emission index calculated based on the particle mass concentrations (EI_mass) obtained by TEOM is shown in Fig. 34[a]. The Smoke Numbers (SN) for the three engine-fuel combinations is shown in Fig. 34[b]. Both plots show similar trend for EI_mass and SN as a function of engine power setting. As the engine power increased, the value of EI_mass or SN increased. This result is consistent for all three cases of the engine-fuel combinations. T700-JP-8 has the highest particulate mass emission for every $\mathrm{kg}$ of fuel burned; while as expected T701C-FT has the lowest particulate mass emission as expected. An 
alternative fuel like the FT fuel could be an attractive solution in the reduction of aircraft particulate emissions, if the price of the FT fuel could be reduced.

The SN increased as the engine power increased, which is similar to the other two engine tests (i.e., T56 and TF33). Use of FT fuel did substantially reduce the particulate mass and number emission as compared to the use of JP-8 fuel; we also noticed that for burning the same JP-8, T701C had a smaller SN value than T700. Remember that T701C was serviced right before our test, while T700 was to be serviced. The difference in engine maintenance made to the emission level is clearly seen in the results.

\section{El_mass}

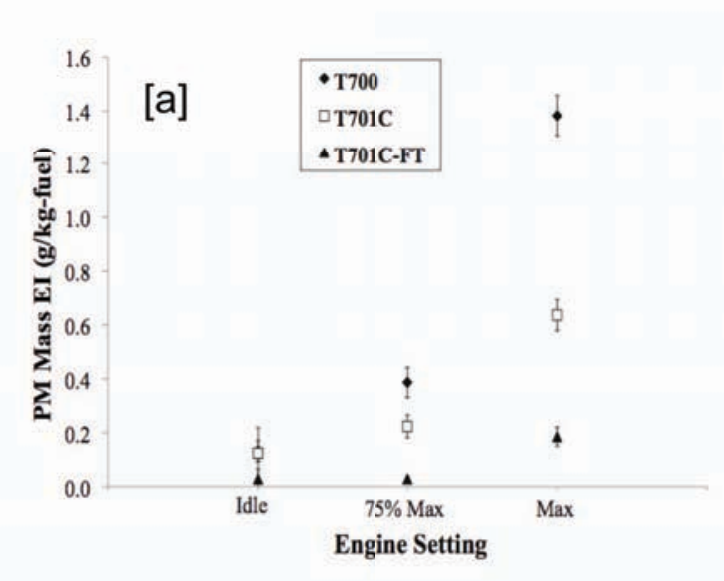

\section{Smoke Number}

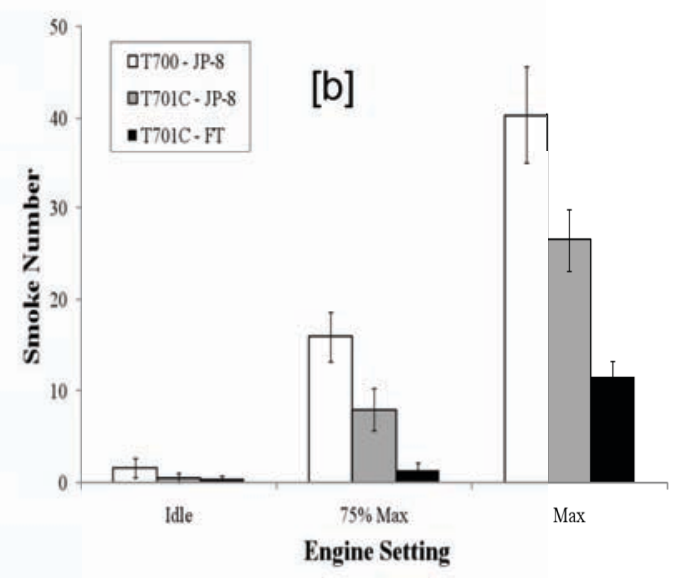

Fig. 34. Plot of EI_mass [a] and Smoke Number [b] for T700 and T701C engines

The result of SN again highlights the importance of fuel in the formation of engine particles, because all three SN for T701C-FT are much smaller than any JP-8 numbers in Fig. 34[b]. It is also important to note that the $\mathrm{SN}$ values for T701C engines are relatively small to the values for other types of engines like TF33 and T56. In particular, SN for T701C-FT at the idle condition is close to the detection limit of the method used to measure SN. The T700 engine operated with JP-8 did produce comparable a SN value at the max power to the T56 or TF33 engines.

\section{Comparison of Fast Particle Sizer (FPS) to SMPS}

During the third year, a fast particle-sizing instrument was developed and tested for the first time in the field. The major achievement of this sizer (FPS) is that the individual components shown in Fig. 35 are all off-the-shelf and commercially available so they all have been used extensively. The breakthrough lies in the communication module and software developed by ORNL scientists without the electronic module and software these hardware components cannot communicate with each other to perform high- 
speed DMA particle sizing demonstrated here. Current ability for this prototype permits particle sizing as fast as 20 -ms measurement interval if needed. The measurement time can be programmed.

\section{Combine EC/DMA with electrometer Use Labview to -control voltage on DMA -collect particle counts in electrometer}

\author{
Flow Rates: \\ Sheath $=10 \mathrm{LPM}$ \\ Aerosol $=1 \mathrm{LPM}$
}

Control Parameters:

- Collection Time

-\# of Channels

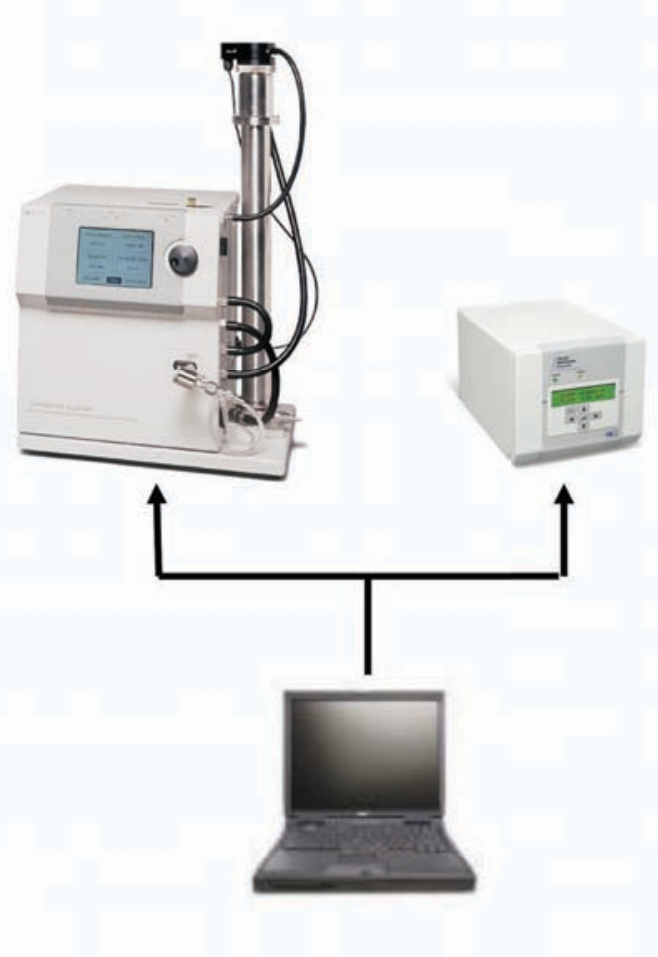

Fig. 35. Schematics of ORNL FPS

The comparison of the peak diameter obtained by the FPS prototype instrument and SMPS particle sizer for T700 and T701C engines at the three power settings is shown in Fig. 36. Remember that the particle size measurements by these two instruments were located at different locations, but the peak diameters obtained and shown in Fig. 36 are surprisingly close. The FPS was located right next to the engine connected to the sampling probe shown in Fig. 24 with a 1-m long sampling line, while the SMPS was located at 23-m away. Both units run on long-DMA designed by TSI, Inc. The $23-\mathrm{m}$ length line connected to the SMPS was heated and particles were diluted at the probe tip, while particles were also probe-tip diluted for the FPS but the sampling line length was 23 times shorter and not heated. 


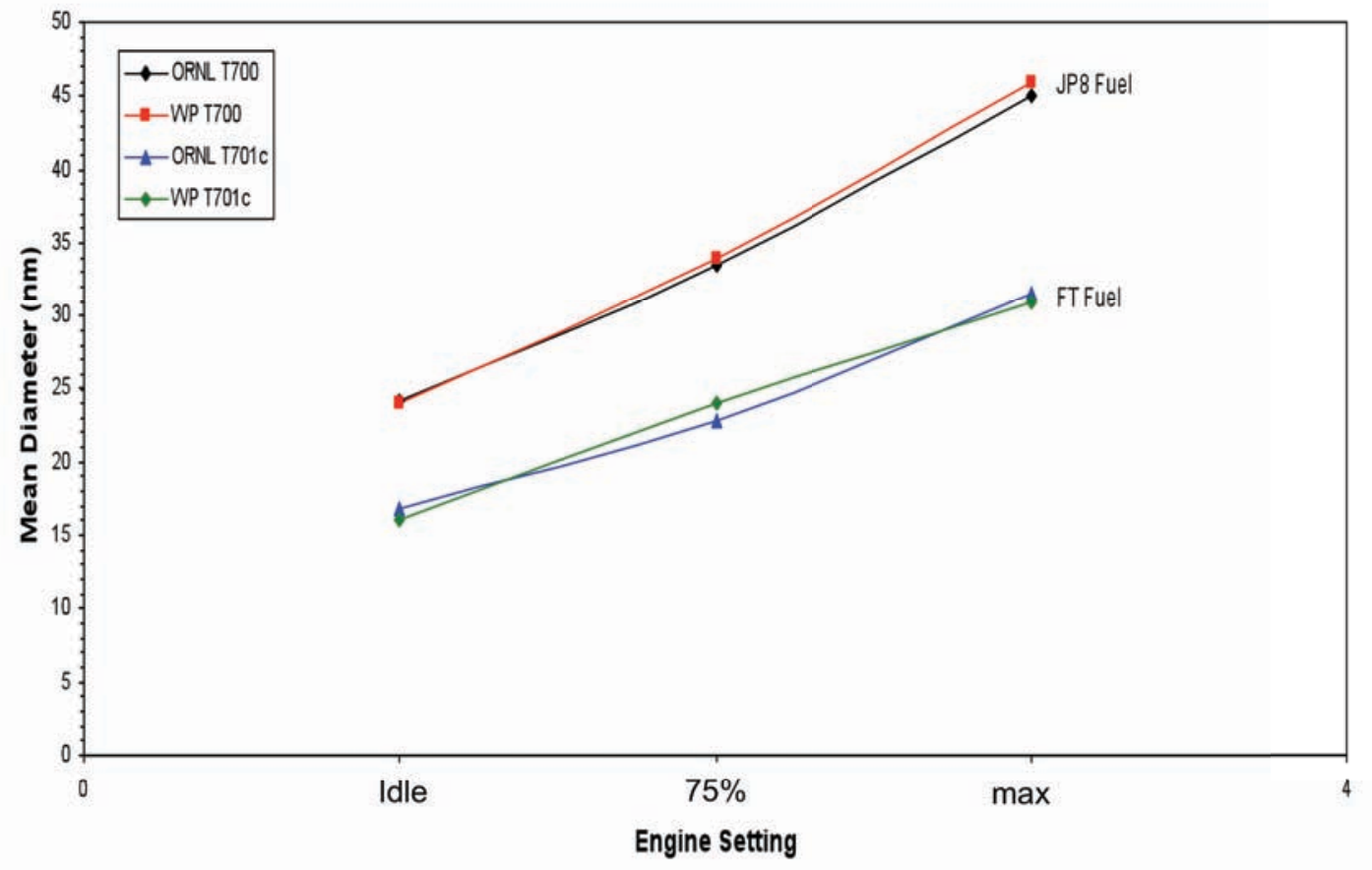

Fig. 36. Comparison of FPS with SMPS particle diameters for T700/T701C JP-8 particles

With the fast particle-size capability, it was interesting to observe the "emission-resetting" process during the startup of the T700 engine running JP-8 fuel; otherwise, it could not be observed with the commercial SMPS. The result is shown in Fig. 37 where the legend of higher number indicates a later time since the engine was started. Each curve was a $40-\mathrm{sec}$ measurement in this example. One can see the modal diameter decreased from $28 \mathrm{~nm}$ down to $22 \mathrm{~nm}$, a significant decrease. The peak number concentration was also decreased from a level that was greater than $7 \mathrm{E}+7 \# \mathrm{~cm}^{-3}$ to $5 \mathrm{E}+7$, a $29 \%$ reduction within $200 \mathrm{sec}$ after the engine was started. This engine emission dynamics could be caused by transient fuel flow. The result may also be interpreted as the dynamics of engine combustion approaching its designed efficiency during the start up. It is important to note that particle size distributions taken after $200 \mathrm{sec}$ varied little from the curve labeled \#7 in Fig. 37. 


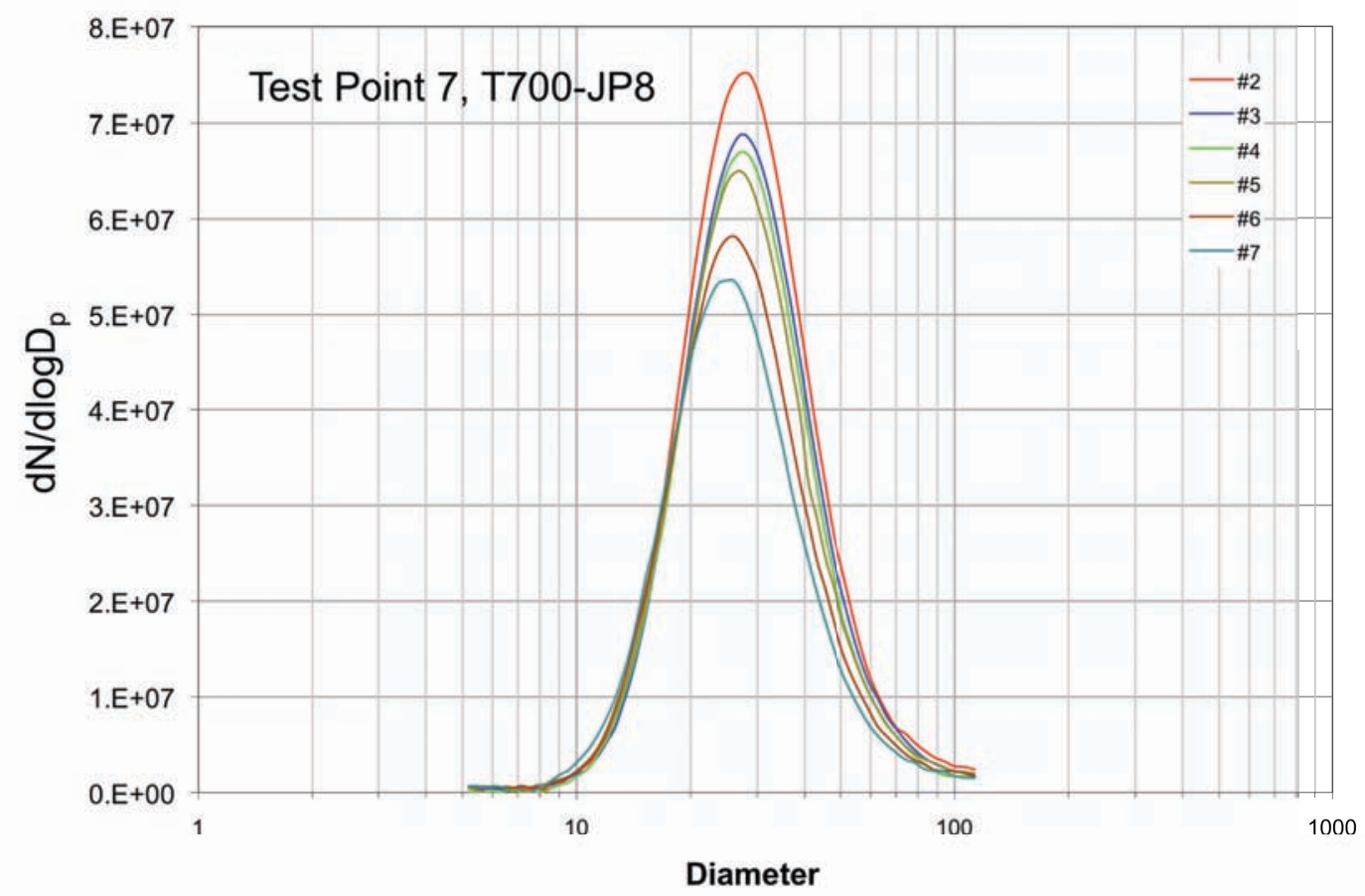

Fig. 37. Transition particle size distributions observed by FPS at HAAF

The result was encouraging and showed that the prototype instrument may be used for fast particle sizing that could not be achieved by SMPS. However, more development work and testing are needed to make the prototype user-friendly and robust for fieldwork.

\section{(III.3.2) Gaseous Emissions}

Again, concentration of gas-phase species were sampled by the extractive platform at the engine exhaust plane (EEP) and measured using the MKS FTIR instrument. Gas-species measurements were also made using OP-FTIR and OP-TDLAS at a downstream location shown in Fig. 26.

The averaged emissions data of carbon monoxide (CO) measured at EEP are displayed in Fig. 38. The emissions were calculated as a ratio of $\mathrm{CO}$ to $\mathrm{CO}_{2}$ to normalize for the dilution effect - the greater the engine power the higher the dilution. The emissions are plotted against the three engine power settings. As expected the level of $\mathrm{CO}$ emissions decreased as the engine power increased. Observation of such decreasing trend for $\mathrm{CO}$ is consistent throughout all engines tested in this program. 


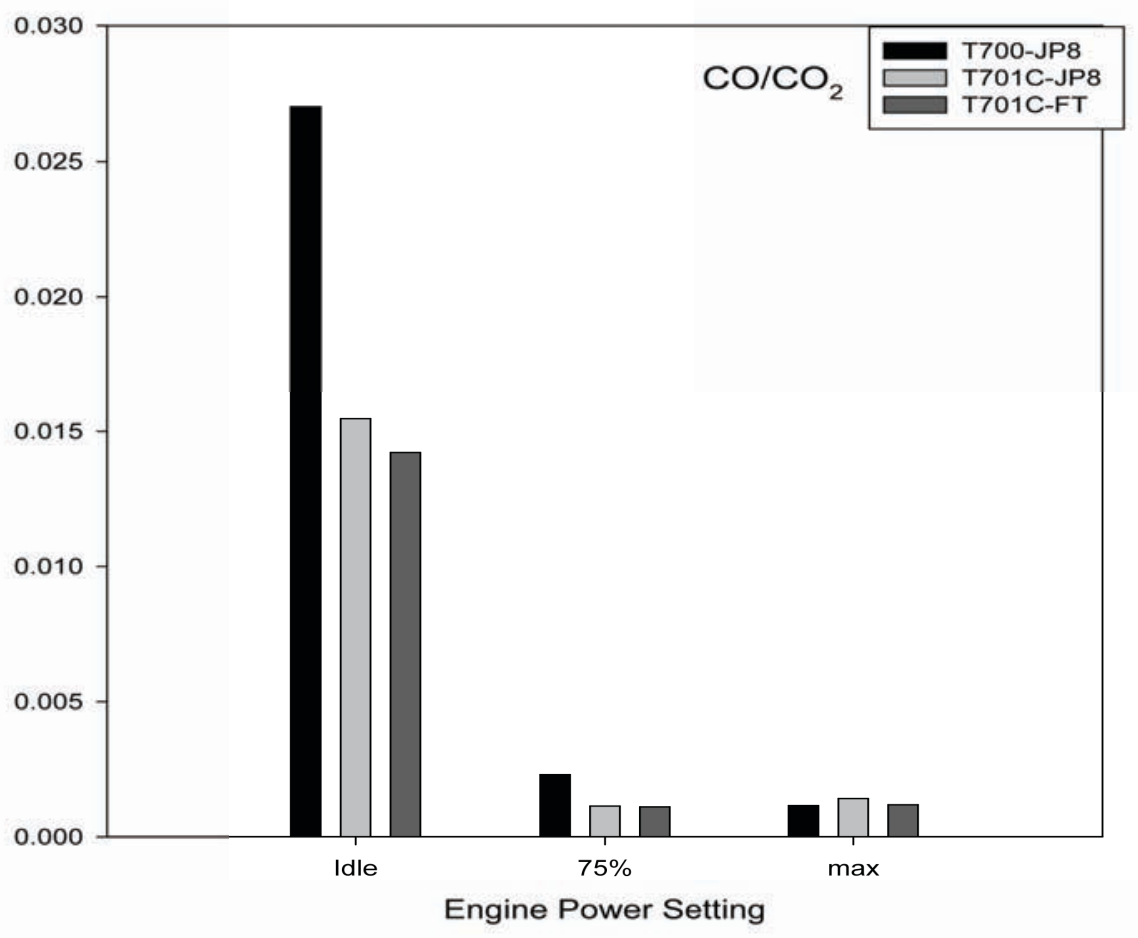

Fig. 38. Plot of $\mathrm{CO} / \mathrm{CO}_{2}$ ratio versus engine power setting for $\mathrm{T} 700$ and $\mathrm{T} 701 \mathrm{C}$

Plot for nitrogen oxide (NO) versus engine power setting was made and displayed in Fig. 39[a]. Each bar in a group represents an engine-fuel combination (e.g., T700-JP8 or T701C-FT). Again to normalize the dilution effect, the trend of $\mathrm{NO}$ to $\mathrm{CO}_{2}$ ratio was shown as a function of the engine power setting. The trend of $\mathrm{NO} / \mathrm{CO}_{2}$ versus engine power setting was in reverse to that for $\mathrm{CO} / \mathrm{CO}_{2}$, because as the combustion temperature increased when the engine power increased, leading to more production of NO. A significant reduction of PM emission was observed when the FT fuel was used as shown in Fig. 39 [a]; however, the reduction of NO emission did not seem to be reduced much by the use of the FT fuel as shown in Fig. 39[a]. 


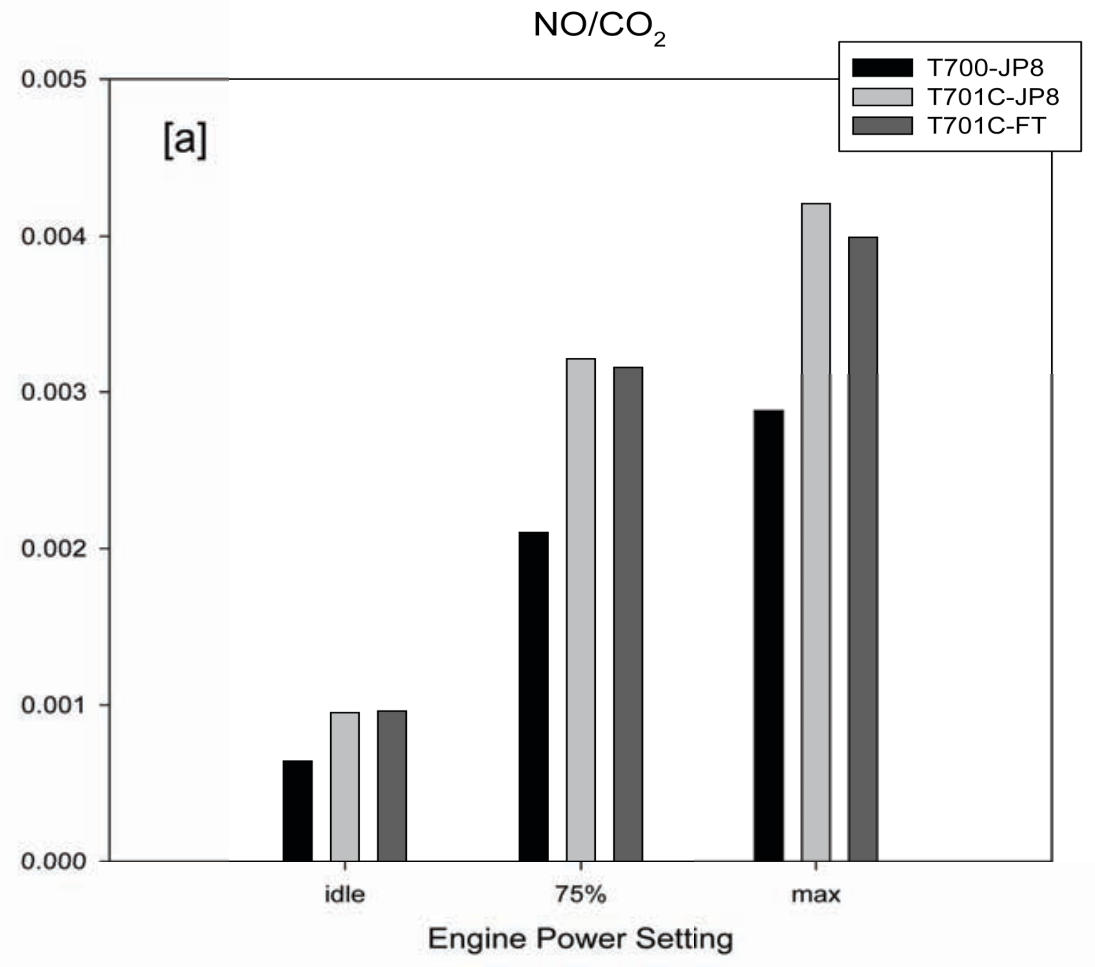

Fig. 39 [a]. Plot of $\mathrm{NO} / \mathrm{CO}_{2}$ vs. engine power setting

In the HAAF test, we added the measurement for an air toxic species by the extractive method. Formaldehyde (HCHO) is an air toxic pollutant produced as aromatic hydrocarbons are converted into lower molecular weight organic hydrocarbons. Emissions of HCHO by the engines running only JP-8 fuel are displayed in Fig. 39[b]. The concentrations of $\mathrm{HCHO}$ were found decreased as the engine power setting was increased. The extractive MKS FTIR measurement indicate HCHO in the emission was reduced by more than half from the idle condition to the high powers. However, the two-fold reduction was un-confirmed by the EPA certified TO-11 protocol

(http://www.epa.gov/ttnamtil/files/ambient/airtox/to-11ar.pdf). TO-11 is an adsorbent cartridge sampling method for measurement of formaldehyde in ambient air. This method is based on the following reaction: 
Formaldehyde Measurement

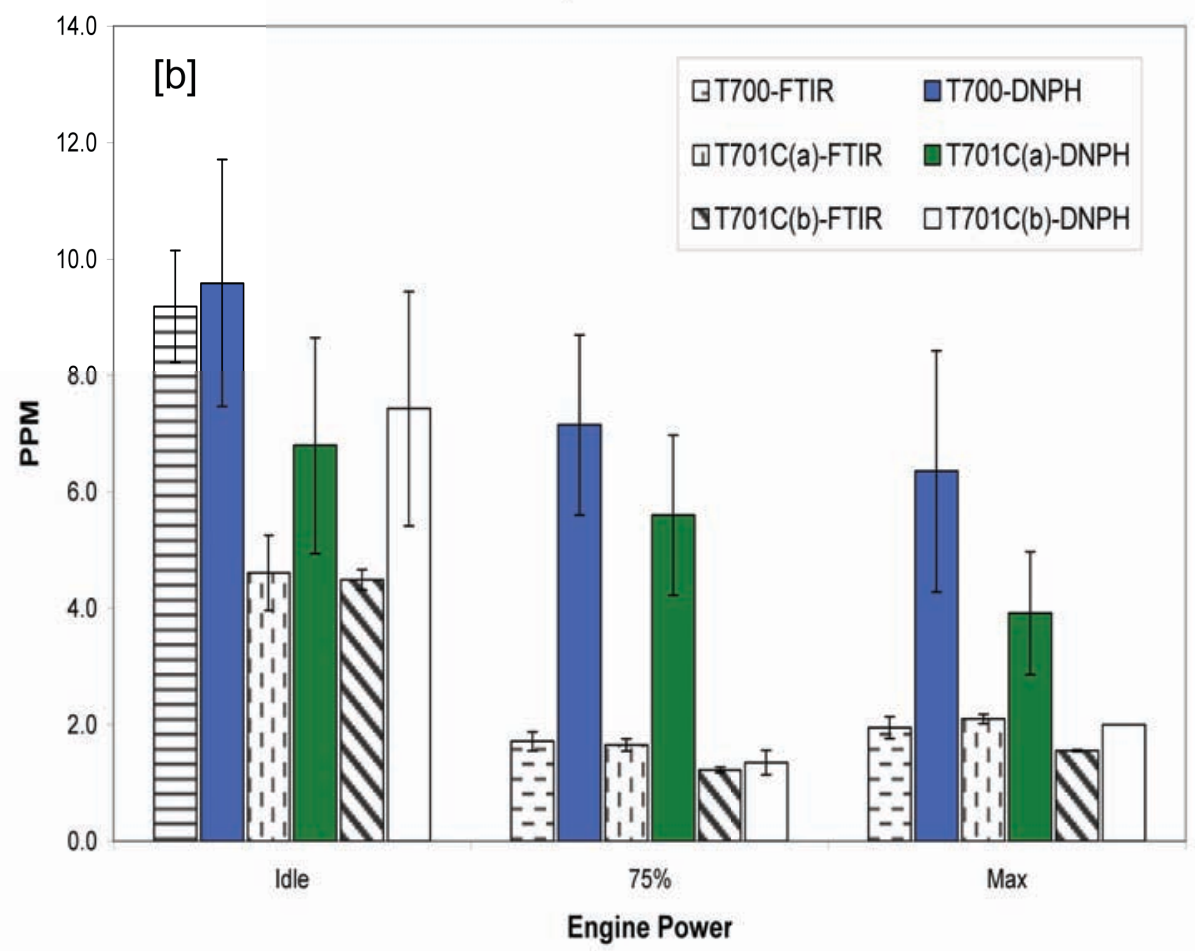

Fig. 39[b]. Plot of Formaldehyde vs. engine power setting

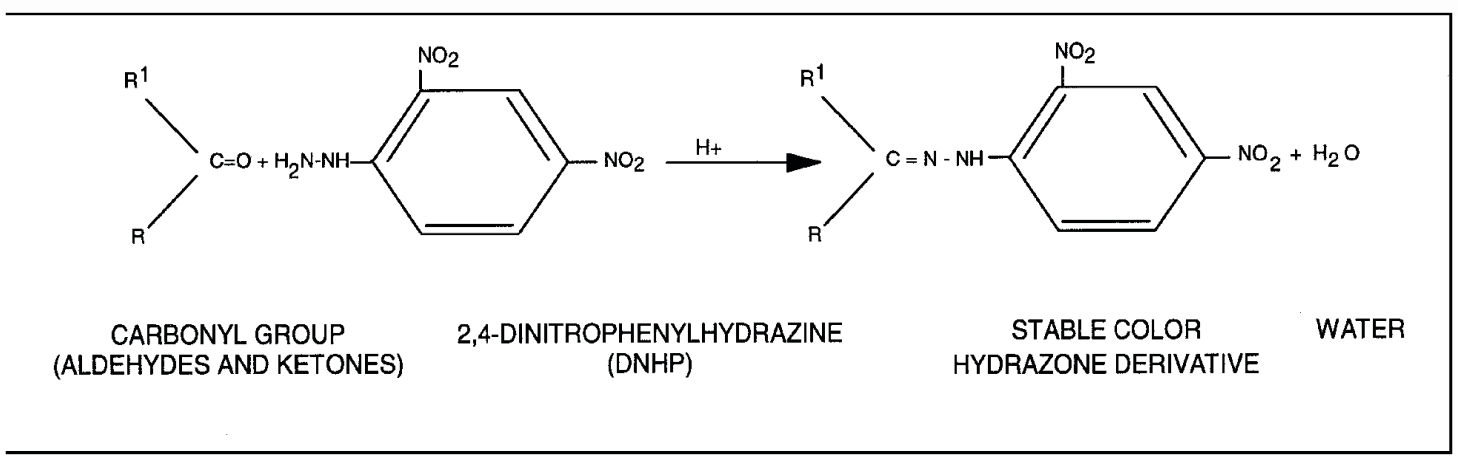

The determination is then followed using high-performance liquid chromatography (HPLC).

In Fig. 39[b], one can see the FTIR instrument values are consistently lower than those obtained by TO-11 across all different power settings. The difference grew larger at high engine power settings. Although the trends of HCHO emissions observed by FTIR and TO-11 were consistent; i.e., the concentration decreased as the engine power setting increased, the differences in measurement were statistically significant. One literature report (http://www.atmos-chem-physdiscuss.net/5/2897/2005/acpd-5-2897-2005-print.pdf) indicates that continuous FTIR measurements were found to be higher than DNPH derived data in one campaign. It is unclear at this point what caused such a difference in the data, because the MKS FTIR was calibrated for HCHO before the field application in 2007. 
The gas-phase species measured by the ORS instruments are carbon dioxide $\left(\mathrm{CO}_{2}\right)$, carbon monoxide $(\mathrm{CO})$, nitric oxide $(\mathrm{NO})$, nitrogen dioxide $\left(\mathrm{NO}_{2}\right)$, formaldehyde $(\mathrm{HCHO})$, ethylene $\left(\mathrm{C}_{2} \mathrm{H}_{4}\right)$, acetylene $\left(\mathrm{C}_{2} \mathrm{H}_{2}\right)$, and saturated alkanes $\left(\mathrm{C}_{\mathrm{n}} \mathrm{H}_{2 \mathrm{n}+2}\right)$. The alkane hydrocarbons, except $\mathrm{HCHO}$, are not distinguished as individual molecules instead they were detected as one single class of organic hydrocarbons.

Continuous $\mathrm{CO}$ and $\mathrm{CO}_{2}$ measurements by the OP-FTIR instrument are shown in Fig. 40 for the T700 engine. Each point on a panel in Fig. 40 was a 32 -second averaged measurement. The plots shown in Fig. 40 contain detailed information about the emissions and combustion efficiency. The left panel is for June 11 and the right panel is for June 12, both were for the T700 engine operated with JP-8 fuel. On June 11, one can see the spike or surge of CO emission at the beginning of engine startup, then the CO emission decreased rapidly to a steady-state value and then further decrease to nearly zero when the engine was turning off.

In Fig. 37 we showed a similar behavior of particles observed by the FPS to the behavior observed here in Fig. 40 for CO, which in Fig. 37 the particle number concentration surged at the engine startup; then it rapidly settled down to a "steady-state" value over the next few hundred seconds. Again, we hypothesized that this could be due to the instability of fuel flow to the combustor and poor mixing in the combustor during the startup causing the correlated transient emissions in $\mathrm{CO}$ and particle size distribution. Other real-time measurements by the ORS instruments are shown in Fig. 41 for $\mathrm{CO}_{2}$, ethylene, HCHO, and alkanes emitted by T700. The left panel is for June 11, while the right panel is for June 12. All organic compounds were found to surge at the engine start up before they were resetting back to steady-state values, close to zeros, in fact.

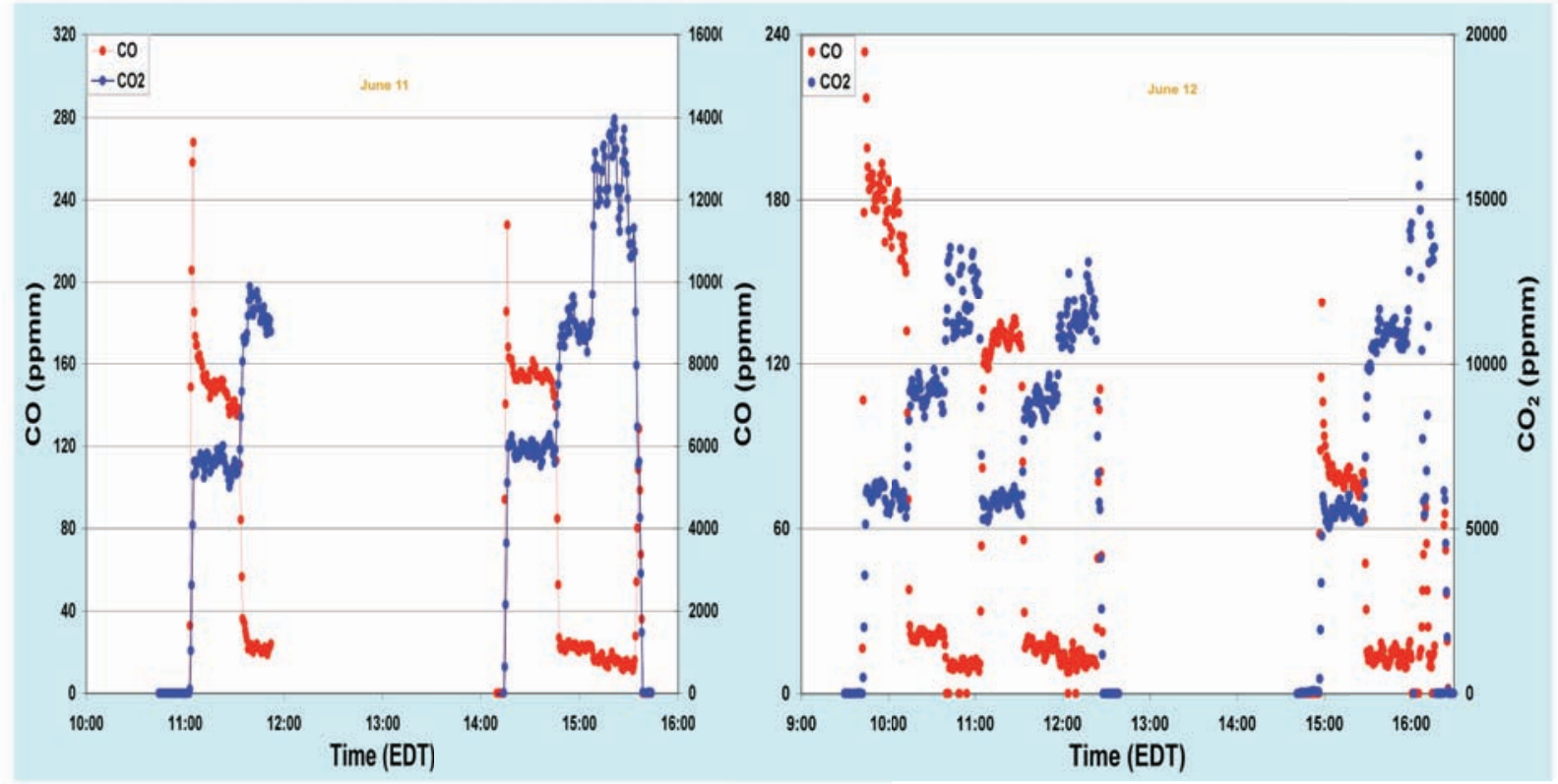

Fig. 40. Time series plots of $\mathrm{CO}$ and $\mathrm{CO}_{2}$ for $\mathrm{T} 700$ engine at different dates 


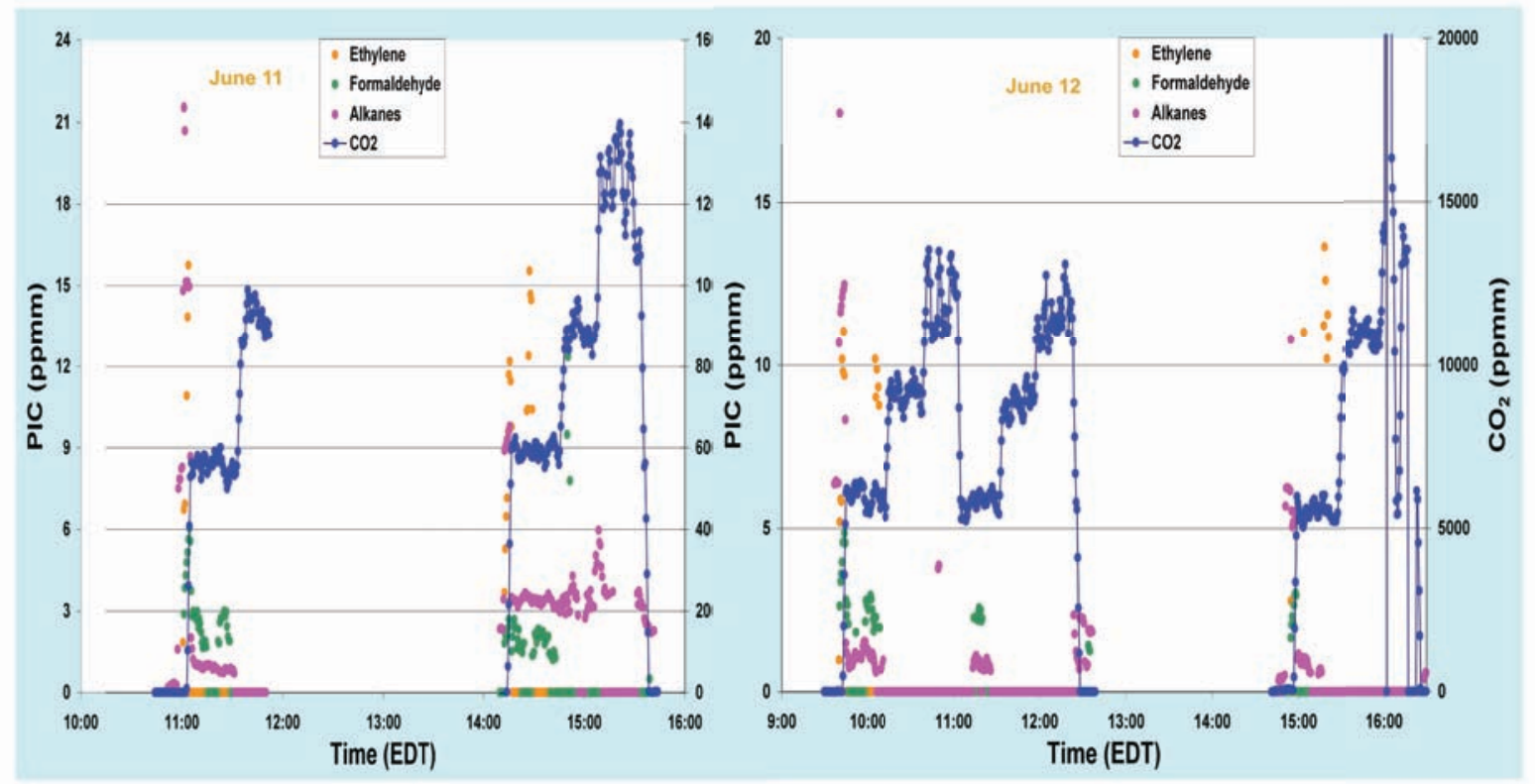

Fig. 41. Time series plots of $\mathrm{CO}_{2}$, ethylene, alkanes, and formaldehyde from $\mathrm{T} 700$ engine

T700/T701C engine emission indices by ORS data

Using the methodology and mathematical formula presented previously in the TF33 data sections, the emission indices were derived for $\mathrm{T} 700$ and $\mathrm{T} 701 \mathrm{C}$ based on the ORS data obtained from the HAAF campaign. The emission indices are shown in Table 3.

Table 3. Emission Indices for Gases by ORS for T700/T701C Engines

\begin{tabular}{|c|c|c|c|c|c|c|c|}
\hline $\begin{array}{c}\text { Engine- } \\
\text { Fuel9 }\end{array}$ & Power & $\begin{array}{c}\text { Fuel } \\
\text { Flow }\end{array}$ & $\mathrm{CO} 2$ & $\mathrm{CO}$ & Ethylene & HCHO & Alkanes \\
\hline & Setting & $(\mathrm{kg} / \mathrm{hr})$ & $(\mathrm{g} / \mathrm{kg})$ & $(\mathrm{g} / \mathrm{kg}$ fuel $)$ & $(\mathrm{g} / \mathrm{kg}$ fuel $)$ & $(\mathrm{g} / \mathrm{kg}$ fuel $)$ & $(\mathrm{g} / \mathrm{kg}$ fuel $)$ \\
\hline T700-JP-8 & Idle & 61 & 2810 & 46.4 & 2.9 & 1.74 & 1.74 \\
\hline & $75 \%$ & 215 & 2489 & 3.6 & & & \\
\hline & Max & 333 & 3358 & 2.2 & & & \\
\hline T701C-JP-8 & Idle & 65 & 1481 & 14.7 & 1.8 & 0.65 & 0.65 \\
\hline & $75 \%$ & 264 & 1757 & 1.4 & & & \\
\hline & Max & 382 & 4098 & 3.0 & & & \\
\hline T701C-FT & Idle & 65 & 1569 & 19.3 & & 0.61 & 0.61 \\
\hline & $75 \%$ & 264 & 1297 & 1.0 & & & \\
\hline & Max & 357 & 2850 & 2.0 & & & \\
\hline
\end{tabular}


Note that there are no data reported for $\mathrm{HCHO}$, ethylene, and alkanes for some engine-fuel combinations because the measurements were lower than the detection limits of OP-FTIR. For example, none of these species was detected at the $75 \%$ of max and max power conditions, and ethylene was not detected even at the idle condition for the T701C-FT case.

In comparison, the emission indices derived for $\mathrm{T} 700$ and $\mathrm{T} 701 \mathrm{C}$ based on the extractive measurements are shown in Table 4.

Table 4. Emission Indices for Gases by Extractive Sampling for T700/T701C

\begin{tabular}{|c|c|c|c|}
\hline T700-JP-8 & Idle & $75 \% \max$ & Max \\
\hline $\mathrm{CO}(\mathrm{g} / \mathrm{kg}$-fuel $)$ & 53.72 & 4.63 & 2.32 \\
\hline $\mathrm{NO}_{\mathrm{x}}(\mathrm{g} / \mathrm{kg}$-fuel $)$ & 3.05 & 7.39 & 9.89 \\
\hline $\mathrm{NO}(\mathrm{g} / \mathrm{kg}$-fuel $)$ & 2.07 & 6.97 & 9.56 \\
\hline $\mathrm{T} 701 \mathrm{C}-\mathrm{a}-\mathrm{JP}-8$ & $\mathrm{Idle}$ & $75 \% \max$ & $\mathrm{Max}$ \\
\hline $\mathrm{CO}(\mathrm{g} / \mathrm{kg}$-fuel $)$ & 29.02 & 2.12 & 3.02 \\
\hline $\mathrm{NO}_{\mathrm{x}}(\mathrm{g} / \mathrm{kg}$-fuel $)$ & 3.98 & 10.73 & 14.37 \\
\hline $\mathrm{NO}(\mathrm{g} / \mathrm{kg}$-fuel $)$ & 3.14 & 10.13 & 13.66 \\
\hline $\mathrm{T} 701 \mathrm{C}-\mathrm{b}-\mathrm{JP}-8$ & $\mathrm{Idle}$ & $75 \% \max$ & $\mathrm{Max}$ \\
\hline $\mathrm{CO}(\mathrm{g} / \mathrm{kg}$-fuel $)$ & 32.82 & 2.46 & 2.67 \\
\hline $\mathrm{NO}_{\mathrm{x}}(\mathrm{g} / \mathrm{kg}$-fuel $)$ & 3.95 & 12.32 & 15.10 \\
\hline $\mathrm{NO}(\mathrm{g} / \mathrm{kg}$-fuel $)$ & 3.15 & 11.41 & 14.22 \\
\hline
\end{tabular}

\section{Comparison of emission index derived by both platforms}

Remember that one of the objectives of this research is to evaluate the feasibility of ORS in aircraft emissions measurement. The results presented so far have shown that ORS instruments are effective in making fast, real-time, observation of engine emissions, useful for study of transient combustion condition. ORS was also used for taking data for derivation of emission index.

Thus, it is important to compare emission index derived from the data collected by the extractive and remote-sensing platforms. This comparison can only be made using the gas-phase data since the ORS instruments did not have sufficient sensitivities to measure small particles (e.g., less than $100 \mathrm{~nm}$ ) emitted by the T700 and T701C engines. We will use the CO data for such a comparison.

The comparison is shown in Fig. 42 for the three engine-fuel combinations (i.e., T700-JP-8, T701C-JP-8 and T701C-FT). The relative difference between the emission indices derived by both extractive and ORS approaches for the corresponding engine-fuel cases is calculated as follows:

$$
\text { Relative Difference in } \%=\left\{\left[\mathrm{ORS}_{\mathrm{i}}-\mathrm{EX}_{\mathrm{i}}\right] / \mathrm{EX}_{\mathrm{i}}\right\} \times 100 \%
$$

$\mathrm{ORS}_{\mathrm{i}}=$ Optical Remote Sensing Emission Index for the case $\mathrm{i}$, $\mathrm{EX}_{\mathrm{i}}=$ Extractive Emission Index for the case $\mathrm{i}$.

The cases for each engine power setting are listed in the legend in Fig. 42. One notice immediately from this figure that the difference in the emission indices derived by both platforms was significantly different. For most of the cases, the negative relative differences between the two approaches are more than $20 \%$ with the ORS emission index consistently lower than that of the extractive sampling approach. The difference was as small as a couple of percentages in the case of T701C-JP-8 for the max 
power to as large as greater than $60 \%$ in the case of T700-JP- 8 for the $75 \%$ max. However, as the engine power reached the maximum, we found the differences tend to be getting smaller than those of the other two power conditions.

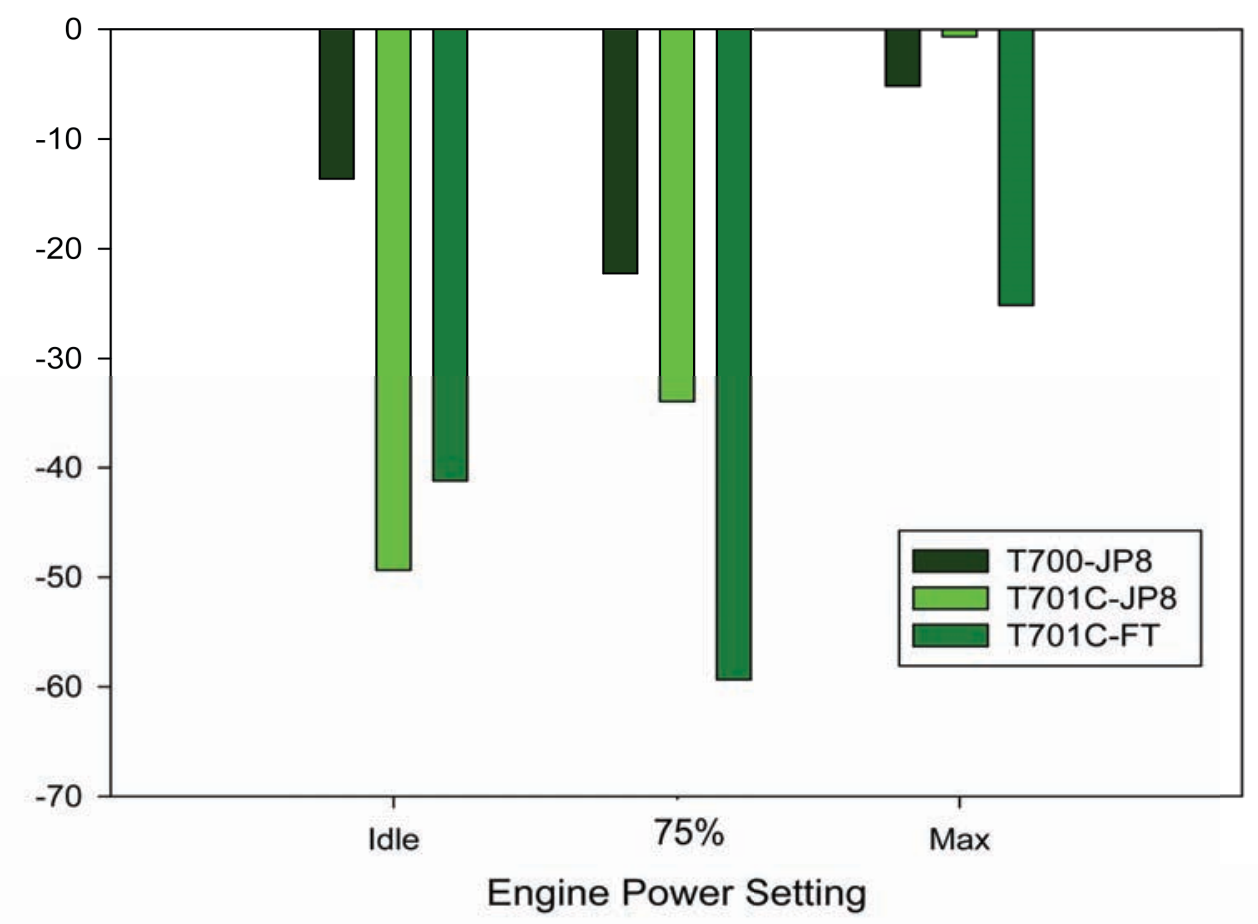

Fig. 42. Relative percent difference of EI derived for $\mathrm{CO}$ by using extractive and ORS data

With the results shown in Fig. 42, we feel that using the ORS approach to derive emission index could require more work. If both ORS and MKS FTIR instruments were properly calibrated, then the difference could be resulted from the assumptions invoked in the mathematical formulation and measurement of the plume cross-section geometry. The additional instruments needed for accurate determination of the plume geometry and flow speed really reduce the convenience that we initially conceived at the beginning of the program. Without those measurements, emission index could not be calculated based on the ORS data. Thus, the ORS approach for aircraft emissions measurement become less attractive due to those additional requirements.

Finally, the ORS measurement was considered initially because we were concerned that the extractive measurement may disturb the plume flow. With the ability of ORS-class of technology to make un-intrusive measurement to the plume flow, the approach was appealing. Similar concern now exists for the ORS approach because it requires additional measurements of plume geometry and flow speed, for instance.. However, the author feels that the ORS approach still has its merits as long as the abovementioned issues can be addressed through further research. 


\section{(IV) CONCLUSIONS}

Aircraft emissions of particulate matter and gaseous pollutants contribute to the exposure of ground-supporting workers and the increased air pollution level in metropolitan airports and the surrounding neighborhoods. Being able to inject pollutants directly into the troposphere and lower stratosphere, aircraft emissions could change atmospheric chemistry and alter atmospheric radiation balance by adding cloud condensation nuclei at a strategic altitude in the atmosphere thereby affecting the life cycle of clouds. Military aircraft consume significant amount of fuel each year, but emissions estimates for in-service military aircraft are seriously lacking. There is no EPA-certified sampling and measurement technology for military aircraft emissions at the engine exhaust and downstream locations. Under the auspices of SERDP office, research was undertaken to evaluate the effectiveness and performance of currently available technologies for military aircraft emissions measurement. An additional objective is to characterize emissions of selected military aircraft to derive emission index and to document the measured emissions levels.

This final report contains three-year field campaign results obtained by the SERDP/WP1401 team. These campaigns focused on (1) T56 engines used by a military C-130H cargo aircraft at the Kentucky Air National Guard in FY2005, (2) TF33 engines used by a B-52H bomber at the Barksdale Air Force Base in FY2006, and (3) T700/T701C engines used by Blackhawk/Apache helicopters at the Hunter Army Airfield in FY2007. The engines used in these studies had a few thousand hours of total operation, and all but the T700 engine was serviced before the tests.

Gaseous and particulate emissions were characterized by an array of technologies based on "extractive" and "optical remote-sensing" sampling platforms. Exhausts obtained by extractive sampling for instruments that performed measurements in real-time on both gaseous and particulate phases. The particulate matter measured in this project was characterized as non-volatile particles due to heating practice used in the sampling line. Particle size, size distribution, number and mass concentrations were measured. Time-integrated particulate filter samples were collected and analyzed for smoke number, elemental composition, carbon contents, and ionic species like sulfate. Gas species measured include $\mathrm{CO}$, $\mathrm{CO}_{2}, \mathrm{NO}, \mathrm{NO}_{2}, \mathrm{SO}_{2}, \mathrm{HCHO}$, ethylene, acetylene, propylene, and alkanes. The first five gaseous species are major gas species, while the remaining species are air toxics or hazardous air pollutants defined by US EPA. The toxic species were noticeable only under low engine-power (e.g., idle) condition. The levels of hydrocarbon species were low or below detection levels at the high engine power levels.

The final emission indices and particulate population statistics are summarized in the following Table 5. It is important to note that the numbers shown in the above table were obtained from the "extractive", not the remote-sensing, platform.

Table 5. Emission Indices of Gaseous and Particulate Pollutants Summarized for All Engines

\begin{tabular}{|c|c|c|c|c|c|c|}
\hline \multicolumn{7}{|c|}{ Emission Indices of Gaseous and Particulate Pollutants } \\
\hline Units & \#/kg-fuel & \multicolumn{3}{|c|}{ g/kg-fuel } & nm & no unit \\
\hline T56/JP-8 & EI_pn & EI_mass & CO & NO & GMD & Smoke \# \\
\hline low speed ground idle & $1.8 \mathrm{E}+16$ & 2.60 & 32.90 & 3.1 & 51.5 & 31 \\
\hline high speed ground idle & $1.4 \mathrm{E}+16$ & 2.80 & 5.50 & 7.54 & 55.0 & 41 \\
\hline flight idle & $1.4 \mathrm{E}+16$ & 2.80 & 4.70 & 7.06 & 55.6 & 43 \\
\hline Cruise & $1.0 \mathrm{E}+16$ & 1.70 & 2.00 & 8.65 & 60.4 & 41 \\
\hline
\end{tabular}




\begin{tabular}{|c|c|c|c|c|c|c|}
\hline max power & $1.2 \mathrm{E}+16$ & 1.35 & 2.00 & 9.42 & 67.4 & 45 \\
\hline TF33/JP-8 & & & & & & \\
\hline Idle & $5.5 \mathrm{E}+15$ & 1.50 & 94.64 & 1.13 & 55.4 & 17 \\
\hline $80 \%$ & $5.3 \mathrm{E}+15$ & 0.90 & 29.82 & 2.04 & 62.5 & 25 \\
\hline $90 \%$ & $9.6 \mathrm{E}+15$ & 2.50 & 9.63 & 4.23 & 79.5 & 44 \\
\hline $95 \%$ & $8.9 \mathrm{E}+15$ & 3.00 & 5.02 & 5.90 & 84.7 & 49 \\
\hline T700/JP-8 & & & & & & \\
\hline Idle & $3.1 \mathrm{E}+15$ & 0.13 & 53.72 & 2.07 & 20.0 & 2 \\
\hline $75 \%$ & $3.3 \mathrm{E}+15$ & 0.39 & 4.62 & 6.97 & 35.0 & 16 \\
\hline max power & $5.5 \mathrm{E}+15$ & 1.38 & 2.32 & 9.56 & 42.0 & 40 \\
\hline T701C/JP-8 & & & & & & \\
\hline Idle & $1.1 \mathrm{E}+14$ & 0.12 & 29.02 & 3.14 & 19.0 & $<1$ \\
\hline $75 \%$ & $1.8 \mathrm{E}+15$ & 0.22 & 2.12 & 10.13 & 34.0 & 8 \\
\hline max power & $3.0 \mathrm{E}+15$ & 0.64 & 3.02 & 13.66 & 37.0 & 27 \\
\hline T701C/FT & & & & & & \\
\hline Idle & $4.0 \mathrm{E}+13$ & 0.03 & 28.4 & 3.8 & 16.0 & $<1$ \\
\hline $75 \%$ & $4.7 \mathrm{E}+14$ & 0.03 & 2.0 & 10.5 & 25.0 & 2 \\
\hline max power & $1.6 \mathrm{E}+15$ & 0.19 & 2.2 & 13.0 & 29.0 & 12 \\
\hline
\end{tabular}

As expected, the smoke numbers are very small at idle or low engine-power levels for the newer engines like T701C, but significantly larger for older engines like T56 and TF33 at all engine power levels even both were serviced before the tests. The smoke number increased as the engine power increased for all engine types indicating a higher mass emission. The exception of this relationship is the T56 engines where the smoke numbers appear to be reasonably unchanged when the engines were operated at higher than the low-speed ground idle setting. We attributed the leveling-off of the T56 smoke numbers with respect to the increased intake of ambient air through its turboprop intake manifold as the engine power increased.

Formation of particulate matter in a turbine combustor is a highly complicated process. There is no known mathematical model at the present that can precisely predict the particulate formation from the combustion of JP-8 fuel. As observed at the engine exhaust plane in our field experiments, the geometric mean diameter (GMD) of the exhaust particles generally increased as the engine power setting increased. The results indicate that larger particles (as measured by the mobility diameter) were produced at high engine power levels. However, the data do not suggest that the primary particle diameter would increase as the engine power increased, because the larger particle diameter at the high power level could be due to the formation of particulate aggregates as reported in the literature rather than the formation of larger spherical solid primary particles.

The CO emission index decreases exponentially as the engine power increases, while the NO index increases as the engine power increases. The patterns of these gaseous emissions in relation to the engine power condition are consistent with currently known turbine engine combustion chemistry. Engine combustion at a higher power level favors the formation of $\mathrm{CO}$ and favoring $\mathrm{CO}_{2}$ production. On the other hand, the combustion temperature is higher at a higher engine power that would promote the formation of NO, which was reflected in our measurements for all engines tested.

Optical Remote Sensing (ORS) technology could significantly reduce the labor needed for fieldtesting of aircraft emission. However, the same ORS technology we deployed failed to detect particulate matter for emission index calculation because the OP-FTIR lacked the sensitivity to provide reliable particle measurements. With the detailed results discussed in the main text of this report, we concluded that the OP-FTIR appears more suitable for gas species measurement. The OP-FTIR, UV DOAS, and 
TDLAS could yield real-time data for gaseous species. It would require more research for the ORS technology to provide satisfactory quantitative emissions indices.

To improve our understanding of volatile particulate matter, we explored the effects of gasderived zero-aromatic and zero-sulfur Fischer-Tropsch (FT) fuel on engine emissions using the T700 and T701C engines in FY2007. The FT fuel was found to significantly reduce particulate emissions, and it decreased the emitted particle diameter as compared to those emitted by similar engines operated with JP8 fuel. As a comparison with the JP-8 fuel, the FT fuel reduced total particulate carbon emissions, significantly, due to lack of aromatics in the fuel. At a residence time less than $1 \mathrm{~s}$, the conversion of fuel sulfur to particulate sulfate appears to be completed as the ratio of the sulfur-in-sulfate to total particulate sulfur remains constant of one throughout the three engine power levels. Further, our results show that sulfate formation appears to occur through reactions on the engine particle surfaces rather than through the condensation of sulfuric acids.

In summary, ambient factors like wind-direction and speed have little impact on the extractive measurement under normal circumstances, because the sampling probes were fully immersed in the exhaust plume at the immediate vicinity of the engine exhaust nozzle and the sampling line is fully heated. Liquid precipitation such as rain and snow, which we did not encounter in this program, could affect the extractive measurement as the liquid water changes the ambient humidity that leads to the dynamic temperature of the sample. Adverse wind direction and high wind speed would cause the plume not to traverse the beam path of the remote-sensing instruments causing the instrument to miss the plume, which would diminish the ORS signal.

The needs to acquire plume geometry and plume travelling speed represent a major challenge for the ORS platform. The assumption of plume material distribution required for the derivation of emission index places an additional burden on the future use of the ORS method. Nevertheless, the ORS approach does have the advantages over the extractive method in that it requires less manpower to operate and has the ability to observe and monitor transitional change in the emissions.

\section{(IV.1) Potential Future Applications}

The emission data our team obtained would augment the EPA mobile source emissions database that currently lacks military aircraft emissions. The emission indices we estimated were derived with estimating the "source terms" for air quality modeling in mind. Air quality modeling is required in the design of air pollution control strategy by the regulatory agency, but the model requires accurate emission estimates or source terms to be able to produce cost-effective design.

However, the most importantly, the results obtained by our project work would add to the validation for the sampling and measurement methodology for non-volatile particulate aircraft emissions. The sampling and measurement methodology examined in this program are reliable and can be applied to collect emission data on gas and non-volatile particulate matter from aircraft that US military needs to have data.

The research results also highlight the needs for further research on sampling and measurement of volatile particulate matter and semi-volatile species in the engine exhaust especially at the low power setting when combustion tends to be incomplete. Additional research is also needed on the emissions of alternative fuel such as FT and other drop-in type of fuels under consideration, because the relationship of particulate emissions from the alternative fuels appear to be different from that of JP-8. 
Results from the optical remote-sensing techniques, i.e., open-path FTIR, UVDOS, TDLAS, or research-grade instrument like FPS yielded new insight on the transient behavior of emissions from the tested engines that would otherwise be difficult to obtain. The ability to "visualize" the transient behavior of the engine emissions could prove to be important for improving our understanding of aircraft engine emissions or engine design.

The experience learned and information gained from using the optical remote-sensing technology research we performed could provide experience to aid in future development of new sampling and measurement technology for military aircraft exhaust species responsible for the formation of secondary particulate matter in the atmosphere. 


\section{(V) REFERENCES}

Birch, M. and R. Cary (1996) "Elemental carbon-based method for monitoring occupational exposures to diesel particulate diesel exhaust", Aerosol Sci. Technol.; 25: 221-41.

Cheng, M.-D., E. Corporan, M. J. DeWitt, C. W. Spicer, M. W. Holdren, K. A. Cowen, A. Laskin, D. B. Harris, R. C. Shores, R. Kagann, and R. Hashmonay (2008) "Probing emissions of military cargo aircraft: description of a joint field measurement SERDP program", J. Air and Waste Management, 58(6):787796, June 2008.

Cheng, M.-D., E. Corporan, M. J. DeWitt, and B. Landgraf (2009) "Emissions of volatile particulate components from turboshaft engines operated with JP-8 and Fischer-Tropsch fuels", J. Aerosol Air Quality Res.: 9: 237-256.

Corporan, E., A. Quick, and M. J. DeWitt (2008) "Characterization of particulate matter and gaseous emissions of a C-130H aircraft”, J. Air \& Waste Management, 58(4): 474-483, April 2008.

Howard, R. P. et al. (1996) "Experimental characterization of gas turbine emissions at simulated flight altitude conditions", AEDC-TR-96-3, Final Report.

Kelly, W.P. and P.H. McMurry (1992) "Measurement of particle density by inertial classification of differential mobility analyzer-generated monodisperse aerosols", Aerosol Sci. Technol., 17(3):199-212.

Maricq, M. M., N. Xu (2004) "The effective density and fractal dimension of soot particles from premixed flames and motor vehicle exhaust.” J. Aerosol Sci.; 35: 1251-1274

Petzold, A. (2008) "Measurement of soot particles with state-of-the-art methods as a basis for a new certification application", Technical Report, L-1/2005-50.0314/2005, Avistra GmbH, Reinhardstr, 58, 10117 Berlin, Germany

Simpson, M. L., M.-D. Cheng et al. (2005) "Intensity-modulated, stepped frequency cw lidar for distributed aerosol and hard target measurements", Appl. Optics; 44: 7210-7217, Nov. 20.

Wade, M. D. (2004) "Aircraft/Auxiliary power units/aerospace ground support equipment emission factors”, USAF Report IERA-RS-BR-SR-2003-0002. 
THIS PAGE IS INTENTIONALLY LEFT BLANK. 


\section{APPENDIX A - LIST OF SCIENTIFIC/TECHNICAL PUBLICATIONS}

\section{(A.1) Publications based on C-130H Data}

1. Probing emissions of military cargo aircraft: description of a joint field measurement SERDP program, M.-D. Cheng, E. Corporan, M. J. DeWitt, C. W. Spicer, M. W. Holdren, K. A. Cowen, A. Laskin, D. B. Harris, R. C. Shores, R. Kagann, and R. Hashmonay, J. Air and Waste Management, 58(6):787-796, June, 2008.

2. Characterization of Particulate Matter and Gaseous Emissions of a C-130H Aircraft, E. Corporan, A. Quick, and M. J. DeWitt, J. Air and Waste Management, 58(4): 474-483, April, 2008.

3. Military Aircraft Particulate Emissions - Case of Hercules C-130H Cargo Plane, Meng-Dawn Cheng, Edwin Corporan, Matthew J. DeWitt, Kenneth A. Cowen, Michael W. Holdren, and Chester W. Spicer, Paper \#27 presented at the AWMA Annual Meeting in Pittsburgh, PA, June 2007.

4. SERDP Military Aircraft Emissions Research Program, Meng-Dawn Cheng, Michael W. Holdren, and Chester W. Spicer, Paper \#28 presented at the AWMA Annual Meeting in Pittsburgh, PA, June 2007.

5. Determination of Emission Fluxes of a Military Aircraft Using Optical Remote Sensing, Ram A. Hashmonay and Robert H. Kagann, Paper \#391 presented at the AWMA Annual Meeting in Pittsburgh, PA, June 2007.

6. Characterization of Particulate Matter and Gaseous Emissions of a C-130H Aircraft, Edwin Corporan and Adam Quick, Paper \#564 presented at the AWMA Annual Meeting in Pittsburgh, PA, June, 2007.

7. Remote Sensing Measurements of Gases and Particulates in Aircraft Engine Plumes, Robert H. Kagann, Ram A. Hashmonay, Richard C. Shores and D. Bruce Harris, Paper \#037 presented at the AWMA Annual Meeting in Pittsburgh, PA, June 2007.

8. Intensity-modulated, stepped frequency $\mathrm{cw}$ lidar for distributed aerosol and hard target measurements, Marc L. Simpson, Meng-Dawn Cheng, Thang Q. Dam, Katey E. Lenox, Jeff R. Price, John M. Storey, Eric A. Wachter, and Walt G. Fisher, Applied Optics, 44(3): 7210-7217, Nov. 20, 2005.

\section{(A.2) Publications based on B-52 Data}

1. \# 122 Investigations of Fine Particle Emissions from B-52 Aircraft, S. M. Mahurin, M.-D. Cheng, E. Corporan, M. DeWitt, AWMA Annual Meeting 2006.

2. Emission Characteristics of a Legacy Military Aircraft, E. Corporan, M. J. DeWitt, C. D. Klingshirn, S. M. Mahurin, and M.-D. Cheng, submitted to ASME J., January 2008, in review. 


\section{(A.3) Publications based on T700/T701C Data}

1. Cheng, Meng-Dawn, Edwin Corporan, Matthew J. DeWitt, and Bradley Landgraf (2009) Emissions of Volatile Particulate Components from Turboshaft Engines Operated with JP-8 and Fischer-Tropsch Fuels, J. Aerosol Air Quality Res., 9(2): 237-256.

2. Cheng, Meng-Dawn, Edwin Corporan, and Matthew J. DeWitt (2009) Characteristics of Particles Emitted by Turbine Engine and In-Plume Conversion, Presented at the 2009 European Aerosol Conference in Karlsruhe, Germany, September.

3. Paper \# 208, Meng-Dawn Cheng, Edwin Corporan, Matthew J. DeWitt, Chris Klingshirn, Shannon Mahurin, Characterization of Rotating-Wing Aircraft Emissions, Air and Waste Management Association 2008.

4. Paper \# 245, Robert H. Kagann, Ram A. Hashmonay, Michael Chase, The Use of Optical Remote Sensing as Part of a Study to Evaluate Methods for Measuring Emission Factors from Military Aircraft Engines - Rotary Wing Engines, Air and Waste Management Association 2008.

5. Corporan, Edwin, Matthew J. DeWitt, Christopher D. Klingshirn, Richard Striebich, and Meng-Dawn Cheng (2008) Emissions Characteristics of Military Helicopter Engines Fueled with JP-8 and a Fischer-Tropsch Fuel, submitted J. ASME. 
APPENDIX B - SERDP PROJECT-OF-THE YEAR 2008 AWARD
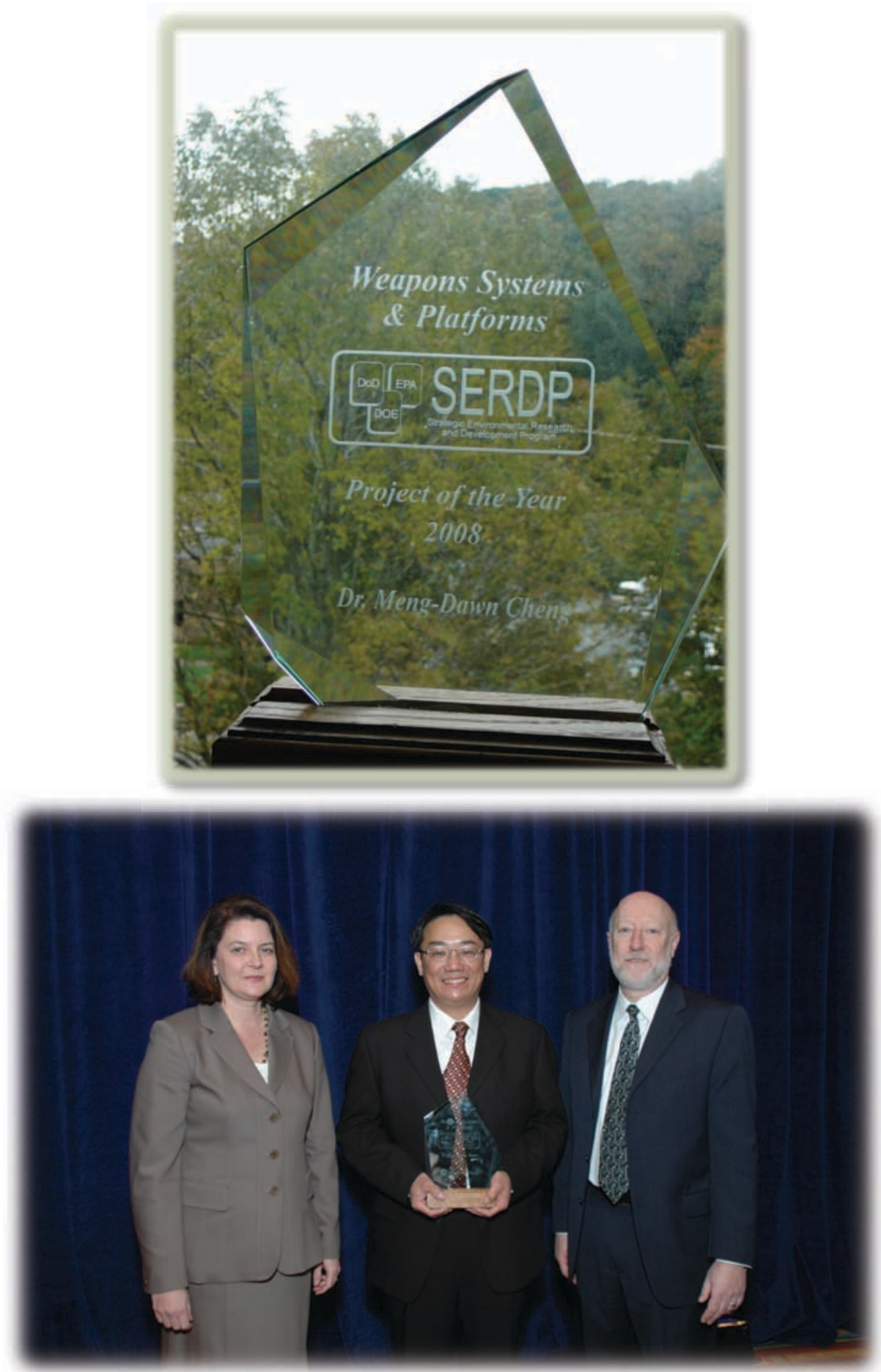


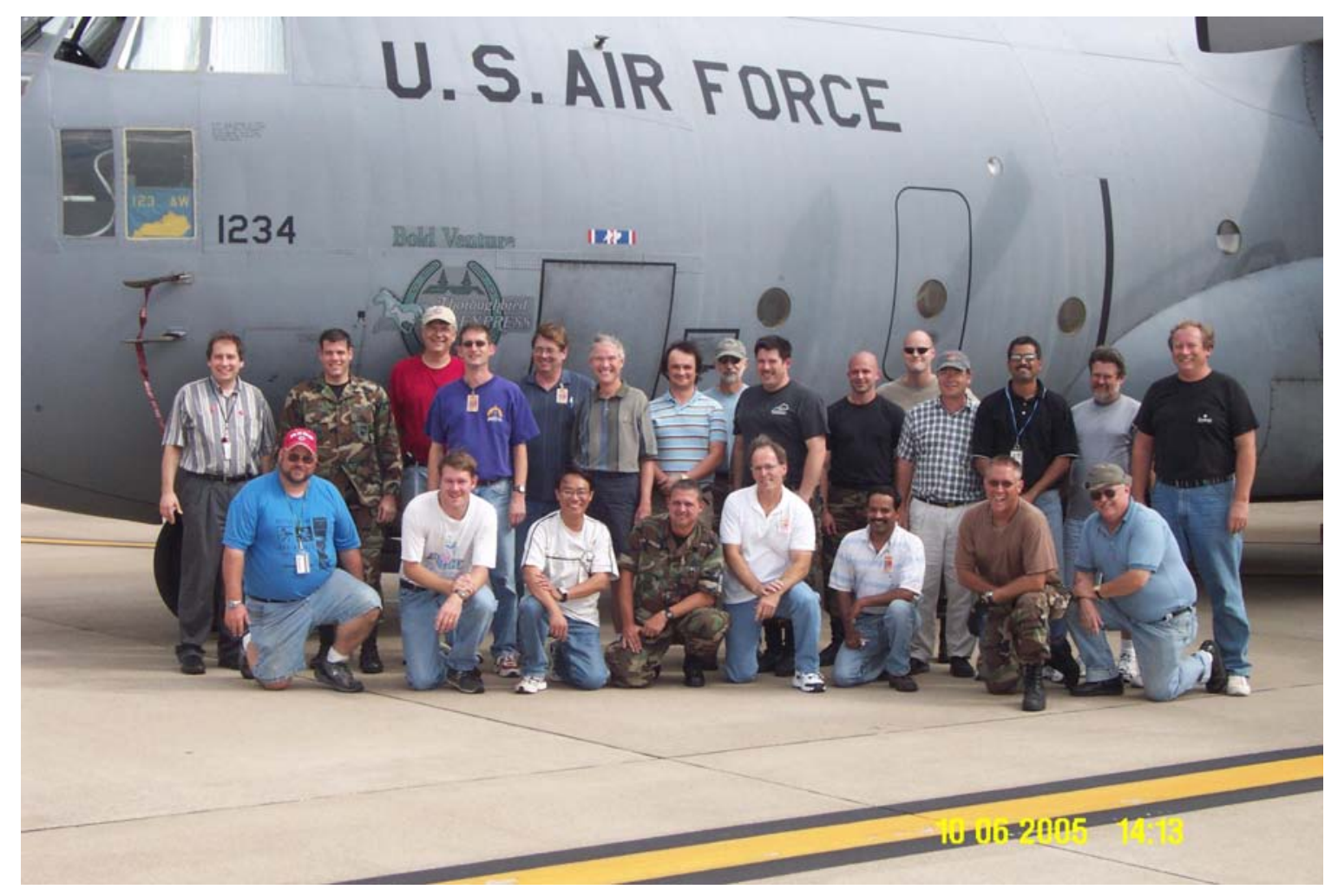

Group in the C-130H campaign at the National Guard Base in Louisville, KY, 2005 (A joint field campaign between crews of WP1401 and WP1402)

Second row from left - Jan Satola, Adam Quick, John Storey, Ken Cowen, Lisbeth Alexander (Formerly Mike), Chet Spicer, Alex Laskin, Darrel Joseph, Joe Smukler, Jim Campbell, Jeff Perry, Robert Kagann, Edwin Corporan, Tom Green, Michael Derlicki

First row from left - Joe Mantz, Matt DeWitt, MD Cheng, Wayne Ashley, Mike Holdren, Ravi Varma, Gary Dunlup, and Bruce Harris 


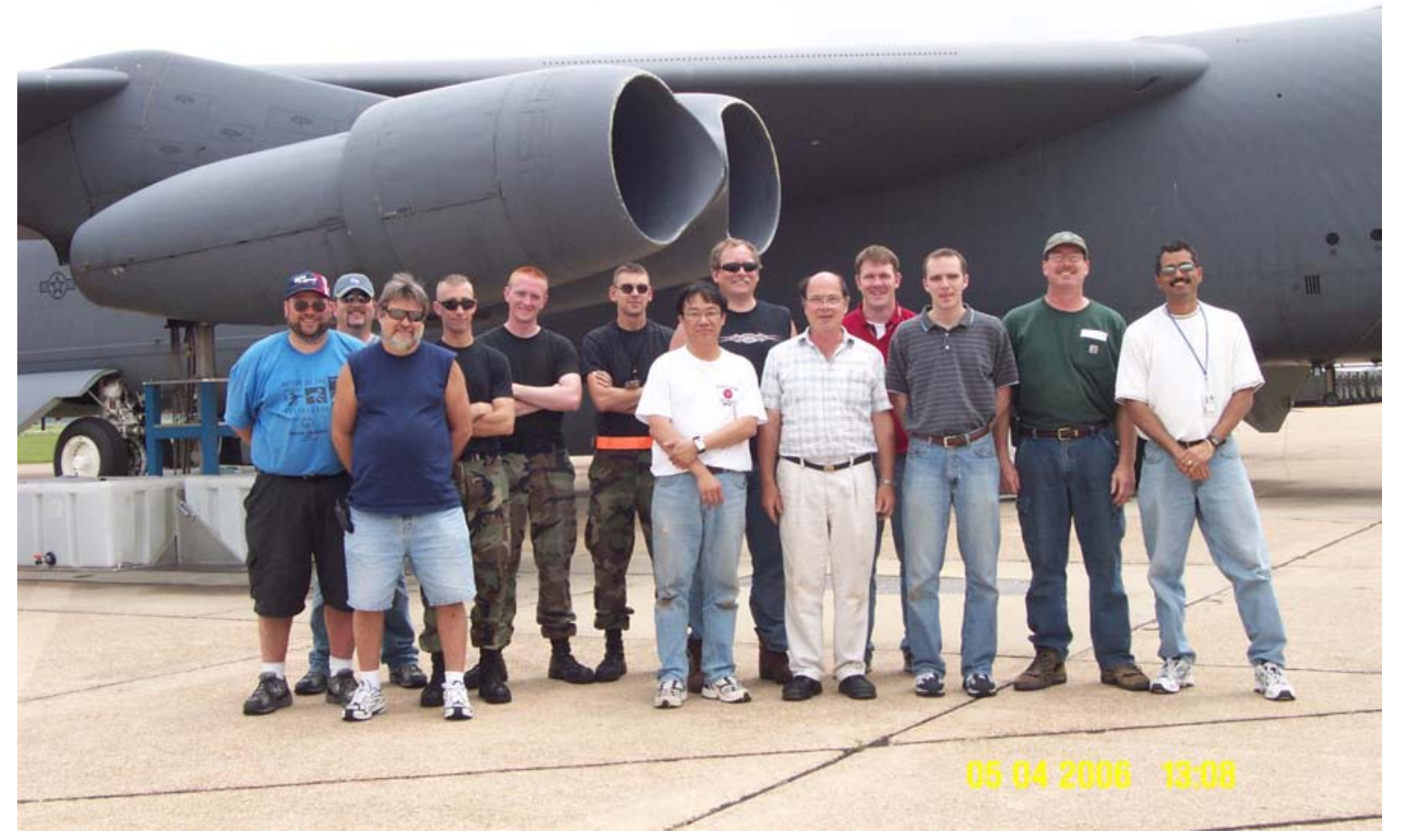

WP1401 Group at the B-52 Campaign at the Barksdale Air Force Base, Louisiana, 2006

From left - Joe Mantz, Chris Klingshirn, Tom Green, Justin Rogers, Jon Craig, Steve King, MD Cheng, Michael Derlicki, Robert Kagann, Matt DeWitt, Shannon Mahurin, Richard Shores, Edwin Corporan 


\section{APPENDIX D - VISUALIZATION IMAGE OF TF33 ENGINE PLUME BY USING THERMO IMAGING TECHNIQUE}

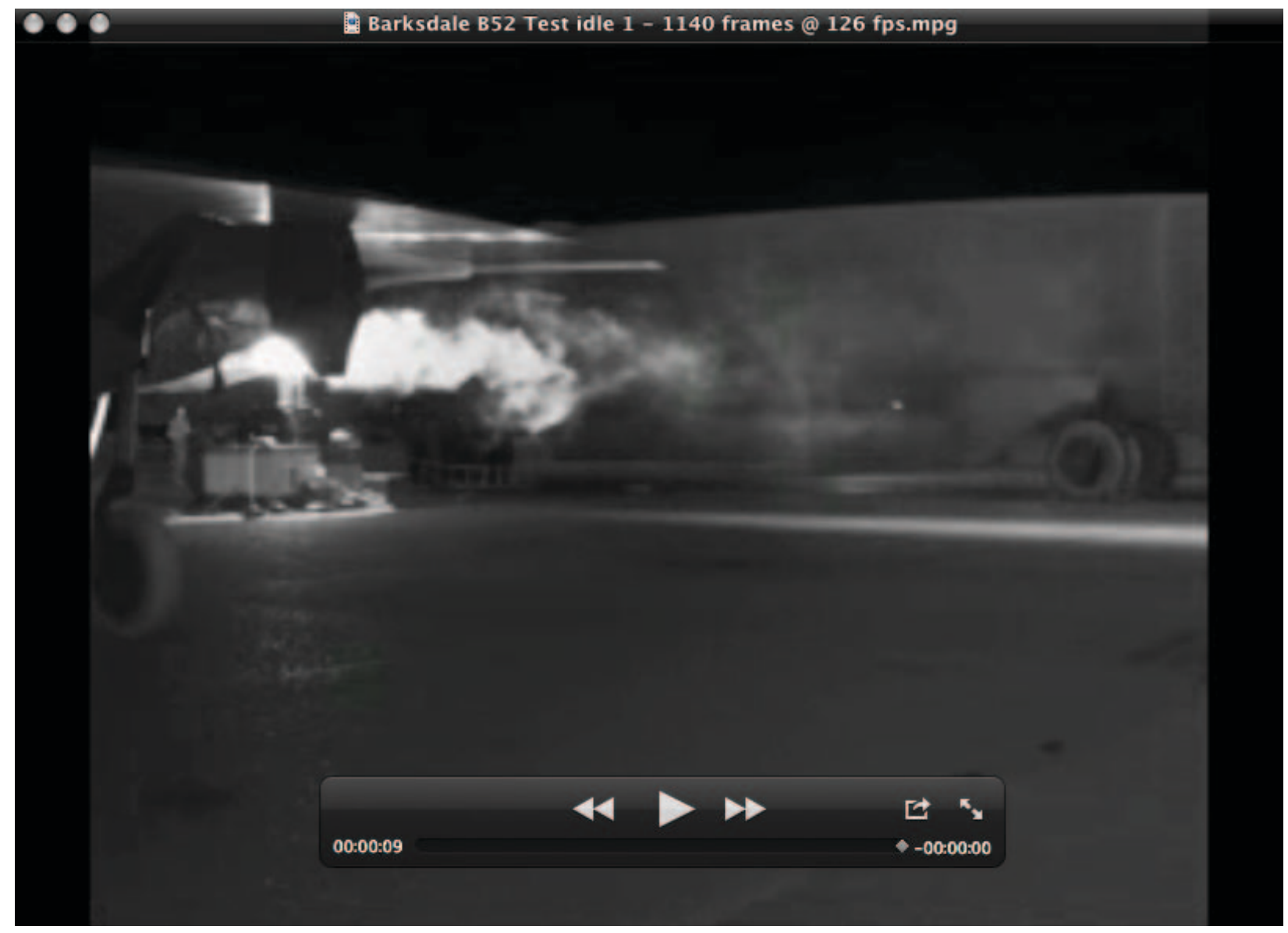

This is a snap-shot of TF33 engine plume taken by a thermo-imaging camera at 1000 local time during the campaign at the Barksdale AFB. The white color indicates a hot area, while the black indicates a cool area. 
THIS PAGE IS INTENTIONALLY LEFT BLANK. 
ORNL/TM-2009/256

\section{INTERNAL DISTRIBUTION}

1. Johnny Green

2. Gary Jacobs

3. Martin Keller

4. Liyuan Liang

5. Shannon Mahurin

6. Curt Maxey

7. James Parks

8. John M. Storey

9. ORNL Office of Technical Information and Classification

\section{EXTERNAL DISTRIBUTION}

10. Bruce Sartwell, Program Manager, Weapons Systems and Platforms, SERDP

11. Jeff Maqussee, Executive Director, SERDP

12. Chris Shaddix, Sandia National Laboratories

13. Edwin Corporan, Fuels Branch, Wright-Patterson Air Force Research Laboratory

14. Mel Roquemore, Combustion Branch, Wright-Patterson Air Force Research Laboratory

15. JoAnn Lighty, Department of Chemical Engineering, University of Utah, Logan, UT

16. Chao-Hsin Lin, Boeing Company

17. Steve Baughcum, Boeing Company

18. Richard Shores, US EPA

19. Connie Oldham, US EPA

20. Dennis Mikel, US EPA

21. John Kinsey, US EPA

22. Brian Gullet, US EPA

23. Ashley Williams, US DOE

24. Robert Howard, US Air Force / Arnold Engineering Development Center 